A PHYTOCHEMICAL INVESTIGATION OF

THE FRUIT OF MACLURA POMIFERA (RAFINESQUE) SCHNEIDER

\title{
DISSERTATION
}

\author{
Presented in Partial Fulfillment of the Requirements \\ for the Degree Doctor of Philosophy in the \\ Graduate School of the Ohio State \\ University
}

By

JOHN GARNET WAGNER, Phm.B., B.S.P., B.A.

The Ohio State University

1952
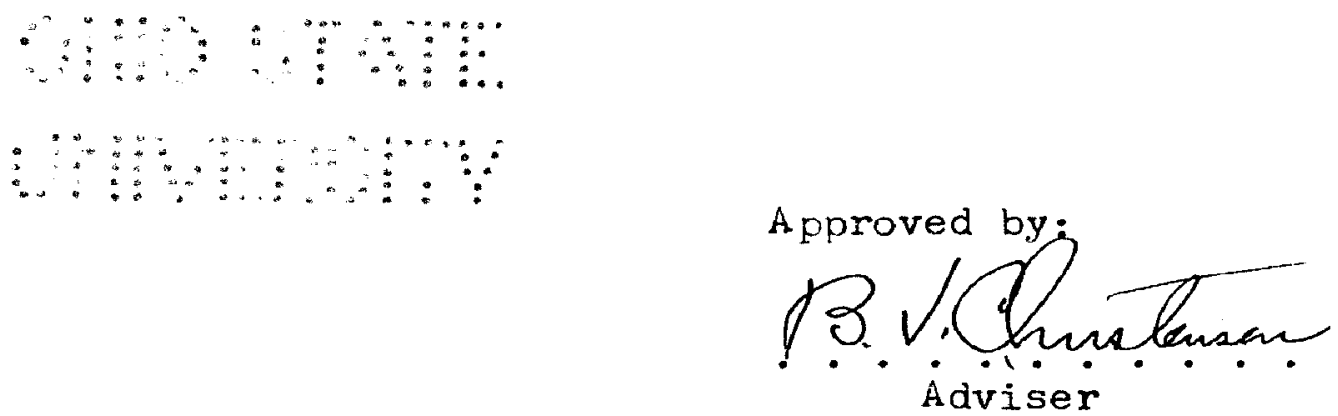
ACKNOWLEDGEMENTS

The author wishes to acknowledge with gratitude, the generous advice, suggestions and helpful direction of:

Dr. Loyd E. Harris, Professor, College of Pharmacy, without whose encouragement this work would not have been completed.

Dr. Bernard V. Christensen, Dean, College of Pharmacy, who extended admirable American hospitality to a Canadian student.

Dr. Frank W. Bope, Assistant Professor, College of Pharmacy, who offered many helpful suggestions in the writing of the Dissertation.

Dr. Albert L. Henne, Professor, Department of Chemistry, who willingly gave his advice and valuable time.

Dr. Christopher L. Wilson, Professor, Department of Chemistry, who arranged for the recording of the Infrared Spectra and offered expert advice.

The American Foundation for Pharmaceutical Education, for its generous financial aid which made it possible to undertake this graduate work at The Ohio State University.

The Department of Veterans Affairs, Ottawa, Canada, for its generous financial aid throughout my University training.

My wife, Eunice W. Wagner, who has been a source of inspiration throughout my University training and who worked willingly with me throughout the past six years.

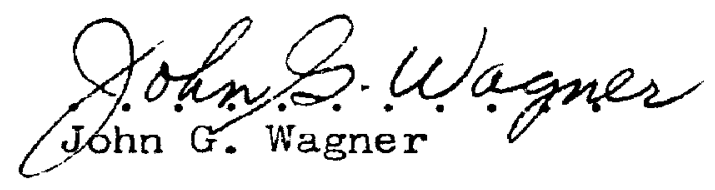


TABLE OF CONTENTS

Page

INTRODUCTION . . . . . . . . . . . . . . . . . . . . . 1

DISCUSSION OF IITERATURE . . . . . . . . . . . . . . . . 2

EXPERIMENTAI . . . . . . . . . . . . . . . . . . . . 22

Collection of Fruit. . . . . . . . . . . . . . . . 22

Drying of Fruit . . . . . . . . . . . . . . . . . . 22

Investigation of the Dried Fruit . . . . . . . . . . . . 24

Extraction of the Dried Fruit by the General Miethod of

Rosenthaler. . . . . . . . . . . . . . . . . . . 24

Investigation of the fetroleum Ether Extract . . . . . . . 27

Extraction A . . . . . . . . . . . . . . . . 27

Extraction B................... . 28

Separation of the Constituents of the Unsaponifiable

Matter . . . . . . . . . . . . . . . 30

Method 1 - Direct Recrystallization of the

Unsaponifiable Matter. . . . . . . . . . . . . 30

Method II - Chromatography of the Unsaponifiable

Natter ................. 32

Preparation of Lupeol Benzoate from Eluted Material. - 35

Method III - Direct Acetylation of the Unsaponifiable

Matter and Fractional Crystallization of the Acetates. - 36

Part A - Preliminary Investigation . . . . . . . 36

Part B - Direct Acetylation of a Large Quantity of the "Unsaponifiable Residue" . . . . . . . . . . 37

Fractional Crystallization of the Mixed Acetates . . 38

Determination of the Specific Rotation of Sample

I of the Unknown Acetate... . . . . . . . . 41 
Determination of the Specific Rotation of Sample

I of Lupeol Acetate . . . . . . . . . . . 43

Part C - Direct Acetylation of a Large Quantity of Unsaponifiable Matter . . . . . . . . . . 44

Fractional Crystallization of the Crude Acetates. . . 45

Determination of the Specific Rotation of Sample

IV of the Unknown Acetate.......... . 49

Preparation of Lupeol by Saponification of Lupeol Acetate . 50

Determination of the Specific Rotation of Lupeol. . . 51

Preparation of Lupeol Benzoate. . . . . . . . . 51

Determination of Specific Rotation of Lupeol Benzoate . . 52

Isolation of Unknown Alcohol by Saponification of the

Unknown Acetate............... 53

Determination of the Specific Rotation of the Unknown

Alcohol ................. 54

Recrystallization of the Unknown Alcohol. . . . . . 54

Isolation of the Unknown Benzoate and Evidence of an

Isomerization .............. 55

Section I................. 55

Part A. . . . . . . . . . . . . 56

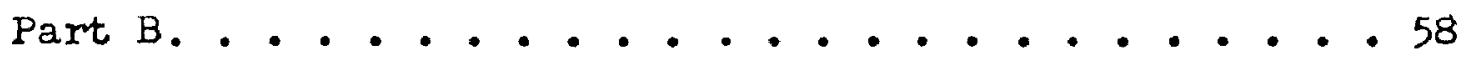

Part C. ................. 59

Determination of the Specific Rotation of the Unknown

Benzoate. . . . . . . . . . . . . . . 60

Section II. . . . . . . . . . . . . . 60

Acetylation of the Unknown Alcohol and Further

Evidence of an Isomerization. . . . . . . . . . 663

Carbon and Hydrogen Determinations on Lie Unknown Alcohol,

Unknown Acetate and Unknown Benzoate..........66 
Saponification Equivalents of the Unknown Acetate and Unknown Benzoate. . . . . . . . . . . . 67

Saponification Equivalent of the Unknown Acetate. . . 67 Saponification Equivalent of the Unknown Benzoate. . 68 Paper Partition Chromatography of the Alcohols and their Derivatives Isolated from the Unsaponifiable Matter. .. . . . . . . . . . . . . 69

Description of the Apparatus. . . . . . . . 70

Development of a Paper Chromatogram . . . . . . 72

Location of the Position of Compounds on the Developed Chromatogram. ............. 73

Calculation of $R_{f}$ Values and Interpretation of Results..................... 74 Chromatograms Comparing the Unknown Acetate with Lupeol Acetate. . . . . . . . . . . . . . 75

Chromatograms Comparing the Unknown Benzoate with Lupeol Benzoate... . . . . . . . . . . . 82

Chromatograms Comparing the Unknown Alcohol with Lupeol. . . . . . . . . . . . . . . . . 84 Reactivity of the Compounds wi th Iodine . . . . . 85 Differentiation of the Compounds Isolated from the Unsaponifiable Hatter on the Basis of Color Tests ....86 Isome rization . . . . . . . . . . . . 90 Suggested Names for the New Compounds . . . . . . . 95 Isolation of Crystalline Fractions from the Resinous Residue D-1................ 95 Infrared Spectra. . . . . . . . . . . . . 99

Investigation of the Diethyl Ether Extract: Isolation of the Pigments, Osajin and Pomiferin. . . . . . . . 106 Investigation of the Chloroform Extract . . . . . . . . 109 Investigation of the Absolute Alcohol Extract . . . . . . 110 
Investigation of the 70 Per Cent Alcohol Extract. . . . . 111 Investigation of the Acidified Aqueous Ext ract . . . . . 113 Preparation of Mucic Acid from the Jelly-Like Material. - 114 Investigation of the 5 Per Cent Sodium Hydroxide Extract. . 116 Investigation of the Fresh Fruit. . . . . . . . . . . 117 Preparation of Phenyl-D-Glucosazone from the Latex of Osage Orange Fruit. . . . . . . . . . . . . . 117 Preparation of Phenyl-D-Glucosotriazole from the Phenyl-DGlucosazone . . . . . . . . . . . . . . . . 118 Color Tests for Sugars. . . . . . . . . . . . . 119 Extraction of the Sugars with Aqueous Alcoholic Media . 120 Paper Partition Chromatography of Sugars. . . . . . . . 121 Attempted Isolation of Crystalline Sugars or Their Derivatives . . . . . . . . . . . . . . . 123 SUMALARY AND CONCLUSIONS . . . . . . . . . . . . 125 APPENDIX I: Botanical Description of Maclura Pomifera . . . 129 BIBLIOGRAPHY . • . . . . . . . . . . . . . . • 133 AUTOBIOGRAPHY . . . . . . . . . . . . . . . . . . 141 
INTRODUCTION

The phytochemical investigation of the fruit of Maclura pomifera was suggested by reports that the fruit and some of its constituent parts exhibited certain pharmacological actions. A survey of the literature revealed that some phytochemical investigation of the fruit had been carried out, but that further research might be of value.

The objectives of the research were to determine the presence or absence of common classes of organic compounds and to isolate chemically-pure compounds with acceptable physical constants.

The value of such an investigation would be: (1) the investigation would contribute to the phytochemical knowledge of the fruit of Maclura pomifera; (2) the methods of separation and chemical knowledge of the constituents should be of value to anyone intending to carry out a pharmacological investigation of the fruit or its constituents; (3) the economic importance of Maclura pomifera was established and further research on the constituents of the fruit would be of value from the standpoint of commercial production. 


\section{DISCUSSION OF LITERATURE}

Maclura pomifera, commonly known as the Osage Orange, was originally described (I) by Constantine Sarnel Rafinesque in 1817 under the botanical name Ioxylon pomiferum. Rafinesque wrote (I) that the tree was "discovered by Captain Lewis, and called by him the Osage Apple or Arrow-Wood of the Missouri." According to Rafinesque the tree belongs to the first natural class Eltrogynia, fourth natural order Axanthia, and to the natural family Axarcodia; he ascertained that the tree belonged to a genus unknown at that time and to which he gave the name Ioxylon, which means Arrow-Wood in Greek.

Thomas Nuttall (2) described the tree in 1818 under the botanical name Maclura aurantica and gave Bow-Wood and Yellow-Wood as synonyms. The name, Maclura, was "dedicated to William Maclure, Esq. of the United States, a philosopher, whose devotion to natural science, and particularly to the geology of North America, has scarcely been exceeded by Ramond or Soussure in Europe." (2)

In a criticism of Nuttall's book, Rafinesque (3) claimed priority for the description of the tree and stated that the name Ioxylon must be retained. In Rafinesque's book Autikon Botanikon (4) the name Toxylon maclura appears, and it is stated that Maclura aurantica is the same species.

Camillo Karl Schneider (5) described the Osage Orange under the name Ioxylon pomiferum in his botanical textbook; the monograph is illustrated well and reproductions of these drawings are included in this dissertation in Appendix I.

Fammel (6) lists the Osage Orange under the name Maclura pomifera 
(Raf.) Schneider, and states that "the fruit is said to be poisonous." However, Rafinesque (1) mentioned that "the fruit is very good to eat." Muenscher (7) reported that certain individuals develop a dermatitis upon coming in contact with the milky sap from the stems, leaves and fruits.

The American Joint Committee on Horticultural Nomenclature (8) in 1917 recommended the botanical name Maclura pomifera for the common Osage Orange hence that name will be used herein.

Active interest in the Osage Orange developed when Professors Emerson and Roess of the Chemical Department of the University of Kansas announced the discovery of rubber or a rubber-like substance in the fruit of the Osage Orange. However, after a chemical investigation of the fruit, undertaken during the years 1904 to 1912, Fox (9) claimed there was no rubber in the fruit of the Osage Orange.

Certain enzymes, - a lipase, an amylase, and a proteinase - have been reported $(10,11)$ to be present in the fresh latex of the Osage Orange. Gerber (11) compared the lipolytic, amylolytic, and proteolytic activities of the latexes obtained from Maclura aurantica (Maclura pomifera), Ficus carica, and Broussonetia papyrifera; the author stated that each of these latexes merits the name "pancreatic vegetable juice", since they solubilize the hydrates of carbon, fatty substances, and protein substances. Injection of the fresh latex of Maclura pomifera, diluted 75:25 with physiological saline, into the breast of the pigeon and back of the rat caused (10) the animals to pass through a fever period with intense thirst and agitation then through an abating period during which the rat's coat bristled and its head fell while the pigeon 
4

vomited; finally, there was a comatose phase which terminated in death after seventeen hours for the pigeon and eight hours for the rat. The author described (10) necrosis of tissues with digestion of the internal part of the skin and attributed the elevated temperatures of the pigeons to these processes. After boiling the latex of Maclura pomifera for thirty minutes at $100^{\circ}$ and injecting the boiled latex into animals, Gerber and Salkind (10) reported that the liquid was absorbed little by little, leaving only the caoutchouc mass. All animals injected with the boiled latex remained living. The authors (10) concluded that the heating destroyed the enzymes, and that the boiled latex acted only as an inert substance.

Osage Orange juice containing macin, a proteolytic enzyme, may be employed to tenderize sausage casings and meat. Swift and Company obtained a patent (12) which stated that Osage Orange juice could be used for this purpose.

The first detailed analysis of the fruit of Maclura pomifera was reported by McHargue (13) in 1915. This author reported that "the pulp and seed of the Osage Orange contain valuable feed, fertilizer, oil and resin constituents." On the basis of its physical properties McHargue described the oil obtained from the seeds of the fruit as a semi-drying oil belonging to the linseed oil class. His analysis of the fruit is shown in Table 1. McHargue concluded that "it is quite probable that with due care and intelligence this tree could be made the source of a profitable industry throught the utilization of its timber and the different products of its fruit." 
TABLE I

Analysis of Osage Orange Fruit (11)

Percentage

Water in the ripe fruit......... 80.00

Gums and resins in dry pulp (acetone extract). 29.30

Nitrogen in the dry pulp. . . . . . . 2.81

Protein in the dry pulp $(\mathrm{N} \times 6.25)$. . . . 17.56

Nitrogen in the pulp after acetone extraction 21.34

Oil in the seeds (ether extract)...... 42.04

Nitrogen in the oil-free meal . . . . . 10.80

Protein in the oil-free meal $(\mathrm{N} \times 6.25) . .67 .50$

Mineral constituents

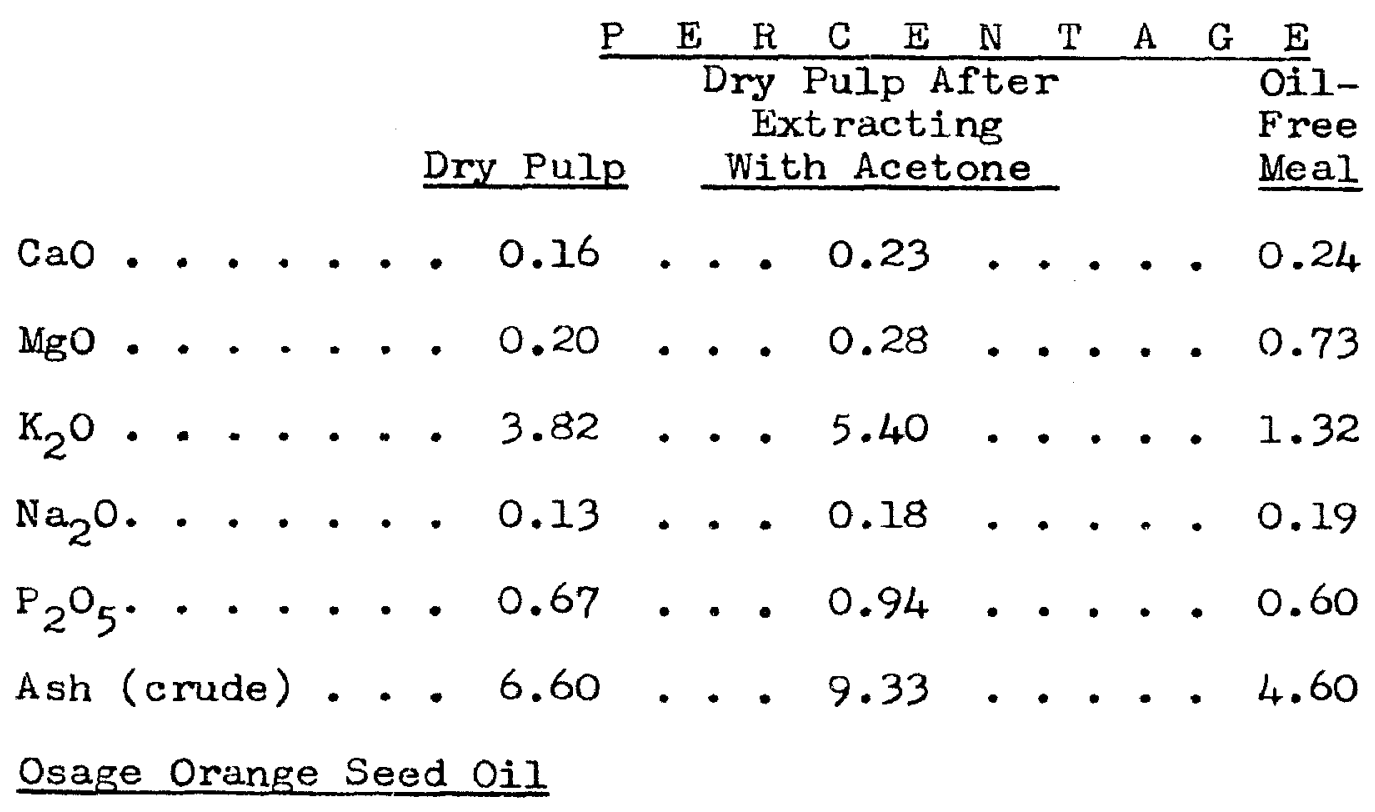

Specific Gravity 0.929; Iodine number 134-136;

Saponification Value 1.92 . 
The milky juice of the Osage Orange contains enzymes, carbohydrates, fats, and albumins according to Wehmer (14).

The pigments present in the Osage Orange have been used as a commercial dyestuff for many years. In 1914, Kressman (15) discussed the similarity between the dyestuff present in the Osage Orange and that of fustic. Yellow colors produced by direct dyeing or by aluminum or tin mordants are not fast; but orange-yellow, old gold, deep tan, olive, and chocolate shades obtained with chromium and iron mordants are equal to, or better than, those obtained with fustic. Kressman (15) stated that the mill waste from the manufacture of dyes from the Osage Orange was 25,000 tons annually at that time. A yellow pigment was isolated from the fruit of the Osage Orange in 1938 by Walter, Wolfrom and Hess (16); they named the new pigment "Osajin". Further investigation at The Ohio State University indicated that two pigments were present; the second pigment was named "Pomiferin" by the authors (17). In a series of thirteen papers (16-28) published during the years 1939 to 1951 inclusive, M.L. Wolfrom and his students established the structures of Osajin and Pomiferin. The pigments are isoflavones and differ only in that pomiferin has an additional hydroxyl group at the $3^{1}$ position. Their stmetures may be represented as follows:

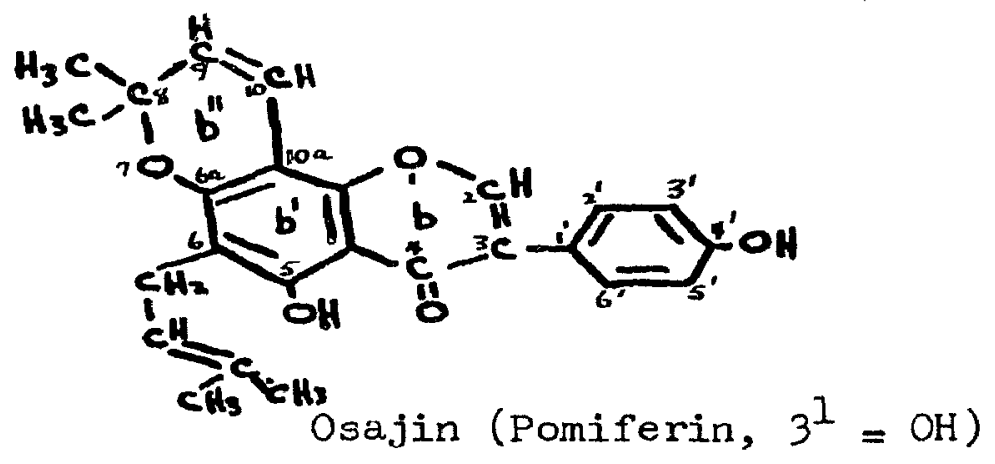


The systematic name for Osajin would be (27): 5-hydroxy-3(p-hydroxyphenyl)-8, 8-dimethyl-6-(3-methyl-2-butenyl)-4, 8-benzo ( $\left.1,2-b ; 3,4-b^{1}\right)$ dipyran-4-one. (Ring Index No. 1989.)

In support of the proof of structure of Osajin and Pomiferin by degradative methods Wolfrom and his students synthesized (28) dihydroiso-osajin and dihydro-isopomiferin which may be represented as follows:

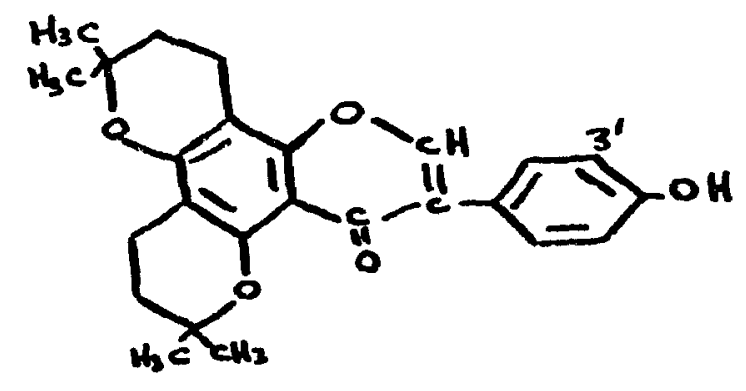

Dihydro-iso-osajin (dihydro-isopomiferin, $3^{1}=\mathrm{OH}$ )

In order to isolate the pigments, Osajin and Pomiferin, from Osage Orange fruit, Wolfrom and co-workers (17) collected the fruit in the autumn, chopped them into small pieces with a hat:het, and oven-dried the pieces at $80^{\circ}-90^{\circ}$ until they were brittle. The dried material was comminuted in a hammer mill and the resulting meal was extracted in $1.6 \mathrm{Kg}$. quantities with $4 \mathrm{~L}$. of low-boiling petroleum ether in a soxhlettype extractor. When the extract was colorless the resulting marc was extracted with $4 \mathrm{~L}$. of commercial grade ether until the ether extract was colorless. This ether extract was treated with decolorizing charcoal and was filtered through a layer of fuller's earth and charcoal. On concentrating the filtrate the crude mixture of yellow pigments was obtained. The crude mixture of pigments was first resolved into its two components, Osajin and Pomiferin, by fractional crystallization. 
Pomiferin was obtained on repeated recrystallizations from xylene whereas the material obtained from the xylene mother liquor on repeated recrystallization from ethanol yielded Osajin. The material designated Osajin was a light lemon-yellow crystalline substance melting at $189^{\circ}$ (uncorr.) and had an absorption maximum at $2730 A^{\circ}$. The material designated Pomiferin was a deeper yellow than Osajin, was crystalline and had a melting point of $200.5^{\circ}$ (uncorr.); its absorption maximum was $2750 A^{\circ}$ (16). An improved separation (24) of Osajin and Pomiferin is based upon the fact that Pomiferin forms a lead salt insoluble in methanol while Osajin does not react with lead acetate in methanolic solution.

Regarding the dyeing properties of Osajin and Pomiferin, Wolfrom et al. (27) reported that the pigments are acid dyes which require mordants. They have no effect upon cotton but dye wool and silk. Wool is dyed most readily and Pomiferin is better on silk. The same authors (27) performed insecticidal assays on Osajin and Pomiferin and a number of their derivatives as well as on the crude meal and dried fruit; none of these showed activity under conditions wherein rotenone was very active. The Western Regional Research Laboratory of the United States Department of Agriculture is now including the pigments of the fruit and wood of the Osage Orange in their physiological studies on capillary fragility and radiation siokness, comparing their action to rutin and heparin. At the time of writing, no results of this work had been published. However, Smith and Waud (30) compared the activity of a crystalline substance obtained from the Osage Orange with that of hesperidin (vitamin P) and tannic acid B.P. in increasing the capillary 
resistance of guinea pigs formerly fed a scorbutic diet. They found that hesperidin increased the capillary resistance to some degree while both the crystalline substance from the Osage Orange and tannic acid produced a marked rise in capillary resistance. They stated that the effects of hesperidin and tannic acid were much reduced as the scorbutic condition advanced, while that of the substance from the Osage Orange was not reduced. The authors also pointed out that the substance from the Osage Orange had a marked stimulating effect on the isolated heart. Smith and Waud (39) gave no details as to the method of separation of the crystalline substance from the Osage Orange fruit.

In another publication, Waud (29) described the isolation of a crystalline substance from the fruit of the Osage Orange which produced augmentation of the isolated frog's heart. This substance, when perfused through the isolated frog's heart in a concentration of only one in $20,000,000,000$, produced definite augmentation. There was an increase in both systole and diastole. The rate of the heart was not changed, and any existing irregularities disappeared. He described a definite latent period between the application of the drug and the onset of the characteristic effects. Although the exposed rabbit's heart showed the same augmentation as observed in the perfused frog's heart on application of the drug, the concentration of the drug required in the blood stream appeared to be much greater than that in the perfusion liquid. The substance described crystallized in fine, faintly yellow needles and, after being boiled with hydrochloric acid, was found to reduce copper solutions; tests for the flavone group were positive. The substance was described as a flavone glucoside. There was insufficient chemical data 
in the publication to indicate exactly what chemical compound the author was describing. Walter, Wolfrom, and Hess (16) reported that the yellow pigment, Osajin,, reduced Fehling's solution and Tollen's reagent. Wolfrom and co-workers (19) also reported that Osajin and Pomiferin gave positive flavone color tests and later reported (21) that the reduction color tests of Asahina and co-workers are not only characteristic of flavones and flavanones but also of isoflavones and isoflavanones. On the basis of this evidence the "flavone glucoside" described by Waud (29) may have been Osajin or Pomiferin or a mixture of the two pigments. Wolfrom and co-workers (21) found no isoflavone glycoside but only the free isoflavones in the fruit of Maclura pomifera.

Several years later, Waud $(31,32)$ reported that the cardiacactive constituent of the fruit of the Osage Orange is a phytosterol closely related to cholesterol. Isolation was effected by extraction of the dried fruit, saponification of the fat, extraction with ether, and crystallization of the unsaponifiable matter from alcohol. The white crystalline product obtained gave the characteristic color reactions of phytosterols. As will be pointed out later in this discussion, lupeol, a triterpene alcohol, which was isolated from the unsaponifiable matter by the same procedure, gave color reactions similar to phytosterols. In response to a personal communication which requested clarification of the evidence that the unsaponifiable matter contained a phytosterol, Dr. Waud replied that his only proof was by the ordinary color reactions. He stated that the crystaline compound might be lupeol and that a paper covering all the work had never been published due to the fact that they were unable to isolate the very 
active substance, which at times, but not consistently, had been isolated in an impure state. The crystalline product which gave the characteristic color reactions of the phytosterols had a very low activity compared with some impure extracts.

Lupeol, a triterpene alcohol, was isolated from the unsaponifiable fraction of the petroleum ether extract of dried Osage orange fruit by Swift and Walter (33), in 1942. The method used to isolate lupeol was as follows. Dried Osage Orange fruit was completely extracted with low boiling petroleum ether. The extract was concentrated and passed through an aluminum silicate adsorbent described by Kraybill ( 34 ) et al. which removed a wax-like material. The concentrated petroleum ether extract was saponified with twice its volume of 95 per cent ethanol saturated with potassium hydroxide. The mixture was diluted with water and extracted with ether. Evaporation of the ether left a residue which was then mixed with an equal weight of Nuchar and extracted in a soxhlet apparatus with ether. The ether was subsequently evaporated. Repeated crystallizations of the residue from acetone and then from 85 per cent ethanol gave a product melting at $208^{\circ}-211^{\circ}$. Final purification was effected through formation of the acetate and subseauent saponification to give lupeol melting at $214^{\circ}-215^{\circ}$. The yield reported was $5.1 \mathrm{Gm}$. of crude Iupeol or $2.3 \mathrm{Gm}$. of pure lupeol from one kilogram of dried Osage Orange fruit. The authors (33) reported the melting points, specific rotations, and crystallographic optical properties of lupeol, lupeol acetate and lupeol benzoate.

Lupeol (35) was first isolated from the seeds of Lupinus luteus. Likiernik investigated the substance in larger amounts and named the 
compound (35). In the course of time it was shown that lupeol occurs in a large number of plants partly as the alcohol and partly as esters. It occurs in the form of its cinnamic acid ester in the Guttapercha of Palaquium Treubi, and in the free form in the flowering tops of Roman Camomile (35). Lupeol acetate occurs in the milky juice of Ficus (35). Lupeol frequently occurs with its isomers, a-amyrin and B-amyrin; for example lupeol, a-amyrin and B-amyrin occurs in Shea nut oil (47). Lupeol and its derivatives have been adequately described in the German literature (35-41). The structure proposed by Ruzicka and Rosenkrantz (42), in 1940, for the monohydric triterpene alcohol is as follows.

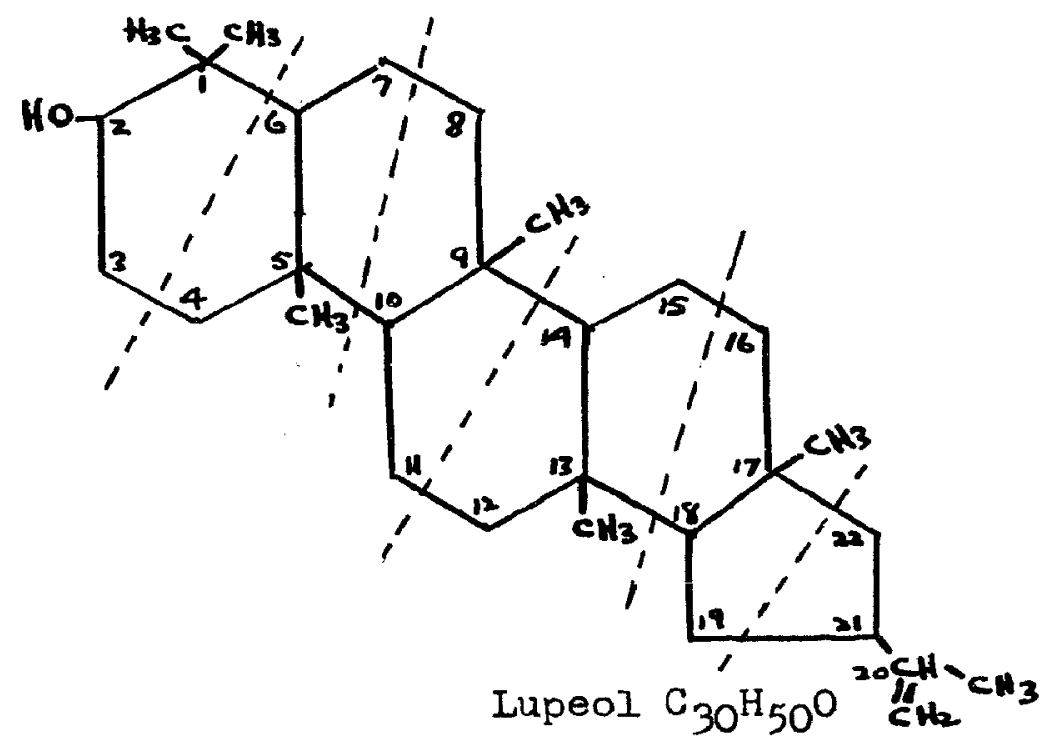

The dotted lines divide the structure into isoprene units. On the basis of new chemical and physical evidence Jones and Meakins $(43,44)$ proposed other possibilities for the structure of lupeol; excellent reviews on the assignment of structures to the triterpenes are given by Spring (45) and Noller (47). Ames and Jones (48) forwarded new evidence in 1949; they found an interrelationship between lupeol and B-amyrin and tentatively formulated the following structures for the 
three isomers, lupeol, a-amyrin and B-amyrin:

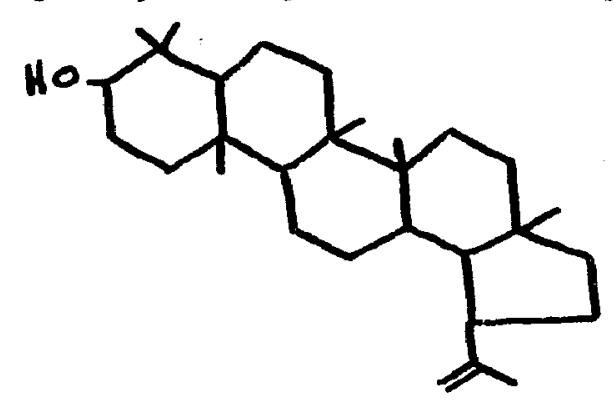

Lupeol

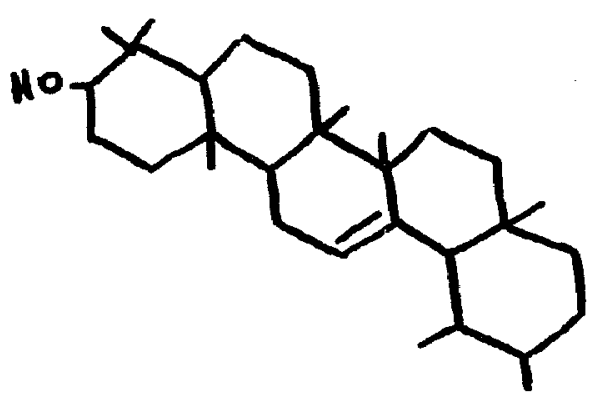

a-amy rin

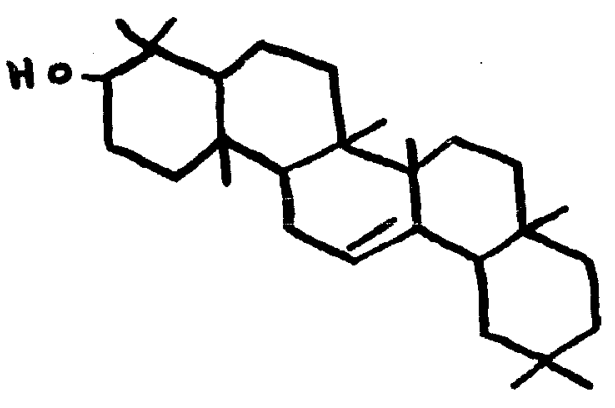

B-amy rin

In order to make the mass of experimental data on the triterpenes intelligible, Noller (47) used one structure for oleanolic acid as a reference even though this structure may eventually be displaced by another. The structure for oleanolic acid on which the arguments are based is that originally proposed by Haworth:

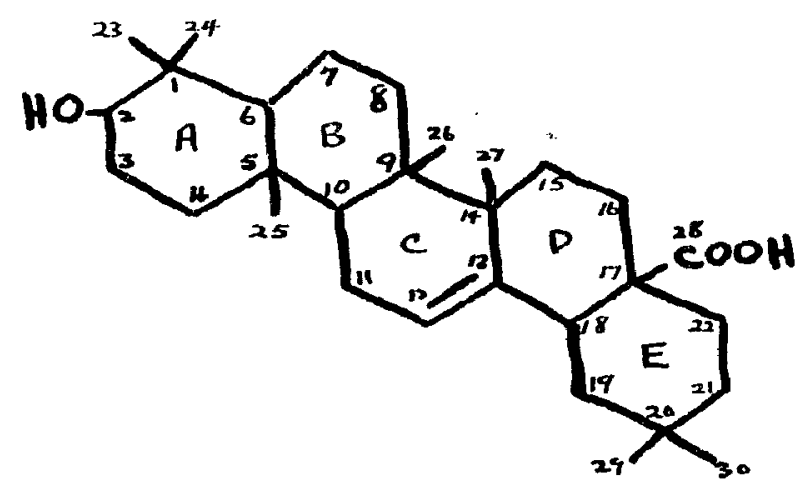

Oleanolj.c Acid 
Oleanolic acid is a triterpenoid sapogenin found as a saponin in guaiac bark, sugar beet, calendula flowers and other plants and in the free form in olive leaves, clove buds and grape skins (47). It belongs to the B-amyrin group of triterpene alcohols. Noller (47) gives a table of interconversions of triterpenes in the B-amyrin group and bases the structures of the other members of the group on the structure of oleanolic acid.

As a class of organic compounds the triterpenes are natural products containing thirty carbon atoms whose carbon skeleton is believed to be divisible into isoprene units. They are distributed widely in the plant kingdom and may occur in all parts of the plant, free or combined with sugars. Triterpenes have also been obtained from animal sources, an example being lanosterol isolated from wool fat. There appears to be a relationship between the type of triterpene and the type of pigment isolated from a given plant. Triterpendiols appear to be associated with carotenoid pigments, while triterpene hydroxy acids are associated with anthocyanins (47). It is of interest, therefore, in this paper to draw attention to the fact that lupeol, a monohydric triterpene, occurs in the fruit of Maclura pomifera along with the isoflavone pigments, Osajin and Pomiferin. Wolfrom et al. (21) stated that to their knowledge Osajin is the first free (non-glycosidic) isoflavone to be isolated from a natural product; it is probable that the isoflavone is present in the free form in the fruit, since the glgcoside would not be expected to be highly colored and yet the fruit is highly pigmented; this is rendered more probable by the fact that only neutral solvents were employed in the isolation of Osajin. 
Certain isomerizations have been reported in the triterpene field of chemistry and since these have a relationship to the experimental part of this dissertation they will be briefly reviewed. In 1937, the first example of the conversion of a naturally occurring tetracyclic terpene to a naturally occurring pentacyclic terpene was reported (49). From the non-saponifiable matter of shea nut oil Benyon, Heilbron and Spring (49) isolated the three triterpenes Bamyrin, lupeol and basseol by fractional crystallization of their acetates. They found that basseol acetate, a tetracyclic terpene, is isomerized to B-amyrin acetate by the action of bromine, the halogen acids, formic acid and sulfuric acid. Perbenzoic acid titrations indicated that basseol had two double bonds but only one double bond is reduced by catalytic hydrogenation ( 50 ). The authors (50) diagnosed the reactive ethylenic linkage of basseol as an exocyclic methylene group since its acetate, but not dihydrobasseol acetate, gives formaldehyde on ozonolysis. The isomerization is schematized by the authors (50) as follows:
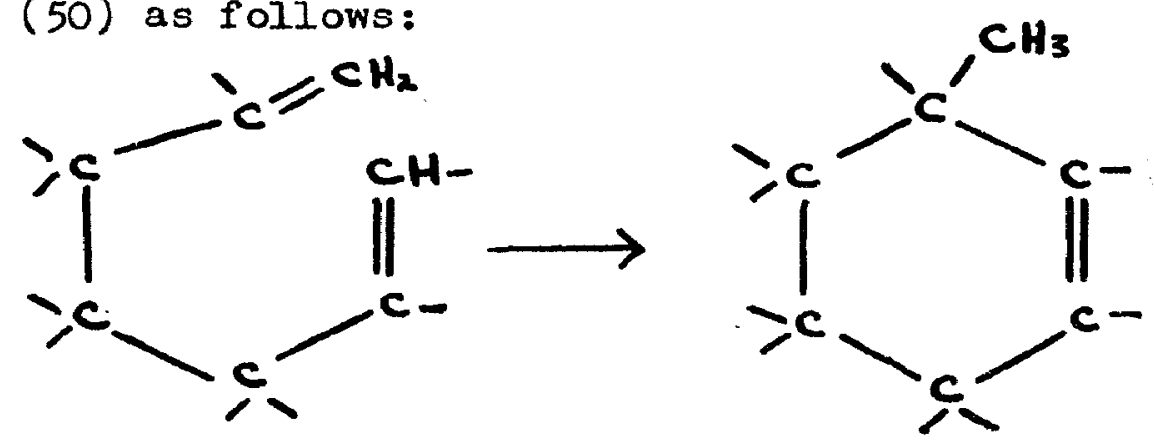

Another isomerization was reported by Duerden and co-workers (51). They obtained the hydrochloride of lupeol, $\mathrm{C}_{30} \mathrm{H}_{51} \mathrm{OCl}$, by treating lupeol with ethanol saturated with hydrogen chloride. They obtained lupeol acetate by refluxing the lupeol hydrochloride with silver acetate in ethanol for three days followed by refluxing with acetic anhydride for 
two hours. However, when the lupeol hydrochloride was refluxed for twenty-four hours with dimethylaniline, followed by acetylation, they obtained isolupeol acetate. A third isomeric acetate was isolated by working up the mother liquors. They stated that the isolupeol acetate has an endocyclic double bond while lupeol acetate has an exocyclic double bond but that both give formaldehyde on ozonolysis, the former yielding 6 per cent and the latter yielding 18 per cent. They accounted for the anomalous results with isolupeol acetate by pointing to a possible degree of mobility between the endocyclic double bond of isolupeol and the exocyclic double bond of lupeol. Biedebach (53) found that when lupeol was heated with concentrated formic acid for two hours, a mixture of three isomeric formates were obtained. The formate mixture was divided into two parts by treatment with alcohol. Saponification of the two fractions and conversion of the alcohols to acetates allowed their separation. He obtained lupeol acetate, a-allolupeol acetate, and $\gamma$-allolupeol acetate all of which differed widely in melting point and specific rotations. A fourth example of isomerizations in the triterpene field was reported by Ames and Jones (48). They isolated two isomerides in about forty per cent yields by treating lupenone (the ketone corresponding to lupeol) with sulfuric acid in acetic acid benzene solution. Under the mildest conditions, that is at $20^{\circ}$ for seven days, lupenone was converted to lupenone-I, an isomeride, which on further treatment with the same reagents gave lupenone-II, a second isomeride, also obtained under more vigorous conditions directly from Iupenone. When the carbonyl of lupenone-II was converted to a methylene group by the Wolff-Kishner procedure a hydrocarbon, lupene-II, was 
obtained which was found to be identical with B-amyrene-III obtained by the reduction of B-amyrone (the ketone corresponding to B-amyrin) with amalgamated zinc and hydrochloric acid. Their partial formulations for the rearrangements which are believed to be involved in the formation of the common hydrocarbon from both B-amyrin and lupeol are illustrated below.

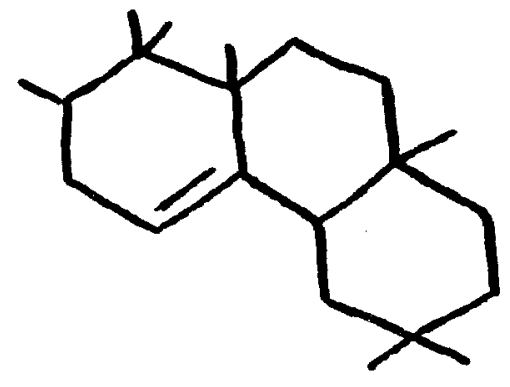

B-Amyrone

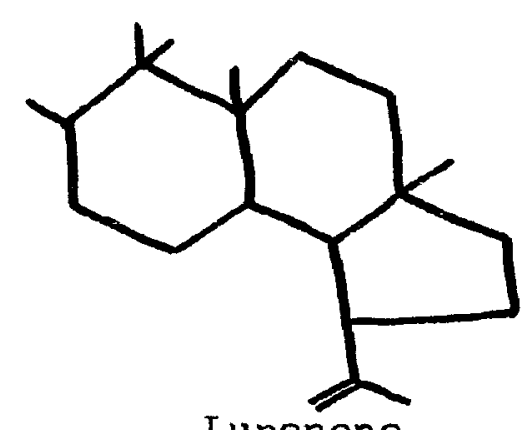

Lupenone

$$
\downarrow \begin{aligned}
& \text { Isome rization } \\
& \mathrm{Zn}-\mathrm{Hg} \\
& \mathrm{HCl} \\
& \text { Reduction of } \\
& \quad \text { carbonyl }
\end{aligned}
$$

Isome rization $\mathrm{H}_{2} \mathrm{SO}_{4}$ in Acetic AcidBenzene

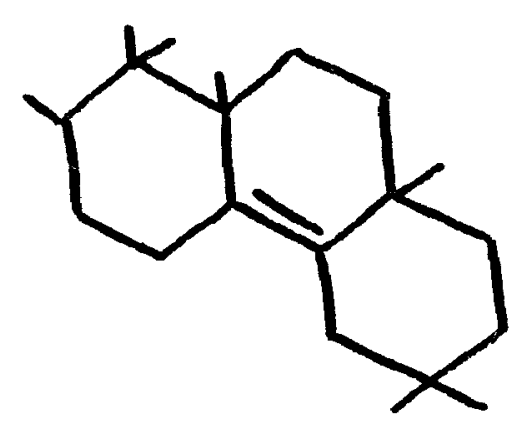

B-Amy rene-III or Lupene-II
(1) Isome rization $\mathrm{H}_{2} \mathrm{SO}_{4}$ in Acetic Acid-Benzene.

(2) Reduction of the carbonyl by WolffKishner method.

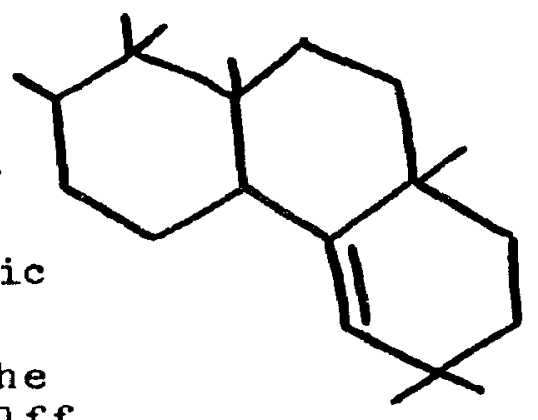

Lupenone-I

The above survey indicates that rearrangements and isomerizations of 


\section{8}

triterpenes, including lupeol, under conditions of esterification, reduction in acid media, various othe $r$ acidic conditions, and removal of the elements of hydrogen chloride from the hydrochloride of lupeol with dimethylaniline, are well established. The experimental work in this dissertation indicates the possibility of another example of such an isomerization.

The toxicity of Osage Orange fruit for sheep was described by Pullar (54). Tests for cyanogenetic glycosides were negative.

Beal (55) examined extracts of Osage Orange wood and fruit for quercitin-like substances with the hope of finding a new source of rutin; results indicated that no such substances were present in the Osage Orange.

A second analysis of the fruit of the Osage Orange, very similar to that done by McHargue (1I), was performed by Clopton and Roberts (56) in 1949. The results of their analyses are given in Table 2. The authors (56) pointed out that the resin extracted by acetone contained a liquid and a solid portion. The solid portion consisted of the pigments, Osajin and Pomiferin, which could be polymerized to a hard resinous mass by heating. They stated that the liquid resin makes up 10-15 per cent of the Osage Orange fnit. Amyrins, mostly B-amyrin, were reported to be present in a concentration of 0.91 per cent of the dried fruit; however, no chemical evidence was presented which would differentiate the amyrins from lupeol, an isomer. No derivatives of a- or B-amyrin were reported. The authors (56) stated that the watersoluble sugars present consist mainly of a mixture of glucose, arabinose and an unidentified disaccharide but gave no experimental details to 
substantiate this statement.

TABLE 2

"Composition of Osage Orange Fruit and its Constituents." (44)

Water (in ripe fruit). . . . . . . . . . . . . Pe rentage Fruit pulp as a whole (dry weight):

Oils, resins, and pigments (acetone extract) . . . 4 40.03 Oil (petroleum ether extract) . . . . . . . . . 18.34 Resins and Pigments . . . . . . . . . . . . . 21.69 Nitrogen . . . . . . . . . . . . . . . 2.56 Crude Protein .................... . 16.00 Total Sugars . . . . . . . . . . . . . 15.3 Reducing Sugars . . . . . . . . . . . 10.8 Hydrolysable Sugars . . . . . . . . . . . 4.5

Other hydrolysable carbohydrates (by difference) . . 7.0 Crude Fiber.................... . . 12.0 Total Ash

Ashed at $900^{\circ} \mathrm{C}\left(\mathrm{K}_{2} \mathrm{O}\right.$ volatalized $) . . . . . . . .4 .07$ Rubber (benzene after acetone). . . . . . . . . . 2.24 Amyrins (mostly B). . . . . . . . . . . . . 0.91 Seeds (dry weight):

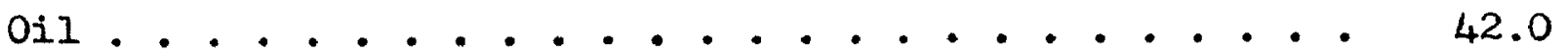
Nitrogen. . . . . . . . . . . . . . . . . . 6.2

On oil-free basis. . . . . . . . . . . . . 10.7 Crude protein . . . . . . . . . . . . . . 38.9

On oil-free basis. . . . . . . . . . . . 67.0 Other constituents. . . . . . . . . . . . . . 19.1 
Regarding the toxicity of Osage Orange fruit they stated that there are no definite indications that any toxic substances are present in the dried fruit; however, they stated that when dairy cattle eat the fruit lactation decreases. Their opinion was that the low molecular weight resins present in the latex caused some inflammatory action in the digestive tract; no biological tests were reported (44).

By personal communication, Dr. Robert Uhlmann of Kansas City, stated that it is a well known fact among farmers that cows become dry without any toxic reaction when they eat the fruit of the Osage Orange. By personal communication, Robert D. Coghill, Director of Research, Abbott Laboratories Research Division, stated that his own experience with the fruit was not that they suppressed lactation in dairy cattle but that the milk became very bitter and the casein seemed to become partially coagulated. He advised that it would be a rather strenuous problem to measure suppression of lactation.

The properties of Osage Orange oil and the identification of some of its constituents were reported by Beal and Wenzel (57) in 1951. From the major constants of the oil it is shown to be not a semi-drying oil of the cottonseed type as previously reported (1.3) but instead its physical constants closely approximate those of rape seed oil, although the viscosity of Osage Orange oil is greater (57). Separation of the fatty acids of the oil by the lead salt - ether method yielded 48.9 per cent of unsaturated fatty acids based on the weight of the oil. Oleic acid and linoleic acid were the unsaturated acids isolated as the bromides. The iodine value in conjunction with the thiocyanogen value indicated that they were present in the ratio of 6 to 1 respectively. 
Myristic acid was identified as a saturated fatty acid of the oil by mixed melting point and by formation of the anilide. From the "foots" of the oil, obtained by filtration of crude Osage Orange oil, were isolated arachidic acid, a saturated fatty acid identified by mixed melting point and by formation of the anilide, lupeol, and an unidentified compound of melting point range $90^{\circ}-97^{\circ}$ in small quantity. From the unsaponifiable matter of the oil was obtained lupeol. Lupeol acetate, Iupeol benzoate and lupeol-amnaphthyl carbamate were prepared and described. The authors pointed out that the oil in the raw form is not edible because of the delayed buming sensation which it produces. The oil was purified by shaking it with 10 per cent sodium carbonate solution then washing it with distilled water until the washings were noutral to litmus. The oil was then extracted with ether and the ether evaporated yielding a clear, amber colored oil with a bland taste. 


\section{EXPERIMENTAL}

COLLECTION OF FRUIT

Maclura pomifera is a native tree of Arkansas, Oklahoma, and Texas and now grows extensively throughout the southern, midwestern and eastem states $(56,58)$. Its greatest use is as a hedge plant (9); it is hardy, grows rapidly, has the ability to withstand drought, is indifferent to the quality of the soil, is cheap and omamental in appearance (9). The particular fritt used in this work was collected from a row of Osage Orange trees making up a hedge fence on Trabue Road about two miles from Olentangy River Road in Franklin County, Ohio. The fruit was collected in October, approximately one week after the first frost. Most was gathered from the ground where it had fallen but some was gathered from the trees. Immediately after collection the fruit was placed in a refrigerated room where it remained until just before being used. DRYING OF FRUIT

Some work was done on the fresh fruit, but most of the fruit was dried. Just before drying the fruit was removed from the cold room, washed well under the hot water tap, dried with a towel, weighed, comminuted by one of three methods and the comminuted material dried in an oven.

Sample I was comminuted by cutting the fruit into quarters and forcing it through an electrically operated meat-grinder. The pulp obtained by this method was spread out on trays for drying but it was found that the pulp adhered together and did not dry evenly. It was necessary to mix the pulp frequently on the trays during the drying 
operation to prevent buming of the surface layers. This sample was dried in a steam-heated oven at temperatures between $48^{\circ}$ and $69^{\circ}$ over a period of three to four days.

Sample II was comminuted by cutting the fruit into thin slices, then cutting the slices into narrow strips by means of a knife. The pieces were dried in a steam-heated oven at a temperature of $80^{\circ}$ to $85^{\circ}$ for forty-three hours.

Sample III was cut into strips with a knife similar to Sample II, but was dried in an air-conditioned Precision Scientific Oven Type B at a temperature of $80^{\circ}$ for twenty-four hours.

Sample IV was comminuted by cutting the fruit into thin slices by means of a mechanical slicer (Model Al20 manufactured by The Hobart Manufacturing Company, Troy, Ohio). The thin slices were dried in an air-conditioned Precision Scientific Oven Type $B$ at a temperature of $80^{\circ}$ for twenty-four hours. This method of drying was found to be the best since the thin slices dried evenly and rapidly.

All four samples of dried fruit were ground in a Wiley Drug Mill to about a number 20 powder. The powdered dried fruit had a light reddish-brown color and an odor resembling Grape-Nuts. The powder was placed in large, completely-ifilled, sealed jars. To each jar of powder was added a few drops of chloroform to act as a preservative.

The moisture content of the fresh fruit is summarized in Table 3. The average weight per fresh fruit for samples II and III was calculated to be $733 \mathrm{Gm}$. The average moisture content was 81.97 per cent of the fresh fruit; McHargue (13) reported the ripe fruit to contain 80.00 per cent water; Clopton and Roberts (56) reported 80.0 
24

per cent water; Beal and Wenzel (57) reported 77.9 per cent water in the fresh fruit by weight difference.

TABLE 3

Moisture Content of Fresh Fruit

$\begin{array}{lccc}\text { Sample } & \begin{array}{l}\text { Weight of } \\ \text { Fresh Fruit (Gm.) }\end{array} & \begin{array}{l}\text { Weight of } \\ \text { Dried Fruit (Gm.) }\end{array} & \begin{array}{c}\text { Percentage Loss } \\ \text { In Weight } \\ \text { on Drying }\end{array} \\ \text { I } & 37,544 . & 7,163.5 & 80.93 \\ \text { II } & 1,229 . & 225.0 & 81.69 \\ \text { III } & 12,698 . & 2,171.5 & 82.90 \\ \text { IV } & 38,500 . & 6,787.0 & 82.37\end{array}$

INVESTIGATION OF THE DRIED FRUIT

EXTRACTION OF THE DRTED FRUIT BY THE GEIERAL METHOD OF ROSENTHALER (59)

Utilizing a Wester extractor, $200.0 \mathrm{Gm}$. of sample II of the dried fruit was extracted with a series of solvents in the order given in Table 4, according to the procedure described by Rosenthaler (59). For each organic solvent the extraction was continued until no residue was obtained on evaporation of a sample from the extractor. The solvent was removed from each organic extract by distillation under reduced pressure, using a water aspirator, and at a temperature not above $38^{\circ}$. The extracts were dried to constant weight in a vacuum desiccator over Drierite. The weights of the extracts are given in Table 4. The marc from the absolute alcohol extraction was removed from the Wester extractor and placed in a 1 L. flask to which was added $800 \mathrm{ml}$. of 70 per cent by rolume ethanol-water. The suspension was heated to boiling under a reflux condenser and then filtered on a steam-heated 
Buchner funnel. The marc was washed with $100 \mathrm{ml}$. of the same solvent. The combined filtrates constituted the 70 per cent alcohol extract.

The residual marc was macerated for seventy hours with $800 \mathrm{ml}$. of water at room temperature. Filtration yielded $525 \mathrm{ml}$. of cold aqueous extract.

The wet marc obtained from the cold water extract was heated with $400 \mathrm{ml}$. of boiling water and the suspension filtered while hot. The filtrate constituted the hot water extract.

The drained marc from the hot water extraction was macerated with $800 \mathrm{ml}$. of one per cent hydrochloric acid for seven days at room temperature with occasional shaking. The aspended plant material was removed by straining through heavy cloth. The marc was washed with two $50 \mathrm{ml}$. portions of water and the washings added to the acidified aqueous extract. The combined filtrates constituted the acidified aqueous extract.

The residual plant material, removed from the cloth, was suspended in $1 \mathrm{~L}$. of 5 per cent aqueous sodium hydroxide solution and the hot solution was filtered through heavy cloth. The filtrate was neutralized with concentrated hydrochloric acid. The resulting solution constituted the 5 per cent aqueous sodium hydroxide extract.

The marc from the latter extraction was suspended in $800 \mathrm{ml}$. of boiling one per cent aqueous hydrochloric acid and the suspension filtered while hot. The solid matter on the filter was washed with $200 \mathrm{ml}$. of water and the washings added to the hot acidified aqueous extract.

The final marc was dried at $80^{\circ}$ for nineteen hours; this dried 
material constituted the residual marc.

\section{TABLE 4}

Extraction of $200.0 \mathrm{Gm}$. Dried Osage Orange Fruit (Sample II)

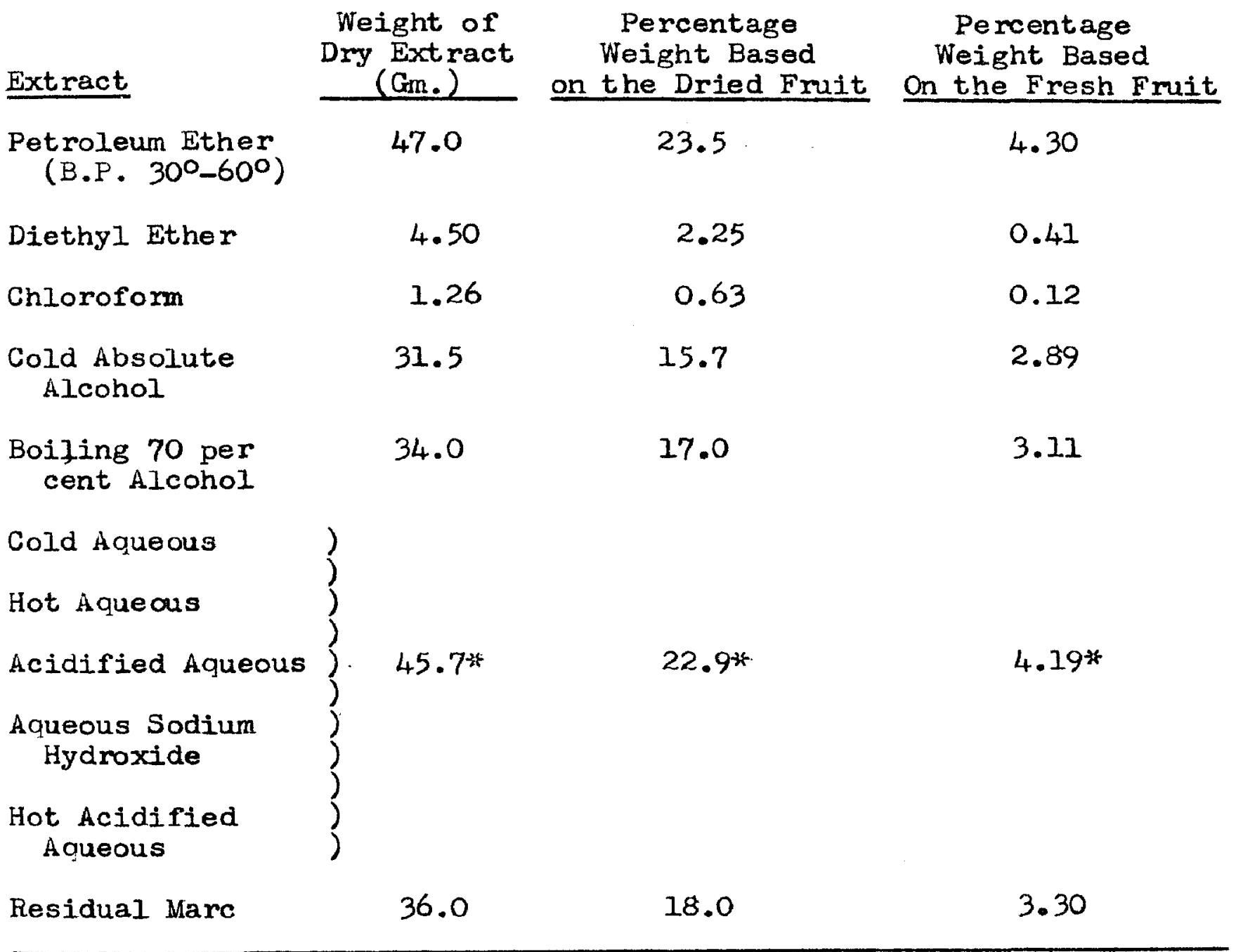

* Obtained by calculation.

A phytochemical investigation of these extracts of the dried f mit was undertaken in order to repeat the isolation of constituents formerly reported to be present and to determine the presence or absence of other members of common classes of organic compounds. The objective was to isolate chemically-pure compounds with acceptable physical constants. 
INVESTIGATION OF THE PETROLEUM ETHER EXTRACT

The fact that a cardiotonic constituent had been reported to be present in the unsaponifiable fraction of the petroleum ether extract of the dried fruit made investigation of this fraction an interesting pharmaceutical problem. As the discussion of the literature reveals, it was not clear which part of the unsaponifiable matter was responsible for the action. The isolation of lupe ol from the unsaponifiable matter was well established, but the yield of lupeol accounted for only a small fraction of the total unsaponifiable matter. A detailed analysis of the unsaponifiable was carried out in order to separate this fraction into its constituent parts.

Preliminary experiments were carried out with the $47 \mathrm{Gm}$. of dry petroleum ether extract (Table 4) but it was soon evident that much larger quantities would have to be used. In order to obtain larger quantities two large scale extractions, described below, were carried out.

\section{Extraction A}

Sample I was extracted with petroleum ether; $2347 \mathrm{Gm}$. of the dried fruit was extracted in a Soxhlet apparatus for eighteen and one half hours with $4430 \mathrm{ml}$. of petroleum ether, having a boiling point range of $30^{\circ}-60^{\circ}$. The petroleum ether was removed by distillation on a team-bath. A yield of $385 \mathrm{Gm}$. of oil was obtained; this amount of oil represented 16.4 per cent of the dried fruit.

The $385 \mathrm{Gm}$. of oil was saponified by boiling it under reflux for two hours with a solution of $415 \mathrm{Gm}$. of potassium hydroxide in $1250 \mathrm{ml}$. of aldehyde-free ethanol (60). Approximately one-half of the alcohol 
was removed by distillation, then to the concentrated soap solution was added $2 \mathrm{~L}$. of water. The soap solution was transferred to a 5L. separatory funnel and was extracted ten times with $100 \mathrm{ml}$. portions of ethylene chloride (Eastman Kodak Company). The extracts we re at first dark brown, but gradually lightened in color, the tenth extract being a pale yellow color. The soap solution was then extracted with five $100 \mathrm{ml}$. portions of diethyl ether; the final extract gave no residue on evaporation. The conbined ethylene chloride extracts were extracted with $300 \mathrm{ml}$. of 0.5 per cent sodium hydroxide, then with water until the aqueous washings were neutral to 1itmus. The ethylene chloride was removed by distillation under reduced pressure until a very concentrated solution of the unsaponifiable matter remained. The combined ether extracts were washed with 0.5 per cent sodium hydroxide, then with water until the washings were neutral to litmus. The ether solution was added to the concentrated ethylene dichloride solution and the combined solutions were concentrated by distillation under reduced pressure. The solid, unsaponifiable matter obtained from the solutions was dried to constant weight by heating in a vacuum oven at $60^{\circ}$ for three and one-half hours. The total yield of unsaponifiable matter (Sample I) was $43.15 \mathrm{Gm}$. ; this amount of unsaponifiable matter represented 1.86 per cent of the dried fruit or 11.3 per cent of the oil obtained by petroleum ether extraction.

\section{Extraction B}

Sample IV was extracted with petroleum ether; $3000 \mathrm{Gm}$, of the dried fruit was extracted in a Soxhlet apparatus for twenty-eight hours with $4500 \mathrm{ml}$. of petroleum ether, having a boiling point range of $30^{\circ}-60^{\circ}$. 
The petroleum ether was removed by distillation on a steam-bath. A yield of $351 \mathrm{Gm}$. of oil was obtained; this amount of oil represented 11.7 per cent of the dried fruit.

The $351 \mathrm{Gm}$. of oil was saponified by boiling it under reflux for three hours with a solution containing $80 \mathrm{Gm}$. of potassium hydroxide in $2100 \mathrm{ml}$. of aldehyde-free ethanol (60). Approximately threequarters of the alcohol was removed by distillation, then $1000 \mathrm{ml}$. of water were added to the concentrated soap solution. The soap solution was cooled in the refrigerator overnight. The soap solution was extracted with $1000 \mathrm{ml}$. of ether, then with seven $250 \mathrm{ml}$. portions of ether. During these extractions $1100 \mathrm{ml}$. of water was added in divided portions, with gently stirring, to break emulsions. The aqueous phase was then divided into two equal portions, $1000 \mathrm{ml}$. of water was added to each portion and each solution was extracted with six $250 \mathrm{ml}$. portions of ether. The final ether extracts gave no residue on evaporation. The ether extracts were combined and were washed with $500 \mathrm{ml}$. of water, then with three $250 \mathrm{ml}$. portions of water. The final wash water was neutral to litmus. The ethereal solution of the unsaponifiable matter was a golden yellow color; it was dried over Drierite for two days. The Drierite was removed from the ethereal solution by filtration and the filtrate concentrated by distillation. The concentrated ethereal solution was then evaporated to dryness on a hot plate and the unsaponifiable matter dried to constant weight at $105^{\circ}$ for twenty-four hours. The total yield of unsaponifiable matter (Sample II) was $83.5 \mathrm{Gm}$; this amount of unsaponifiable matter represented 2.78 per cent of the dried fruit or 23.8 per cent of the oil obtained by 
petroleum ether extraction.

SEPARATION OF THE CONSTITUENTS OF THE UNSAPONIFIABLE MATTER

The unsaponifiable matter appeared as yellow to white, heterogeneous granules and powder. Preliminary investigations indicated that it consisted of white, crystalline material and a yellow, resinous substance which was very difficult to separate from the crystalline material. Three methods were used to separate the constituents and are discussed below. The first two methods did not yield satisfactory results but the third method led to the separation of the constituents and the isolation of a new compound.

Method 1 - Direct Recrystallization of the Unsaponifiable Matter

Thirty grams of unsaponifiable matter (Sample I) was recrystallized twice from acetone and once from 85 per cent ethanol according to the method used by Swift and Walter (33). Two fractions of crystalline material were obtained; one fraction weighed $2.00 \mathrm{Gm}$. and had a melting point* range of $195.0^{\circ}-197.0^{\circ}$; the other fraction weighed $1.30 \mathrm{Gm}$. and had a melting point range of $151.5^{\circ}-154.5^{\circ}$.

*All melting points reported herein were taken in uniform capillary tubes, $1.5-2.0 \mathrm{~mm}$. in diameter and $100 \mathrm{~mm}$. long, using a $400^{\circ} \mathrm{C}$. thermometer which was standardized with a series of standard Eimer and Amend thermometers. The melting points were taken in a cottonseed oil bath which was mechanically stirred continuously; the rate of heating was such as to cause a rise in temperature of $1^{0}$ per minute.

All melting points are uncorrected unless otherwise stated. Corrected melting points are enclosed by brackets and preceded by the 
abbreviation corr. The stem correction was calculated by means of the formula: correction $=+N\left(t_{1}-t_{2}\right) 0.000154$, where $N=$ degrees of mercury thread above the level of the oil bath; $t_{1}=$ observed melting point; $t_{2}=$ average temperature of the mercury thread. This correction was added to the uncorrected melting point to give the corrected melting point.

No further crystalline material with a satisfactory melting point range could be isolated since the resinous substance precipitated as a yellowish, sticky oil from the solutions on cooling. A quantitative recovery of the remainder of the unsaponifiable matter was made by combining all the acetone and alcoholic mother liquors, evaporating to dryness on a steam-bath and drying to constant weight at $80^{\circ}$ for six hours. $26.70 \mathrm{Gm}$. of residue was recovered; this residue is herein called the "unsaponifiable residue".

The two fractions of crystalline material were combined to give $3.30 \mathrm{Gm}$. which were acetylated by refluxing with $1.65 \mathrm{Gm}$. of anhydrous sodium acetate and $15 \mathrm{ml}$. of acetic anhydride for one and a quarter hours at a temperature of $120^{\circ}-130^{\circ}$. The reaction mixture was poured into $100 \mathrm{Gm}$, of ice and water with vigorous stirring and allowed to stand for twelve hours. The white, crystalline material which had precipitated was removed by filtration, washed with water until free of acid, then partially dried with suction. The crude acetate was dissolved in the minimum amount of boiling ethanol and the solution filtered while hot. After standing for three days at room temperature the filtrate yielded $2,21 \mathrm{Gm}$. of crystals having a melting point of 
$203.0^{\circ}-204.0^{\circ}$. Concentration of the mother liquor yielded $0.40 \mathrm{Gm}$. of crystals which, after two recrystallizations from acetone, gave a top fraction weighing $0.32 \mathrm{Gm}$. and having a melting point of $199.5^{\circ}-200 \cdot 5^{\circ}$

The $2.21 \mathrm{Gm}$. of acetate was saponified by heating under reflex on a steam-bath for one and a half hours with $110 \mathrm{ml}$. of $0.5 \mathrm{~N}$. alcoholic potassium hydroxide. The solution was cooled and $20 \mathrm{ml}$. of water was added. The white suspension which resulted was refrigerated overnight. The crystalline precipitate was removed by filtration and washed with water until the washings were neutral to litmus. After being dried at $80^{\circ}$, the yield of the product was $1.90 \mathrm{Gm}$. This 1.90 $\mathrm{Gm}$. of crude crystalline material was subjected to an extensive recrystallization procedure using ethanol and acetone as solvents but the melting point of any fraction could not be raised to $214.0^{\circ}-215.0^{\circ}$, the reported (33) melting point of pure lupeol. It was evident that no separation of the components could be made by fractionally crystallizing the crude alcohols. Swift and Walter (33) raised the melting point of the alcoholic fraction to $208^{\circ}-211^{\circ}$ but had to purify the lupeol by forming the acetate and saponifying the recrystallized Iupeol acetate to obtain pure lupeol. During this research it was found that much better results were obtained by acetylating the crude unsaponifiable matter directly, then fractionally crystallizing the crude acetates; this procedure is discussed below (Method III). Method II - Chromatography of the Unsaponifiable Matter The procedure used was the one described by Reichstein and Shoppee (61). The chromotographic tube used was $460 \mathrm{~mm}$. long and had an intemal 
diameter of $23 \mathrm{~mm}$. One end of the tube was fire-polished, the other end terminated in a glass stop-cock. All solvents used were purified by methods outlined by Fieser (62) and were anhydrous. The adsorbent used was Adsorption Alumina (Fisher Scientific Co.)

The column was prepared in benzene by filling the chromatography tube with benzene then slowly adding $30 \mathrm{~cm}$. of Adsorption Alumina through the open end of the tube. When the al umina had settled, the benzene was run out until the top of the column just remained covered. The eluate was recycled until the column ceased to pack. The top of the column was never allowed to become dry throughout the entire procedure.

A solution of $1.000 \mathrm{Gm}$. of the "unsaponifiable residue" (see page 31) in $100 \mathrm{ml}$. of benzene was poured onto the top of the column. The stop-cock was opened and the eluate collected. Fresh solvent was added to the top of the column and the various fractions collected as shown in Table 5. Each of the eluates was concentrated by distillation, the concentrate was poured into a previously weighed $50 \mathrm{ml}$. beaker, the flash washed with ether and the washings added to the beaker. The solution in the beaker was then evaporated to dryness on a steam-bath and the beaker, containing the residue, dried to constant weight at $105^{\circ}$ in an air-oven. Table 5 indicates the fractions collected, the time required to collect the fractions, the volumes of the fractions, the solvents used, the constant weights of the residues obtained and the nature of the residues.

After the fifteenth eluate was collected, the column was extruded 
and the alumina extracted with an ether-ethanol mixture then with two portions of hot acetone. The combined extracts were filtered and the filtrate evaporated to leave a residue of $186 \mathrm{mg}$.

\section{TABLE 5}

\section{Chromatography of the Unsaponifiable Matter}

\begin{tabular}{|c|c|c|c|c|c|}
\hline Fraction & $\begin{array}{l}\begin{array}{l}\text { Volume } \\
(\mathrm{ml} .)\end{array} \\
\end{array}$ & $\begin{array}{l}\text { Time } \\
\text { Required } \\
\text { to elute } \\
\text { (minutes) } \\
\end{array}$ & $\begin{array}{l}\text { Solvent } \\
\text { (Parts by } \\
\text { Volume) }\end{array}$ & $\begin{array}{l}\text { Weight of } \\
\text { Dried } \\
\text { Residue } \\
\text { (mg.) }\end{array}$ & $\begin{array}{l}\text { Nature of } \\
\text { Residue } \\
\end{array}$ \\
\hline $\begin{array}{l}1 \\
2 \\
3 \\
4\end{array}$ & $\begin{array}{l}200 \\
200 \\
100 \\
200\end{array}$ & $\begin{array}{l}30 \\
24 \\
14 \\
30\end{array}$ & $\begin{array}{l}\text { Benzene } \\
\text { Benzene } \\
\text { Benzene } \\
\text { Benzene (99) }\end{array}$ & $\begin{array}{r}11.9 \\
16.3 \\
35.4 \\
141.5\end{array}$ & $\begin{array}{l}\text { Yellow oil } \\
\text { Soft and oily } \\
\text { Soft and oily }\end{array}$ \\
\hline 5 & 200 & 30 & $\begin{array}{l}\text { Benzene }(98) \\
\text { Ether }(2)\end{array}$ & 149.1 & \\
\hline 6 & 200 & 18 & $\begin{array}{l}\text { Benzene (98) } \\
\text { Ether (2) }\end{array}$ & 109.4 & $\begin{array}{l}\text { White crystalline } \\
\text { material contam- }\end{array}$ \\
\hline 7 & 200 & 30 & $\begin{array}{l}\text { Benzene }(98) \\
\text { Ether }(2)\end{array}$ & 60.6 & $\begin{array}{l}\text { inated with some } \\
\text { yellow colored }\end{array}$ \\
\hline 8 & 200 & 30 & $\begin{array}{l}\text { Benzene }(95) \\
\text { Ether }(5)\end{array}$ & 59.1 & material. \\
\hline 9 & 100 & 15 & $\begin{array}{l}\text { Benzene (90) } \\
\text { Ether (10) }\end{array}$ & 30.6 & \\
\hline 10 & 100 & 16 & $\begin{array}{l}\text { Benzene( } 80) \\
\text { Ether (20) }\end{array}$ & 32.5 & \\
\hline 11 & 100 & 21 & $\begin{array}{l}\text { Benzene }(70) \\
\text { Ether }(3)\end{array}$ & 33.9 & \\
\hline 12 & 100 & 17 & $\begin{array}{l}\text { Benzene }(60) \\
\text { Ether }(40)\end{array}$ & $28.2)$ & \\
\hline 13 & 100 & 10 & $\begin{array}{l}\text { Benzene }(50) \\
\text { Ether }(50)\end{array}$ & 17.9 & \\
\hline $\begin{array}{l}14 \\
15\end{array}$ & $\begin{array}{l}100 \\
100\end{array}$ & $\begin{array}{l}12 \\
18\end{array}$ & $\begin{array}{l}\text { Ether } \\
\text { Ether }\end{array}$ & $\begin{array}{r}10.8 \\
9.0\end{array}$ & $\begin{array}{l}\text { Principally } \\
\text { yellowish resinous } \\
\text { material. }\end{array}$ \\
\hline
\end{tabular}

PREPARATION OF LUPEOL BENZOATE FFOM ELUTED MATERIAL

Attempts were made to purify some of the eluted solids by recrystallizations but these attempts failed. From fractions 4 to 13 inclusive, $603 \mathrm{mg}$. of the original $662.8 \mathrm{mg}$. of solids eluted in these 
fractions were recovered. This $603 \mathrm{mg}$. of yellowish-white solid was dissolved in hot ethanol, activated charcoal added, and the suspension filtered while hot. On cooling, the solution yielded $250 \mathrm{mg}$. of white, microcrystalline powder most of which melted in the range $120^{\circ}$ $124^{\circ}$ but some of which melted in the range $152^{\circ}-156^{\circ}$. Concentration of the mother liquors and cooling yielded only a white oil which could not be crystallized.

The $250 \mathrm{mg}$. of white microcrystalline powder was dissolved in 10 $\mathrm{ml}$. of anhydrous pyridine containing $1 \mathrm{ml}$. of benzoyl chloride and the solution heated under reflux on a steam-bath for three hours. The hot solution was poured, with vigorous stirring, into about $100 \mathrm{ml}$. of ice and water. The precipitated product was extracted with ether, the ether extract washed with 5 per cent aqueous potassium carbonate solution and then with water until the washings were neutral to litmus. Evaporation of the ether yielded a yellowish-white residue which on recrystallization from benzene-ethanol $(1,10)$, decolorizing charcoal being used, gave three fractions of crystalline material; $70 \mathrm{mg}$. having a melting point of $253^{\circ}-255^{\circ}, 30 \mathrm{mg}$. having a melting point of $241^{\circ}-$ $243^{\circ}$ and $100 \mathrm{mg}$. having a melting point of $180^{\circ}-190^{\circ}$. These fractions on recrystallization twice from acetone gave $36 \mathrm{mg}$. having a melting point of $260.0^{\circ}-262.0^{\circ}$ (corr. $268.5^{\circ}-270.5^{\circ}$ ) and $47 \mathrm{mg}$. having a melting point of $256.0^{\circ}-258.0^{\circ}$ (corr. $264.0^{\circ}-266.0^{\circ}$ ). These melting points are in the ranges reported for lupeol benzoate. Apparently another benzoate, other than lupeol benzoate, was present but it could not be obtained pure in this particular experiment. This chromatographic experiment, and another of a similar nature, 
did not provide a satisfactory method for separating the components of the unsaponifiable matter. The yellow material present in the unsaponifiable matter showed a yellow fluorescence in ultra-violet light. By examining the column with an ultra-violet lamp it could be seen that the yellow substance (or substances) was eluted from the column. The residues obtained by evaporation of the different fractions contained white, crystalline material contaminated with the yellow substance (or substances). Elution of pure, or almost pure, components was therefore not accomplished.

Method III - Direct Acetylation of the Unsaponifiable Matter and

Fractional Crystallization of the Acetates.

Part A - Preliminary Investigation

In a preliminary investigation by this method, $2.00 \mathrm{Gm}$. of the "unsaponifiable residue" (page 31) was acetylated. By fractional crystallization the crude acetates, which crystallized from the acetylation mixture, were divided into a high and a low melting point fraction. Three recrystallizations of the high melting point fraction from absolute ethanol yielded $0.24 \mathrm{Gm}$. of pure lupeol acetate having a melting point of $216.5^{\circ}$. Three recrystallizations of the low melting point fraction from alcohol-water mixtures yielded $0.33 \mathrm{Gm}$. of an acetate which melted at $131.0^{\circ}-132.0^{\circ}$ and which had not formerly been described as being present in the unsaponifiable matter. After the original crude mixture of acetates was removed from the acetylation mixture by filtration, the filtrate was poured into water, whereupon a dark yellow resinous material precipitated. 
The mixture was allowed to stand to hydrolyze the acetic anhydride, then was extracted with ether until the extracts were colorless. The combined ether extracts were washed with sodium carbonate solution, then with water until the washings were neutral to litmus. Evaporation of the ethereal solution yielded $0.308 \mathrm{Gm}$. of a semisolid resinous material which was a dark yellow in color. This resinous substance had not formerly been described.

The above investigation is not described in detail since the same procedure was followed in the direct acetylation of a larger quantity of the "unsaponifiable residue", the detailed description of which is given in part $B$, below.

Part B - Direct Acetylation of a Large Quantity of the "Unsaponifiable Residue".

23.70 Gm. of "unsaponifiable residue" was placed in a one liter, three-necked, ground-glass flask fitted with a mechanical stirrer and reflux condenser. An equal weight of anhydrous sodium acetate and 287 ml. of acetic anhydride was added. The mixture was heated to $135^{\circ} \mathrm{C}$. whereby most of the material dissolved, the solution being a yellow color. The mixture was maintained at a temperature of $135^{\circ} \pm 5^{\circ}$ for three hours, during which tine a considerable amount of the acetates crystallized from the hot solution. The mixture was cooled to room temperature and then refrigerated. The crystalline material was removed by filtration and washed with $500 \mathrm{ml}$. of water. The crystalline material was then suspended in $500 \mathrm{ml}$. of water; the suspension was stirred for thirty minutes and then allowed to stand overnight. The 
suspension was filtered and the crystalline residue washed with one liter of water. After thoroughly drying the crystals in an oven at $105^{\circ}$ the yield was $18.65 \mathrm{Gm}$. of mixed acetates having a melting point range from $129^{\circ}-170^{\circ}$.

The original filtrate and the first $500 \mathrm{ml}$. of wash water were poured into about $600 \mathrm{ml}$. of ice and water; the resulting mixture was stirred mechanically for one hour. This mixture contained large masses of semi-solid, brown, resinous material. The suspension was extracted with ether until colorless, a total of $650 \mathrm{ml}$. of ether being used. The brown ethereal solution was washed with $700 \mathrm{ml}$. of 5 per cent potassium carbonate solution in divided portions, then with two $100 \mathrm{ml}$. portions of water; the final wash water was neutral to litmus. The ethereal solution was evaporated and yielded a brown, resinous residue which was dried to constant weight at $100^{\circ}$. The yield of brown, resinous residue was $8.00 \mathrm{Gm}$. (A-1). FRACTIONAL CRYSTALLIZATION OF THE IIXED ACETATES

The $18.65 \mathrm{Gm}$. of crude acetates, having a melting point range from $129^{\circ}-170^{\circ}$, was dissolved in the minimum amount of boiling absolute alcohol ( $500 \mathrm{ml}$.$) . After standing at room temperature for eighteen hours,$ the solution deposited a wite, crystalline precipitate. The crystals were removed by filtration and washed with $50 \mathrm{ml}$. of cold absolute alcohol. After drying the crystals at $105^{\circ}$, the yield was $10.39 \mathrm{Gm}$. having a melting point range from $156^{\circ}-177^{\circ}$. The alcoholic filtrate and wash liquor were combined and the resulting solution concentrated by distillation to a volume of $230 \mathrm{ml}$. To this boiling concentrated solution water ( $45 \mathrm{ml}$.) was added until the solution was just turbid. 
Refrigeration of this turbid solution yielded crystals which were removed by filtration, washed with $50 \mathrm{ml}$. of cold 85 per cent ethanol and dried at $105^{\circ}$. The yield was $5.72 \mathrm{Gm}$. having a melting point range from $125^{\circ}-129^{\circ}$. The alcoholic filtrate and wash liquor from the lat ter crystallization were combined and the resulting solution was concentrated to one-half its volume by distillation. On cooling the concentrated solution a yellow, resinous, amorphous material precipitated. This resinous material was extracted from the cold mixture with ether, the ethereal solution was evaporated and the residue dried to constant weight at $100^{\circ}$. A yield of $1.97 \mathrm{Gm}$. of yellowish-brown, resinous residue (A-2) was obtained which was similar to $A-1$.

The $5.72 \mathrm{Gm}$. of acetate, having a melting point range from $125^{\circ}-$ $129^{\circ}$, was recrystallized from a mixture of $130 \mathrm{ml}$. of 95 per cent ethanol and $5 \mathrm{ml}$. of acetone. The solution, which was a pale yellow color, deposited white crystals which were removed by filtration, washed with $40 \mathrm{ml}$. of cold 85 per cent alcohol and dried at $105^{\circ}$. The yield was $4.70 \mathrm{Gm}$., having a melting point of $129.5^{\circ}-131.0^{\circ}$. The combined mother liquor and wash liquor from the recrystallization of the $5.72 \mathrm{Gm}$. were concentrated to one-half volume by distillation. To the boiling concentrated solution water $(22 \mathrm{ml}$.) was added until the solution just became turbid. After refrigeration, this turbid solution deposited a yellow, resinous material which failed to crystallize. The resinous material was extracted with ether, the ethereal solution was evaporated and the residue dried to constant weight at $100^{\circ}$. A yield of $0.53 \mathrm{Gm}$. of yellowish-brown resinous residue $(A-3)$ was obtained which was similar to $A-1$ and $A-2$. 
The $4.70 \mathrm{~cm}$. of acetate, having a melting point of $129.5^{\circ}-131.0^{\circ}$, was dissolved in a boiling mixture of $260 \mathrm{ml}$. of methanol and $60 \mathrm{ml}$. of ethanol. The solution was filtered while hot, the filtrate was cooled to room temperature, then was refrigerated. The solution yielded crystals which were removed by filtration and dried at $105^{\circ}$. The yield was $3.91 \mathrm{Gm}$, having a melting point of $130.0^{\circ}-131.0^{\circ}$. By concentration of the filtrate to one-half volume and addition of $18 \mathrm{ml}$. of water to the resulting concentrate, was obtained $0.44 \mathrm{Gm}$., having a melting point of $177.0^{\circ}-119.0^{\circ}$.

The $3.91 \mathrm{Gm}$. of acetate, having a melting point of $130.0^{\circ}-131.0^{\circ}$, was recrystallized from a mixture of $200 \mathrm{ml}$. of methanol and $50 \mathrm{ml}$. of ethanol. The first fraction, removed by filtration and dried at $105^{\circ}$, weighed $3.11 \mathrm{Gm}$. , and had a melting point of $131.0^{\circ}-132.0^{\circ}$ (corr. $132.5^{\circ}$ $\left.-133.5^{\circ}\right)$. By concentration of the filtrate to one-third its original volume and addition of $17 \mathrm{ml}$. of water to the resulting concentrate, was obtained $0.74 \mathrm{Gm} .,(B-1)$, having a melting point of $126.0^{\circ}-128.0^{\circ}$.

The $3.11 \mathrm{Gm}$. of acetate, having a melting point of $131.0^{\circ}-132.0^{\circ}$ (corr. $132.5^{\circ}-133.5^{\circ}$ ) is herein designated "Sample I of the unknown acetate". A portion of this acetate, when recrystallized three more times, the first time from a mixture of methanol-water $(10: 1)$, the second time from a mixture of acetone-water $(6: 1)$ and the third time from a mixture of acetone-water $(5.5: 1)$ yielded an acetate having the same melting point and which was unchanged on admixture with the original Sample I of the unknown acetate. Microscopically, the unknown acetate appeared as colorless, flat rods. 
DETERMINATION OF THE SPECIFIC ROTATION (63) OF SAMPLE I OF THE UNKNOWN ACETATE

$0.4399 \mathrm{Gm}$. of Sample I of the unknown acetate, dissolved in 10.0 ml. of anhydrous chloroform, gave $\propto \chi_{D}^{28.5^{\circ}}+1.75^{\circ}$ in a 2 decimeter polarimeter tube; $[\alpha]_{D}^{28,5^{\circ}}+19.9^{\circ}\left(\mathrm{CHCl}_{3}, \mathrm{c}=4.399\right)$.

The $10.39 \mathrm{Gm}$. of acetate mixture, having a melting point range of $156^{\circ}-177^{\circ}$, was recrystallized from $350 \mathrm{ml}$. of ethanol. The first fraction obtained weighed $5.92 \mathrm{Gm}$. and had a melting point of $203.0^{\circ}-$ $204.0^{\circ}$. Concentration of the alcoholic mother liquor by distillation to one-half its original volume and addition of water to the boiling concentrate to the point of turbidity, followed by refrigeration of the turbid solution, yielded $3.74 \mathrm{Gm}$. of crystals melting at $131^{\circ}-134^{\circ}$.

The more soluble $3.74 \mathrm{Gm}$. fraction was recrystallized from a mixture of $110 \mathrm{ml}$. of ethanol and $25 \mathrm{ml}$. of water. After refrigeration this solution yielded $3.52 \mathrm{Gm}$, having a melting point of $131.0^{\circ}-132.0^{\circ}$. Concentration of the mother liquor and addition of water to turbidity, yielded $0.10 \mathrm{Gm} .,(\mathrm{B}-2)$, having a melting point range of $124.0^{\circ}-150.0^{\circ}$. The $3.52 \mathrm{Gm}$. of acetate was recrystallized from a mixture of $79 \mathrm{ml}$. of acetone and $4 \mathrm{ml}$. of water. Refrigeration of this solution at $0^{\circ} \mathrm{C}$ for five hours yielded microscopic, flat rod-shaped crystals; these crystals were removed by filtration, washed with cold 85 per cent alcohol and dried at $105^{\circ}$. The yield was $3.10 \mathrm{Gm}$, having a melting point of $131.0^{\circ}$ $-132.0^{\circ}$ (corr. $132.5^{\circ}-133.5^{\circ}$ ); the melting point of these crystals was not depressed on admixture with Sample $I$ of the unknown acetate. The $3.10 \mathrm{Gm}$. of acetate, having a melting point of $131.0^{\circ}-132.0^{\circ}$ (corr. $\left.132.5^{\circ}-133.5^{\circ}\right)$ is herein designated "Sample II of the unknown acetate". The filtrate and wash liquor from this crystallization were combined, 
the solution was concentrated by distillation to one-half its volume and the concentrate was refrigerated after the addition of $10 \mathrm{ml}$. of water. This concentrated mother liquor yielded $0.36 \mathrm{Gm}$. of crystals, (B-3), having a melting point of $127.5^{\circ}-129.0^{\circ}$.

The crystalline fractions $B-1, B-2$, and $B-3$ were combined to give 1.20 Gm. of impure unknown acetate. Three recrystallizations of these combined fractions, the first from a mixture of $50 \mathrm{ml}$. of methanol, $35 \mathrm{ml}$. of ethanol and $6 \mathrm{ml}$. of water, the second from $40 \mathrm{ml}$. of 95 per cent ethanol and $4.5 \mathrm{ml}$. of water, and the third from $25 \mathrm{ml}$. of acetone and $2.5 \mathrm{ml}$. of water, yielded $0.71 \mathrm{Gm}$. of crystals having a melting point of $131.0^{\circ}-132.0^{\circ}$ (corr. $\left.132.5^{\circ}-133.5^{\circ}\right)$. The melting point of these crystals was not depressed on admixture with Sample I of the unknown acetate. This $0.71 \mathrm{Gm}$. of acetate was therefore designated "Sample III of the unknown acetate".

The $5.92 \mathrm{GE}$, of acetate, having a melting point of $203.0^{\circ}-204.0^{\circ}$ was impure lupeol acetate. This fraction was purified by recrystallizam tion from ethanol, the details of which are given below. The $5.92 \mathrm{Gm}$. of acetate was dssolved in $300 \mathrm{ml}$. of ethanol at the boiling point and the hot solution was filtered. The filtrate, after standing at room temperature for twelve hours, yielded $4.46 \mathrm{Gm}$. of colorless rods having a melting point of $209.0^{\circ}-210.0^{\circ}$. Concentration of the mother liquor to one-third its original volume and addition of $20 \mathrm{ml}$. of water, yielded $104 \mathrm{Gm}$. (C-1), having a melting point of $211.0^{\circ}-211.5^{\circ}$.

The $4.46 \mathrm{~cm}$. of acetate was recrystallized from $275 \mathrm{ml}$, of ethanol. This recrystallization yielded $3.82 \mathrm{Gm}$, having a melting point of $213.5^{\circ}-214.0^{\circ}$. Concentration of the mother liquor to one-half its 
original volume and addition of $11 \mathrm{ml}$. of water, followed by refrigeration, yielded $0.54 \mathrm{Gm}$. (C-2), having a melting point of $214.0^{\circ}-214.5^{\circ}$.

The $3.82 \mathrm{Gm}$. of acetate was dissolved in $205 \mathrm{ml}$. of ethanol at the boiling point. The solution was filtered while hot, and the filtrate cooled slowly to room temperature. The filtrate deposited beautiful, long, feathery, needle-shaped crystals, which, after removal by filtration and drying at $105^{\circ}$, weighed $3.34 \mathrm{Gm}$. and melted at $216.0^{\circ}$ $-216.5^{\circ}$ (corr. $222.3^{\circ}-222.8^{\circ}$ ) to a colorless liquid. This is the melting point reported by Swift and Walter (33) for lupeol acetate. This $3.34 \mathrm{Gm}$. of acetate is herein designated "Sample I of lupeol acetate". Concentration of the alcoholic mother liquor, after removal of the lupeol acetate, followed by refrigeration of the concentrate, yielded $0.40 \mathrm{Gm}$. (C-3), having a melting point of $213.5^{\circ}-214.0^{\circ}$. DETERMINATION OF THE SPECIFIC ROTATION (63) OF SAMPLE I OF LUPEOL ACETATE

$0.2009 \mathrm{Gm}$. of Sample I of Iupeol acetate, dissolved in $10.0 \mathrm{ml}$. of anhydrous chloroform gave $\alpha{ }_{D}^{28.5^{\circ}}+1.70^{\circ}$ in a 2 decimeter polarimeter tube; $[\alpha]_{D}^{28.5^{\circ}}+42.3^{\circ}\left(\mathrm{CHCl}_{3}, 6=2.009\right)$.

Swift and Walter (33) reported $[\alpha]_{D}^{25^{\circ}}+41.95^{\circ}\left(\mathrm{CHCl}_{3}, \mathrm{c}=\right.$ 1.652) for lupeol acetate.

The impure lupeol acetate fractions, $\mathrm{C}-1, \mathrm{C}-2$, and $\mathrm{C}-3$ were combined to give $1.98 \mathrm{Gm}$. of impure lupeol acetate which was recrystallized from $131 \mathrm{ml}$. of absolute alcohol. The first fraction weighed $1.62 \mathrm{Gm}$. and had a melting point of $214.5^{\circ}-215.0^{\circ}$. By concentration of the mother liquor was obtained $0.23 \mathrm{Gm}$. having a melting point of $206.0^{\circ}$ $207.0^{\circ}$. 
The $1.62 \mathrm{Gm}$. , when recrystallized from ethanol, yielded $1.42 \mathrm{Gm}$. of lupeol acetate, having a melting point of $216.0^{\circ}-216.5^{\circ}$, (corr. $\left.222.3^{\circ}-222.8^{\circ}\right)$, unchanged on admixture with Sample I of lupeol acetate. This $1.62 \mathrm{Gm}$. of lupeol acetate is herein designated "Sample II of lupeol acetate". From the alcoholic mother liquor was obtained 0.15 $\mathrm{Gm}$. of impure lupeol acetate, having a melting point of $211.0^{\circ}-212.0^{\circ}$. In summary, the $23.70 \mathrm{Gm}$. of "unsaponifiable residue", after acetylation and fractional crystallization, had been separated into the fractions shown in Table 6.

\section{TABLE 6}

Pure unknown acetate, melting point $131.0^{\circ}-132.0^{\circ}$. . . $6.91 \mathrm{Gm}$. Pure lupeol acetate, melting point $216.0^{\circ}-216.5^{\circ}$.... $4.76 \mathrm{Gm}$. Impure Iupeol acetate . . . . . . . . . . $0.38 \mathrm{Gm}$. Yellowish-brown resinous residue $(\mathrm{A}-1, \mathrm{~A}-2, \mathrm{~A}-3) . . . .10 .50 \mathrm{Gm}$.

\section{Part C - Direct Acetylation of a Large Quantity of Unsaponifiable} Matter.

In order to isolate more of the unknown acetate, having a melting point of $131.0^{\circ}-132.0^{\circ}$, another large scale acetylation and fractional crystallization procedure was carried out. The method used was very similar to that described ir Part B. but differed in some details, hence is described below.

Sample II $(83.5 \mathrm{Gm}$.$) of the unsaponifiable matter was acetylated$ by heating at $130^{\circ}-135^{\circ}$ for 3 hours with an equal weight of anhydrous sodium acetate and $1100 \mathrm{Gm}$. of acetic anhydride. The acetylation mixture was allowed to cool slowly to room temperature and then was refrigerated overnight. The crude crystalline acetates, which had 


\section{5}

precipitated in the reaction mixture, were removed by filtration, washed with $300 \mathrm{ml}$. of cold acetone, $2 \mathrm{~L}$. of cold water, $150 \mathrm{ml}$. of 5 per cent aqueous potassium carbonate solution, then with 2 L. of water. The final wash water was neutral to litmus. The crude acetate mixture was dried in the oven at $70^{\circ}$; the yield was $63.5 \mathrm{Gm}$. of crude acetates.

The filtrate of the reaction mixture and the acetone wash liquor were combined and poured into $2 \mathrm{~L}$, of ice and water. The mixture was mechanically stirred for one and a half hours. The brown resinous material which precipitated was extracted with ether, the ether extract was washed with aqueous potassium carbonate solution and subsequently with water, until the aqueous washings were neutral to litmus. Evaporation of the ether from the ether extract left a resinous residue (D-I) which, after drying to constant weight at $105^{\circ}$, weighed $23.5 \mathrm{Gm}$. FRACTIONAL CRYSTALLIZATION OF THE CRUDE ACETATES

The $63.5 \mathrm{Gm}$. of crude acetates was dissolved in $1250 \mathrm{ml}$. of boiling absolute ethanol and the yellow solution was filtered while hot. The filtrate was allowed to stand at room temperature for three hours, then was refrigerated at $0^{\circ}$ for eighteen hours. The white, crystalline precipitate which formed was removed by filtration and washed with 100 $\mathrm{ml}$. of cold absolute ethanol. After drying the crystals at $105^{\circ}$, the yield was $29.67 \mathrm{Gm}$., having a melting point of $177^{\circ}-187^{\circ}$. This fraction was found to consist mainly of impure lupeol acetate.

The filtrate and wash liquor from the above crystallization were combined and the resulting solution concentrated by distillation to about half its original volume. The concentrate was heated to boiling and 


\section{6}

sufficient water $(65 \mathrm{ml}$.) was added to produce a turbid solution. Refrigeration of this turbid solution caused the precipitation of some resinous, yellow oil; the solution was heated to boiling again and sufficient acetone $(60 \mathrm{ml}$.) was added to give a clear solution. Refrigeration of this clear solution for twenty-four hours yielded $10.36 \mathrm{Gm}$. of white, crystalline material, having a melting point range of $120^{\circ}-125^{\circ}$. The filtrate, obtained from removal of this $10.36 \mathrm{Gm}$. fraction, was concentrated by distillation to about half its volume. During the distillation of the solvent from this filtrate some of the yellow resinous material precipitated from the solution. The clear yellow solution was decanted from the resinous material. The decantate was heated to boiling with $2 \mathrm{Gm}$. of activated charcoal and the suspension was filtered while hot through a one-half inch mat of Celite no. 535. Refrigeration of the filtrate yielded white, crystalline material which was removed by filtration; the yield was $4.64 \mathrm{Gm}$., having a melting point range of $114^{\circ}-117^{\circ}$.

The $10.36 \mathrm{Gm}$. of acetate, having a melting point range of $120^{\circ}$ $125^{\circ}$, was dissolved in $180 \mathrm{ml}$. of boiling ethanol, $1 \mathrm{Gm}$. of activated charcoal was added to the solution and the resulting suspension was filtered while hot through a one-half inch mat of Celite no. 535. The filt rate was cooled to room temperature, then refrigerated. This filtrate yielded white crystals which were removed by filtration, washed with $50 \mathrm{ml}$. of cold ethanol and dried at $105^{\circ}$; the yield was $7.08 \mathrm{~cm}$., having a melting point of $130.0^{\circ}-132.0^{\circ}$.

The combined mother liquor and wash liquor, after removal of the $7.08 \mathrm{Gm}$. fraction, were concentrated to half volume by distillation, 
and sufficient water $(35 \mathrm{ml}$.) was added to the hot concentrate to produce a turbid solution. Refrigeration of this turbid solution yielded $1.73 \mathrm{Gm}$. of crystals, having a melting point range of $116^{\circ}$ $165^{\circ}$. Concentration of the filtrate after removal of this crop of crystals yielded a further $0.44 \mathrm{Gm}$, having a melting point range of $163^{\circ}-190^{\circ}$.

The $7.08 \mathrm{Gm}$. of acetate, having a melting point of $130.0^{\circ}-132.0^{\circ}$, was dissolved in a boiling mixture of ethanol - methanol ( $1: 1$ ) and the solution filtered while hot. Refrigeration of the filtrate yielded crystals which were removed by filtration, washed with cold 85 per cent ethanol and dried at $105^{\circ}$; the yield was $6.24 \mathrm{Gm}$. of acetate, having a melting point of $131.0^{\circ} \cdots 132.0^{\circ}$. Concentration of the filtrate to onethird its original volume and addition of $17 \mathrm{ml}$. of water, followed by refrigeration yielded $0.57 \mathrm{Gm}$, having a melting point of $198.0^{\circ}-203.0^{\circ}$.

The $6.24 \mathrm{Gm}$. of acetate, having a melting point of $131.0^{\circ}-132.0^{\circ}$, was dissolved in a boiling mixture of $65 \mathrm{ml}$. of acetone and $6 \mathrm{ml}$. of water and the solution was filtered while hot. Refrigeration of the filtrate at $-18^{\circ}$ for six hours yielded microscopic, colorless, flat rods, which were removed by filtration, washed with cold 85 per cent ethanol and dried at $105^{\circ}$. The yield was $5.73 \mathrm{Gm}$. of acetate, having a melting point of $131.0^{\circ}-132.0^{\circ}$ (corr. $132.5^{\circ}-133.5^{\circ}$ ), unchanged on admixture with Sample I of the unknown acetate. The filtrate and wash liquor from this crystallization were combined, concentrated to onethir volume by distillation and the concentrate refrigerated overnight at $-18^{\circ}$; from this concentrate was obtained $0.14 \mathrm{Gm}$. of crystals, having a melting point range of $140^{\circ}-175^{\circ}$. 
In order to further test the purity of the $5.73 \mathrm{Gm}$. of acetate, having a melting point of $131.0^{\circ}-132.0^{\circ}$ (corr. $132.5^{\circ}-133.5^{\circ}$ ), this fraction was recrystallized from a mixture of $60 \mathrm{ml}$. of acetone and $5 \mathrm{ml}$. of water. The yield was $5.39 \mathrm{Gm}$. , having a melting point of $131.0^{\circ}-132.0^{\circ}$ (corr. $132.5^{\circ}-133.5^{\circ}$ ), unchanged on admixture with Sample I of the unknown acetate. The $5.39 \mathrm{Gm}$. of acetate was recrystallized from a different mixture, namely $57 \mathrm{ml}$. of acetone and $3 \mathrm{ml}$. of water. The yield was $5.08 \mathrm{Gm}$. of acetate, having a melting point of $131.0^{\circ}-132.0^{\circ}$ (corr. $132.5^{\circ}-133.5^{\circ}$ ), unchanged on admixture with Sample I of the unknown acetate. This $5.08 \mathrm{Gm}$. of acetate is herein designated "Sample IV of the unknown acetate". As the above fractional crystallizations indicate, the unknown acetate is very much more soluble in alcohol than lupeol acetate. A further test was made to determine if the unknown acetate was contaminated with lupeol acetate. $3.95 \mathrm{Gm}$. of Sample IV of the unknown acetate was suspended in $50 \mathrm{ml}$. of 95 per cent ethanol, an amount insufficient to dissolve all the crystals. The suspension was heated to the boiling point, boiled for five minutes, then filtered while hot. The undissolved acetate, collected on the filter, was dried in the oven at $105^{\circ}$; the yield was $1.58 \mathrm{Gm}$, which melted at $131.0^{\circ}-132.0^{\circ}$ (conr. $132.5^{\circ}-133.5^{\circ}$ ) to a turbid liquid which cleared at $177^{\circ}$ (corr. $180.3^{\circ}$ ). The filtrate was cooled to room temperature, then refrigerated. The crystals which formed were removed by filtration and dried at $105^{\circ}$; the yield was $2.13 \mathrm{Gm}$, which melted at $131.0^{\circ}-132.0^{\circ}$ (corr. $132.5^{\circ}-133.5^{\circ}$ ) to a turbid liquid which cleared at $177^{\circ}$ (corr. $180.3^{\circ}$ ). A mixed melting point of the $1.58 \mathrm{Gm}$. fraction and the $2.13 \mathrm{Gm}$. fraction was exactly the same. The percentage recovery in 
this experiment was 94 per cent. The melting point of the unknown acetate could not be raised, the refore, by crystallization. DETERMINATION OF THE SPECIFIC ROTATION (63) OF SAMPLE IV OF THE UNKNOWN ACETATE

$0.3310 \mathrm{Gm}$. of Sample IV of the unknown acetate, dissolved in 10.0 $\mathrm{ml}$. of anhydrous chloroform, gave $\chi_{\mathrm{D}}^{30.0^{\circ}}+1.33^{\circ}$ in a 2 decimeter polarimeter tube; $[\alpha]_{D}^{30.0^{\circ}}+20.1^{\circ}\left(\mathrm{CHCl}_{3}, \mathrm{c}=3.310\right)$.

This agrees well with the value $[\alpha]_{\mathrm{D}}^{32.0^{\circ}}+19.9^{\circ}\left(\mathrm{CHCl}_{3}, \mathrm{c}=\right.$ 4.399) obtained for Sample I of the unknown acetate; it is to be noted that the temperatures of the two determinations differed.

The $4.46 \mathrm{Gm}$. of acetate, having a melting point range of $114^{\circ}-117^{\circ}$ (page 46), was dissolved in a boiling mixture of $80 \mathrm{ml}$. of ethanol and $40 \mathrm{ml}$. of methanol. The solution was filtered while hot and the filtrate refrigerated at $-18^{\circ}$ for six hours. The crystals which formed were removed by filtration and dried at $105^{\circ}$; the yield was $2.85 \mathrm{Gm}$., having a melting point of $128.0^{\circ}-130.0^{\circ}$. Concentration of the mother liquor to one-third its original volume and addition of $4 \mathrm{ml}$. of water to the concentrated solution, yielded $0.95 \mathrm{Gm}$. of a yellowish-white solid.

The $2.85 \mathrm{Gr}$. of acetate, having a melting point of $128.0^{\circ}-130.0^{\circ}$ was dissolved in $25 \mathrm{ml}$. of boiling acetone, the solution was filtered while hot and the filtrate was refrigerated at $-18^{\circ}$ overnight. The yield of crystals obtained was $2.27 \mathrm{Gm}$, having a melting point of $131.0^{\circ}-132.0^{\circ}$. Concentration of the mother liquor, after removal of the $2.27 \mathrm{Gm}$. fraction, addition of sufficient water $(6 \mathrm{ml}$.) to give a turbid solution and refrigeration of the turbid solution, yielded 0.16 $\mathrm{Gm}$. of a yellowish-white solid.

The $2.27 \mathrm{Gm}$. of acetate, having a melting point of $131.0^{\circ}-132.0^{\circ}$, 
was recrystallized from a mixture of $25 \mathrm{ml}$. of acetone and $2 \mathrm{ml}$. of water. The yield was $2.10 \mathrm{Gm}$. of acetate, having a melting point of $131.0^{\circ}-132.0^{\circ}$ after filtration. Addition of $15 \mathrm{ml}$. of water to the filtrate to produce turbidity and refrigeration of the turbid solution yielded $0.02 \mathrm{Gm}$, having a melting point of $190^{\circ}-200^{\circ}$.

The $2.10 \mathrm{Gm}$. of acetate, having a melting point of $131.0^{\circ}-132.0^{\circ}$ was recrystallized from a mixture of $27 \mathrm{ml}$. of acetone and $1 \mathrm{ml}$. of water. The yield was $1.89 \mathrm{Gm}$. of acetate, having a melting point of $131.0^{\circ}-132.0^{\circ}$. Concentration of the mother liquor to one-half its original volume, addition of $4.5 \mathrm{ml}$. of water to the concentrate to produce turbidity and refrigeration of the turbid solution, yielded $0.20 \mathrm{Gm}$. of acetate, having a melting point range of $127^{\circ}-134^{\circ}$.

The $1.89 \mathrm{Gm}$. of acetate, having a melting point of $131.0^{\circ}-132.0^{\circ}$ was recrystallized from a mixture of $30 \mathrm{ml}$. of acetone and $20 \mathrm{ml}$. of methanol. The yield was $1.65 \mathrm{Gm}$. of acetate, having a melting point of $131.0^{\circ}-132.0^{\circ}$ (corr. $\left.132.5^{\circ}-133.5^{\circ}\right)$, unchanged on admixture with either Sample I or Sample IV of the unknown acetate. This $1.65 \mathrm{Gm}$. of acetate is herein designated "Sample $V$ of the unknown acetate". PREPARATION OF LUPEOL BY SAPONIFICATION OF LUPEOL ACETATE

$3.00 \mathrm{Gm}$. of Sample I of lupeol acetate, melting point $216.0^{\circ}-216.5^{\circ}$, was dissolved in $180 \mathrm{ml}$. of approximately $0.5 \mathrm{~N}$ aldehyde-free $(60)$ alcoholic potassium hydroxide solution at the boiling point. The solution was refluxed on a steam-bath for two hours, then allowed to cool slowly to room temperature. The addition of $5 \mathrm{ml}$. of water caused some precipitation. The suspension was refrigerated for nine hours. The heavy gelatinous precipitate, which had formed, was 
separated by filtration and washed with water until free of alkali. The crystalline residue was dried in an air-oven at $105^{\circ}$. The yield was $2.65 \mathrm{Gm}$. or 97.1 per cent of the theoretical yield. The lupeol obtained melted at $214.0^{\circ}-214.5^{\circ}$.

The $2.65 \mathrm{Gm}$. of lupeol was recrystallized from ethanol-water; the yield was $2.58 \mathrm{Gm}$. of pure lupeol, having a melting point of $214_{4} 5^{\circ}$ $215.0^{\circ}$. Swift and Walter (33) reported that lupeol melted at $214^{\circ}-$ $215^{\circ}$

DEPERMINATION OF THE SPECIFIC ROTATION (63) OF LUPEOL

$0.4476 \mathrm{Gm}$. of Iupeol, dissolved in $10.0 \mathrm{ml}$. of anhydrous chloroform gave $\alpha{ }_{D}^{28.5^{\circ}}+2.417^{\circ}$ in a 2 decimeter polarimeter tube; $[\alpha]_{D}^{28.5^{\circ}}$ $+27.0^{\circ}\left(\mathrm{CHCl}_{3}, \mathrm{c}=4.476\right)$.

Swift and Walter (33) reported $[\alpha]{ }_{D}^{22^{\circ}}+27.63^{\circ}\left(\mathrm{CHCl}_{3}, \mathrm{c}=\right.$ 3.926) for lupeol.

PREPARATION OF LUPEOL BENZOATE

In a dry $50 \mathrm{ml}$. flask, $1.00 \mathrm{Gm}$. of lupeol, melting point $214.5^{\circ}-$ $215.0^{\circ}$, was dissolved in $30 \mathrm{ml}$. of anhydrous pyridine and to the solution was added $1.0 \mathrm{ml}$. of benzoyl chloride. The solution was heated in an oil-bath at $115^{\circ}-130^{\circ}$ for three hours.

The hot solution was poured, with vigorous stirring, into about $200 \mathrm{Gm}$. of ice and water. The precipitated benzoate was extracted with ether, the ether solution was washed with $50 \mathrm{ml}$. of 5 per cent potassium carbonate solution, then with three $50 \mathrm{ml}$. portions of water. The acid-free ether extract was evaporated to dryness; the residue, after drying at $105^{\circ}$, weighed $1.18 \mathrm{Gm}$.

Three recrystallizations of the crude lupeol benzoate, the first 
from benzene-ethanol $(1: 4.6)$, the second from benzene-ethanol $(1: 3.6)$ and the third from benzene-ethanol-ether (1:5.3:1.3), gave $0.51 \mathrm{Gm}$. of lupeol benzoate of melting point $261.0^{\circ}-263.0^{\circ}$ (corr. $269.2^{\circ}-$ $\left.271.2^{\circ}\right)$. These crystals were in the form of large, flat, brittle, colorless plates.

The benzoate recovered from the mother liquor and that recovered from the determination of the specific rotation were combined and recrystallized from acetone. A yield of $0.23 \mathrm{Gm}$. of long, colorless needles of melting point $264.0^{\circ}-266.0^{\circ}$ (corr. $271.7^{\circ}-273.7^{\circ}$ ) was obtained. From the acetone mother liquor was obtained $0.14 \mathrm{Gm}$. of lupeol benzoate of melting point $263.0^{\circ}-265.0^{\circ}$ (corr. $271.8^{\circ}-273.8^{\circ}$ ). The overall yield of crystalline lupeol benzoate was 62.9 per cent based on the lupeol.

DETERMINATION OF THE SPECIFIC ROTATION OF LUPEOL BENZOATE

$0.1000 \mathrm{Gm}$. of lupeol benzoate, melting point $261.0^{\circ}-263.0^{\circ}$ (corr. $\left.269.2^{\circ}-271.2^{\circ}\right)$, dissolved in $10.0 \mathrm{ml}$. of anhydrous chloroform, gave $\alpha_{\mathrm{D}}^{28.5^{\circ}}+1.183^{\circ}$ in a 2 decimeter polarimeter tube; $[\alpha]_{D}^{28.5^{\circ}}$ $+59 \cdot 2^{\circ}\left(\mathrm{CHCl}_{3}, \mathrm{c}=1.000\right)$.

Swift and Walter (33) reported that lupeol benzoate has a melting point of $263.0^{\circ}-265.0^{\circ}$ and $[\alpha]_{\mathrm{D}}^{25^{\circ}}+61.36^{\circ}\left(\mathrm{CHCl}_{3}, \mathrm{c}=0.9908\right)$. Heilbron et $21 .(64)$ reported the melting point was $261.5^{\circ}$ and $[\alpha]_{D}^{20^{\circ}}$ $+59.9^{\circ}\left(\mathrm{CHCl}_{3}\right)$. Hendricks and Wildman (65) reported a melting point of $260^{\circ}$.

A decomposition range appears to be reasonable for lupeol benzoate since it has been reported (38) to undergo thermic cleavage to the hydrocarbon, $\mathrm{C}_{30^{\mathrm{H}}} \mathrm{8}^{\circ}$ 
The lupeol benzoate, which was prepared, had physical constants which agreed favorably with those in the literature.

ISOLATION OF THE UNKNONN ALCOHOL BY SAPONIFICATION OF THE UNKNOAN ACETATE

Sample $V$ of the unknown acetate $(1.65 \mathrm{Gm}$.$) , having a melting point$ of $131.0^{\circ}-132.0^{\circ}$ (corr. $132.5^{\circ}-133.5^{\circ}$ ), was dissolved in $115 \mathrm{ml}$. of $0.5 \mathrm{~N}$ aldehyde-free (60), alcoholic potassium hydroxide and the solution was heated on a steam-bath for one and a half hours in an atmosphere of nitrogen. Approximately half of the alcohol was removed by distillation under reduced pressure using a water aspirator as source of vacuum and bubbling nitrogen into the solution by means of a capillary tube to prevent bumping. The concentrated solution was removed from the distillation apparatus, $75 \mathrm{ml}$. of water were added, and the cloudy suspension was refrigerated at $-18^{\circ}$ for three hours. At the end of this time the suspension contained some crystals and some yellow oil. The suspension was extracted with $75 \mathrm{ml}, 25 \mathrm{ml}$. and a final $25 \mathrm{ml}$. of ether. The combined ethereal extracts were washed with $25 \mathrm{ml}$. of $0.25 \mathrm{~N}$ hydrochloric acid, then with four $25 \mathrm{ml}$. portions of water, the last wash water being neutral to litmus. The neutral ethereal extract was decolorized by shaking with $0.6 \mathrm{Gm}$. of activated charcoal for ten minutes then filtering the suspension. The ether was removed from the filtrate by distillation under reduced pressure using a water aspirator as a source of vacuum and bubbling nitrogen into the solution by means of a capillary to prevent buning. When the alcohol started to crystallize from the ether, the vacuum distillation was stopped. The alcohol was immediately recrystallized from $20 \mathrm{ml}$. of 80 per cent ethanol. The alcohol was very soluble in hot 80 per cent ethanol but 
readily crystallized from the solution after cooling to room temperature. To ensure as complete crystallization as possible, the recrystallization mixture was refrigerated at $0^{\circ}$ for twelve hours.

The white crystalline alcohol was removed by filtration, washed with $30 \mathrm{ml}$. of cold 80 per cent ethanol, then spread out thinly on filter paper sheets and dried for three hours in a vacuum oven at $62^{\circ}$ $\pm 2^{\circ}$. The yield of unknown alcohol was $0.813 \mathrm{Gm}$. It melted to a white turbid 1iquid at $154.0^{\circ}-156.0^{\circ}$ (corr. $156.5^{\circ}-158.5^{\circ}$ ) which cleared at $161^{\circ}$ (corr. 163.8 $8^{\circ}$. Microscopically, the alcohol was seen to be in the form of double and single pointed needles and rosettes of colorless needles. Macroscopically, the alcohol appeared as a fluffy, white powder.

DETERMINATION OF THE SPECIFIC ROTATION OF THE UNKNOWN ALCOHOL

$0.1044 \mathrm{Gm}$. of the unknown alcohol, melting point $154.0^{\circ}-156.0^{\circ}$, dissolved in $10.0 \mathrm{ml}$. of absolute ethanol, gave $\propto \int_{D}^{32.0^{\circ}}+0.33^{\circ}$ in a 2 decimeter polarimeter tube; $[d]_{\mathrm{D}}^{32.0^{\circ}}+15.8^{\circ}(\mathrm{EtOH}, c=$ $1.044)$.

RECRYSTALLTZATION OF THE UNKNONN ALCOHOL

$100 \mathrm{mg}$. of the unknown alcohol of melting point $154.0^{\circ}-156.0^{\circ}$ (corr. $156.5^{\circ}-158.5^{\circ}$ ), on recrystallization from 80 per cent ethanol, yielded $46 \mathrm{mg}$. of needles which melted unsharply at $166.0^{\circ}-168.0^{\circ}$ (corr. $168.8^{\circ}-170.8^{\circ}$ ), unchanged after one further crystallization from 80 per cent alcohol.

$280 \mathrm{mg}$. of the unknown alcohol of melting point $154.0^{\circ}-156.0^{\circ}$ (corr. $156.5^{\circ}-158.5^{\circ}$ ), was dissolved in $6 \mathrm{ml}$. of boiling 95 per cent ethanol and water $(1 \mathrm{ml}$.$) was added dropwise until a faint turbidity$ 
was produced. Refrigeration of this solution yielded a stiff gel which was placed on the filter and washed with $5 \mathrm{ml}$. of cold 80 per cent ethanol. The white residual solid on the filter was dried in a vacuum oven at $62^{\circ} \pm 2^{\circ}$ for three and a half hours. The yield was $177 \mathrm{mg}$. of needles which melted unsharply at $166.0^{\circ}-168.0^{\circ}$ (corr. $\left.168.8^{\circ}-170.8^{\circ}\right)$. To insure that the alcohol was dry, the $177 \mathrm{mg}$. were heated at $100^{\circ} \pm 2^{\circ}$ in a vacuum oven for a further three hours. The melting point was unchanged. ISOLATION OF THE UNKNOWN BENZOATE AND EVIDENCE OF AN ISOIVERIZATION Section I

Sample II of the unknown acetate $(3.10 \mathrm{Gm}$.$) , having a melting$ point of $131.0^{\circ}-132.0^{\circ}$, was dissolved in $200 \mathrm{ml}$. of aldehyde-free (60), alcoholic potassium hydroxide and the solution was heated under a reflux condenser for two hours on a steam-bath. The solution was cooled for one-half hour, then $100 \mathrm{ml}$. of water were added with swirling. The turbid solution was refrigerated for twenty-four hours. At the end of this time, part of the precipitate was crystalline and part was in the form of an oil. The suspension was heated and $80 \mathrm{ml}$. of solvent removed by distillation. Refrigeration of the concentrated saponification mixture caused the formation of a wax-like cake, which was removed by filtration and partially dried under reduced pressure; the yield was $2.85 \mathrm{Gm}$. Extraction of the filtrate with ether, washing the ether with water until free of alkali and evaporation of the ether, yielded an additional $0.11 \mathrm{Gm}$. of crude alcohol.

The wax-like cake and extracted material was combined (2.96 Gm.) and dissolved in $80 \mathrm{ml}$. of 87.5 per cent ethanol. The solution was 
filtered while not, cooled to room temperature and refrigerated at $-18^{\circ}$ for three days. The solution yielded white crystals which were removed by filtration, washed with cold 85 per cent ethanol, then dried. The yield was $1.78 \mathrm{Gm}$, having a melting point range of $117^{\circ}-$ $124^{\circ}$. This $1.78 \mathrm{Gm}$. was recrystallized from $35 \mathrm{ml}$. of methanol and $2 \mathrm{ml}$. of water. Refrigeration of the solution yielded a white, microcrystalline powder, which was removed by filtration, washed with cold 85 per cent ethanol and dried at $105^{\circ}$. The yield was $1.12 \mathrm{Gm}$, which melted unsharply at $128^{\circ}-132^{\circ}$. Considerable difficulty was experienced in this saponification in obtaining a satisfactory crystalline alcohol. In the previous saponification described, the first recrystallization of the alcohol raised the melting point to $154.0^{\circ}-156.0^{\circ}$, while the second recrystallization raised it to $166.0^{\circ}-168.0^{\circ}$, which melting point remained the same after one further recrystallization. Since the purpose of this saponification was to obtain the alcohol in order to prepare a benzoate of the alcohol, this $1.12 \mathrm{Gm}$, which melted unsharply over the range $128^{\circ}-132^{\circ}$, was benzoylated directly (Part $A$ ). From the combined mother liquors and wash liquors of the above two crystallizations only a colorless oil could be recovered. The colorless oil was extracted with ether, the ether was evaporated and the residual oil dried at $105^{\circ}$; the yield was $1.35 \mathrm{Gm}$. Since the difficulty in recrystallization may have been due to the two different alcohols being present, this $1.35 \mathrm{Gm}$. of oil was benzoylated separately (Part B).

Fart $\mathrm{A}$ : The $1.12 \mathrm{Gm}$. of unknown alcohol, which melted unsharply at $128^{\circ}-132^{\circ}$, was dissolved in $30 \mathrm{ml}$. of anhydrous pyridine and to 
the solution was added $1.5 \mathrm{ml}$. of benzoyl chloride. The solution was heated in an oil-bath at a temperature between $120^{\circ}$ and $150^{\circ}$ for two hours. The reaction mixture was allowed to cool, then was poured into $125 \mathrm{ml}$. of ice and water. The precipitated benzoate was extracted with ether, the ether extract was washed with two $50 \mathrm{ml}$. portions of 5 per cent aqueous potassium carbonate solution, then with six $50 \mathrm{ml}$. portions of water; the last wash water was neutral to litmus. The ether extract was dried for two hours over Drierite, filtered, then evaporated to dryness. The crude benzoate yield was $1.50 \mathrm{Gm}$.

The $1.50 \mathrm{Gm}$. of crude benzoate was dissolved in a boiling mixture of acetone-ethanol $(5: 4), 0.2 \mathrm{Gm}$. of activated charcoal was added and the suspension was filtered while hot. Refrigeration of the filtrate yielded $0.82 \mathrm{Gm}$. of colorless crystals which melted at $126.5^{\circ}-127.5^{\circ}$. Concentration of the mother liquor to one-half its original volume, addition of sufficient water $(7 \mathrm{ml}$.) to produce slight turbidity, followed by refrigeration, yielded $0.28 \mathrm{~cm}$. of benzoate which melted at $120.0^{\circ}-121.5^{\circ}$ (D-1).

The least soluble fraction, the $0.82 \mathrm{Gm}$. of benzoate, melting at $126.5^{\circ}-127.5^{\circ}$, was recrystallized from ethanol-acetone $(5: 3.3)$. The first crop of crystals weighed $0.44 \mathrm{Gm}$, and had a melting point range of $255^{\circ}-258^{\circ}$. Concentration of the mother liquor and refrigeration yielded two crops of crystals; the first weighed $0.19 \mathrm{Gm} .(\mathrm{D}-2)$ and melted at $120^{\circ}-121^{\circ}$; the second weighed $0.12 \mathrm{Gm} .(D-3)$ and melted at $118^{\circ}-119^{\circ}$.

The $0.44 \mathrm{Gm}$. of benzoate which melted over the range $255^{\circ}-258^{\circ}$ after two recrystallizations from acetone, yielded $0.30 \mathrm{~cm}$. of benzoate 
which melted at $261.0^{\circ}-263.0^{\circ}$ (corr. $\left.269.2^{\circ}-271.2^{\circ}\right)$, unchanged on admixture with lupeol benzoate having the same melting point.

Part B: The $1.35 \mathrm{Gm}$. of colorless oil, formerly described, was benzoylated by heating with $30 \mathrm{ml}$. of anhydrous pyridine and $2.0 \mathrm{ml}$. of benzoyl chloride at $115^{\circ}-130^{\circ}$ for two hours. The hot solution was poured, with vigorous stirring into $200 \mathrm{Gm}$. of ice and water. The precipitated benzoate was extracted with ether, the ether extract was washed with 5 per cent aqueous potassium carbonate, then with water until the washings were neutral to litmus. The ether extract was dried over Drierite, then filtered. Evaporation of the ether yielded $1.69 \mathrm{Gm}$. of crude benzoate.

The $1.69 \mathrm{Gm}$. of crude benzoate was dissolved in a boiling mixture of acetone-ethanol $(3: 1), 0.2 \mathrm{Gm}$. of activated charcoal was added and the suspension was filtered while hot. Refrigeration of the filtrate overnight yielded $0.95 \mathrm{Gm}$. of benzoate which melted at $123.5^{\circ}-124.5^{\circ}$. Concentration of the mother liquor to half its original volume, addition of sufficient water $(7.5 \mathrm{ml}$.) to produce a faint turbidity, followed by refrigeration, yielded $0.38 \mathrm{Gm}$. of benzoate which melted at $113^{\circ}-115^{\circ}$, but which after one further recrystallization from ethanol-water ( $5: 1$ ) yielded $0.31 \mathrm{~cm}$. (D-4) having a melting point of $118^{\circ}-119^{\circ}$.

The $0.95 \mathrm{Gm}$. of benzoate, having a melting point of $123.5^{\circ}-124.5^{\circ}$, was recrystallized from acetone $(28 \mathrm{ml}$.)-ethanol $(17 \mathrm{ml}$ ). The first crop of crystals weighed $0.87 \mathrm{Gm}$. and melted at $123.5^{\circ}-124.5^{\circ}$. Concentration of the mother liquor and refrige ration of the concentrate, yielded $0.04 \mathrm{Gm}$, having a melting point of $112.0^{\circ}-114.0^{\circ}$ (D-5). 
The $0.87 \mathrm{Gm}$. of benzoate, having a melting point of $123.5^{\circ}-124.5^{\circ}$, was recrystallized from $60 \mathrm{ml}$. of ethanol. The first crop of crystals weighed $0.69 \mathrm{Gm}$. and melted at $124.0^{\circ}-125.0^{\circ}$. Concentration of the mother liquor and refrigeration of the concentrate yielded $0.13 \mathrm{Gm}$, having a melting point of $115^{\circ}-117^{\circ}(D-6)$.

The $0.69 \mathrm{Gm}$. of benzoate, having a melting point of $124.0^{\circ}-125.0^{\circ}$, was recrystallized from a mixture of methanol-acetone (1:1). The first crop of crystals weighed $0.59 \mathrm{Gm}$. and melted at $124.0^{\circ}-125.0^{\circ}$ (corr. $125.5^{\circ}-126.5^{\circ}$ ). Concentration of the mother liquor and refrigeration of the concentrate yielded $0.09 \mathrm{Gm}$, having a melting point of $120^{\circ}-121^{\circ}$.

It is to be noted above that recrystallization of the $0.95 \mathrm{Gm}$. of benzoate did not raise the melting point. When the first crop $(0.87$ $\mathrm{Gm}$.) of crystals were recrystallized from a different solvent, the melting point was raised $0.5^{\circ}$. Recrystallization of the $0.69 \mathrm{Gm}$. from a third solvent did not change the melting point, which remained constant at $124.0^{\circ}-125.0^{\circ}$ (corr. $125.5^{\circ}-126.5^{\circ}$ ). A sample of the $0.59 \mathrm{Gm}$. of benzoate, having a melting point of $124.0^{\circ}-125.0^{\circ}$ (corr. $125.5^{\circ}$ $126.5^{\circ}$ ), when recrystallized from a fourth solvent, namely acetonewater mixture, yielded crystals of the benzoate with the same melting point. It was, therefore, evident that the melting point of this benzoate could not be changed by recrystallization from three different solvents. The $0.59 \mathrm{Gm}$. of benzoate, having a melting point of $124.0^{\circ}-$ $125.0^{\circ}$ (corr. $125.5^{\circ}-126.5^{\circ}$ ) is herein designated "Sample I of the unknown benzoate".

Part $C:$ The benzoate fractions, D-1, D-2, D-3, D-4, D-5 and D-6, 
obtained from the mother liquors in the above recrystallizations were combined to give $1.07 \mathrm{Gm}$. of benzoate. This $1.07 \mathrm{Gm}$. was recrystallized from a mixture of ethanol-acetone-water $(10: 5: 1)$ and yielded $0.91 \mathrm{Gm}$, having a melting point of $119.0^{\circ}-120.0^{\circ}$.

The $0.91 \mathrm{Gm} .$, of melting point $119.0^{\circ}-120.0^{\circ}$, on recrystallization from methanol-acetone-water $(10: 10: 1)$ yielded $0.83 \mathrm{Gm}$. , having a melting point of $122.0^{\circ}-123.0^{\circ}$.

The $0.83 \mathrm{Gm}$. , of melting point $122.0^{\circ}-123.0^{\circ}$, on recrystallization from methanol-acetone-water (15:15:1) yielded $0.78 \mathrm{Gm}$, having a melting point of $123.0^{\circ}-124.0^{\circ}$.

The $0.72 \mathrm{Gm} .$, of melting point $123.0^{\circ}-124.0^{\circ}$, on recrystallization from methanol-acetone $(10: 7)$, yielded $0.63 \mathrm{Gm}$. of benzoate which melted at $124.0^{\circ}-125.0^{\circ}$, unchanged on admixture with Sample I of the unknown benzoate. This $0.63 \mathrm{Gm}$. of benzoate, having a melting point of $124.0^{\circ}-$ $125.0^{\circ}$ (corr. $125.5^{\circ}-126.5^{\circ}$ ) is herein designated "Sample II of the unknown benzoate". DETERMINATION OF THE SPECIFIC ROTATION (63) OF THE UNKNONN BENZOATE

$0.3146 \mathrm{Gm}$. of Sample I of the unknown benzoate, dissolved in 10.0 $\mathrm{ml}$. of anhydrous chloroform, gave $\propto \mathrm{D}^{27.5^{\circ}}+2.75^{\circ}$ in a 2 decimeter polarimeter tube; $[\alpha]_{D}^{27.5^{\circ}}+43.7^{\circ}\left(\mathrm{CHCl}_{3}, c=3.146\right)$.

\section{Section II}

In the foregoing section it was shown that when $3.10 \mathrm{Gm}$. of the unknown acetate, having a melting point of $131.0^{\circ}-132.0^{\circ}$ was saponified and the resulting alcohol benzoylated yields of $0.30 \mathrm{Gm}$. of lupeol benzoate, melting at $261.0^{\circ}-263.0^{\circ}$ and $1.22 \mathrm{Gm}$. of the unknown benzoate, melting at $124.0^{\circ}-125.0^{\circ}$, were obtained. The conversion of some of the 
unknown to lupeol at some point in the sequence of reactions:

Unknown acetate $\stackrel{\text { Saponify }}{\longrightarrow}$ Alcohol $\stackrel{\text { Benzoylate }}{\longrightarrow}$ Unknown benzoate + warranted further investigation.

Lupeol benzoate

A portion ( $200 \mathrm{mg}$ ) ) of the $0.813 \mathrm{Gm}$. of unknown alcohol, having a melting point of $154.0^{\circ}-156.0^{\circ}$ (corr. $156.5^{\circ}-158.5^{\circ}$ ), (See page 54) was benzoylated by dissolving the alcohol in $3 \mathrm{ml}$. of anhydrous pyridine, adding $0.5 \mathrm{ml}$. of benzoyl chloride to the solution and heating the resulting solution in an oil-bath at $130^{\circ} \pm 5^{\circ}$, under a reflux condenser, for two hours. The hot solution was poured, with vigorous stirring, into $20 \mathrm{ml}$. of ice water. The precipitated benzoate, in the form of an oil, was extracted with ether, the ether extract was washed with three portions of 5 per cent aqueous potassium carbonate solution to remove the benzoic acid, then with water until the aqueous washings were noutral to litmus. The ether solution was decolorized by shaking it with $100 \mathrm{mg}$. of activated charcoal and subsequent filtration. The filtrate was evaporated to dryness on a steam-bath and the residual colorless oil was dissolved in a boiling mixture of $20 \mathrm{ml}$. of acetone and $20 \mathrm{ml}$. of ethanol. Slowly cooling the solution to room temperature and subsequent refrigeration of the solution at $-18^{\circ}$ for two days, yielded a crystalline benzoate. The crystals were removed by filtration, washed with a few ml. of cold 80 per cent ethanol, then dried in the oven at $105^{\circ}$ for one and a half hours. This first crop of benzoate crystals weighed $95 \mathrm{mg}$; a sample of the crystals melted to a semisolid over the wide range $143^{\circ}-251^{\circ}$, with subsequent decomposition of the semi-solid to a yellow oil over the range $251^{\circ}-253^{\circ}$. Evaporation of the combined mother liquor and wash liquor to one-half their original 
volume, addition of water until a faint turbidity was produced, followed by refrigeration of the turbid solution, yielded crystals which were removed by filtration, washed with cold 80 per cent ethanol, then dried in the oven at $105^{\circ}$ for one and a half hours; the yield was $52 \mathrm{mg}$. of a benzoate which melted at $113.0^{\circ}-116.0^{\circ}$.

The $95 \mathrm{mg}$. of benzoate crystals, which melted over the wide range, were recrystallized from $20 \mathrm{ml}$. of acetone. Beautiful, long, colorless needle-shaped crystals were isolated which melted over the range $246.0^{\circ}$ $-249.0^{\circ}$. Recrystallization of these needle-shaped crystals from $15 \mathrm{ml}$. of acetone yielded the same type of needles. The crystals were removed by filtration, washed with $2 \mathrm{ml}$. of cold acetone and dried at 105\%. The yield was $50 \mathrm{mg}$. of long, colorless, needle-shaped crystals, which melted at $261.0^{\circ}-263.0^{\circ}$ (corr. $269.2^{\circ}-271.2^{\circ}$ ); the melting point of this benzoate was not depressed on admixture with a sample of lupeol benzoate, having the same melting point. This $50 \mathrm{mg}$. of colorless needles was lupeol benzoate.

The $52 \mathrm{mg}$. of benzoate crystals, which were more soluble and which melted over the range $113.0^{\circ}-116.0^{\circ}$, were dissolved in a boiling mixture of $2 \mathrm{ml}$. of acetone, $1 \mathrm{ml}$. of ethanol and $0.5 \mathrm{ml}$. of water. Cooling of the solution to room temperature, yielded a flocculent, crystalline precipitate. The suspension was refrigerated for four hours, the wite crystals were centrifuged to the bottom of the test-tube, the mother liquor was decanted and the crystals were dried at $105^{\circ}$. The crystals obtained were microscopic, flat, colorless plates which melted at $116.0^{\circ}-118.0^{\circ}$. These crystals were recrystallized from a mixture of $1.5 \mathrm{ml}$. of acetone, $2 \mathrm{ml}$. of ethanol and 3 drops of water. The yield 
was $33 \mathrm{mg}$. of microscopic, flat, colorless plates, which melted at $121.0^{\circ}-122.0^{\circ}$. This melting point was not depressed when the crystals we re admixed with some of the unknown benzoate crystals, having a melting point of $124.0^{\circ}-125.0^{\circ}$. This $33 \mathrm{mg}$. of flat, colorless plates was an impure sample of the unknown benzoate.

A mixed melting point of some of the $33 \mathrm{mg}$. of benzoate, having a melting point of $121.0^{\circ}-122.0^{\circ}$ and some of the $50 \mathrm{mg}$. of benzoate, having a melting point of $261.0^{\circ}-263.0^{\circ}$, was taken; the mixture melted gradually over the range $119.0^{\circ}$ (corr. $120.5^{\circ}$ ) to $232^{\circ}\left(\operatorname{corr} .237 .8^{\circ}\right.$ ), existing between these extremes as a white melt, which finally became a liquid at the higher temperature; the liquid cleared at $252^{\circ}$ (corr. $\left.259.4^{\circ}\right)$. The wide melting point range of the mixture was further proof that two different benzoates were isolated. ACETYLATION OF THE UNKNOWNN ALCOHOL AND FURTHER EVIDENCE OF AN ISONERTZATION

In the experimental work above it was shown that when the unknown acetate, having a melting point of $131.0^{\circ}-132.0^{\circ}$, which could not be changed by recrystallization from several solvent mixtures, was saponified and the resulting alcohol benzoylated, two benzoates were isolated. One of these benzoates was lupeol benzoate, the other was the unknown benzoate. It was desirable to see whether the sequence of reactions: Unknown acetate $\stackrel{\text { Saponify }}{\longrightarrow}$ Unknown alcohol $\stackrel{\text { Acetylate }}{\longrightarrow} \begin{aligned} & \text { Unknown acetate } \\ & \text { Lupeol acetate }\end{aligned}$ could be carried out.

Since samples of the unknown alcohol had al ready been obtained by saponification of the unknown acetate it was not necessary to repeat the saponification.

$85 \mathrm{mg}$. of the unknown alcohol, having a melting point of $154.0^{\circ}-$ 
$156.0^{\circ}$, was acetylated by heating it with an equal weight of anhydrous sodium acetate and $4 \mathrm{ml}$. of acetic anhydride at $130^{\circ}-135^{\circ}$ for one and a quarter hours. To the hot solution was added $20 \mathrm{ml}$. of ice water with vigorous stirring and the resulting suspension was allowed to stand for four hours in order to hydrolyze the acetic anhydride. The white, crystalline acetate was removed by filtration and washed with water until the washings were neutral to litmus.

After drying the crude acetate by suction it was recrystallized by dissolving it in $10 \mathrm{ml}$. of boiling ethanol, then adding sufficient water ( $2 \mathrm{ml}$.) to produce a faint turbidity. Refrigeration of the turbid solution overnight yielded white crystals, which were removed by filtration, washed with two $5 \mathrm{ml}$. portions of cold 80 per cent ethanol and dried at $105^{\circ}$. The yield was $56 \mathrm{mg}$. of an acetate, which melted at $131.0^{\circ}-132.0^{\circ}$. By concentration of the mother liquor and addition of a few drops of water to the concentrate, followed by refrigeration, $3 \mathrm{mg}$. of acetate were isolated.

The $56 \mathrm{mg}$. of acetate and $3 \mathrm{mg}$. of acetate were combined and dissolved in $5 \mathrm{ml}$. of acetone and $0.5 \mathrm{ml}$. of water at the boiling point. After refrigeration of this solution white crystals formed. The crystals were removed by filtration, washed with cold 80 per cent alcohol, then dried at $105^{\circ}$. This least soluble fraction of crystals weighed $20 \mathrm{mg}$. and melted at $211.0^{\circ}-212.0^{\circ}$ to a turbid liquid which cleared at $213^{\circ}$. By concentration of the combined mother liquor and wash liquor, addition of water to produce a faint turbidity, and refrigeration of the turbid solution, was obtained $18 \mathrm{mg}$. of an acetate, which melted at $126.0^{\circ}-127.0^{\circ}$ to a turbid liquid which cleared at about $150^{\circ}$. A 
mixture of some of the $20 \mathrm{mg}$., having a melting point of $211.0^{\circ}-212.0^{\circ}$ and some of the $18 \mathrm{mg}$. , having a melting point of $126.0^{\circ}-127.0^{\circ}$, melted over the range $126^{\circ}$ to $152^{\circ}$ to a white melt which cleared at $213^{\circ}$. This wide range indicated that two different acetates were isolated from the acetylation mixture.

The $20 \mathrm{mg}$. of acetate, melting point $211.0^{\circ}-212.0^{\circ}$, was placed in a centrifuge tube and dissolved in $1.5 \mathrm{ml}$. of ethanol. The clear solution which resulted was cooled slowly to room temperature, then refrigerated. The crystals which formed were centrifuged to the bottom of the tube, the mother liquor was decanted and the crystals were dried at $105^{\circ}$. The yield of needle-shaped crystals was $9 \mathrm{mg}$. which melted at $216.0^{\circ}-216.5^{\circ}$ (corr. $222.3^{\circ}-222.8^{\circ}$ ) to a clear liquid; the melting point of this acetate was not depressed on admixture with lupeol acetate having the same melting point. This $9 \mathrm{mg}$. of needleshaped crystals were, therefore, lupeol acetate.

The $18 \mathrm{mg}$. of acetate, molting point $126.0^{\circ}-127.0^{\circ}$, was placed in a centrifuge tube and dissolved in $0.6 \mathrm{ml}$. of acetone at room temperam ture. The solution was heated to boiling, water ( 3 drops) was added to produce a cloudiness, then one drop of acetone was added to produce a clear solution. The solution was cooled slowly to room temperature, then refrigerated overnight. The crystals, which had formed, were centrifuged to the bottom of the tube, the mother liquor was decanted and the crystals were dried at $105^{\circ}$. These crystals melted at $129.0^{\circ}$ $130.0^{\circ}$. These acetate crystals were recrystallized from $0.5 \mathrm{ml}$. of acetone and 3 drops of water, using the same procedure as described above. The yield was $6 \mathrm{mg}$. of an acetate which melted at $131.0^{\circ}-132.0^{\circ}$ 
(corr. $132.5^{\circ}-133.5^{\circ}$ ), unchanged on admixture with the unknown acetate of the same melting point.

The sequence of reactions:

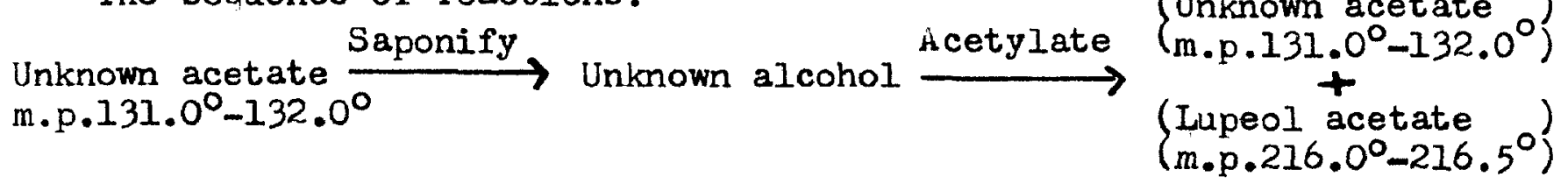

was carried out, and, like the corresponding sequence involving a benzoylation, indicated that an isomerization had occurred at some step in the sequence.

CARBON AND HYDROGEN DETERMINATIONS ON THE UNKNONN ALCOHOL, UNKNONN ACETATE AND UNKNONN BENZOATE

Samples of the unknown alcohol, having a melting point of $166.0^{\circ}$ $168.0^{\circ}$ (corr. $168.8^{\circ}-170.8^{\circ}$ ), the unknown acetate, having a melting point of $131.0^{\circ}-132.0^{\circ}$ (corr. $132.5^{\circ}-133.5^{\circ}$ ) and the unknown benzoate, having a melting point of $124.0^{\circ}-125.0^{\circ}$ ( corr. $125.5^{\circ}-126.5^{\circ}$ ) were sent

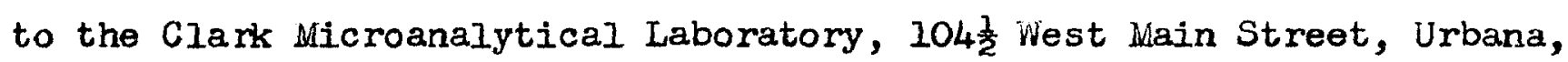
Illinois, for carbon and hydrogen determinations. The results of these analyses are reported below.

Unknown Alcohol

Calculated for: $\quad \mathrm{C}_{30} \mathrm{H}_{49} \mathrm{OH} ; \mathrm{C}, 84.45$ per cent; $\mathrm{H}, 11.81$ per cent. Found; C, 84.73 per cent; H, 11.78 per cent.

Unknown Acetate

Calculated for: $\mathrm{C}_{30} \mathrm{H}_{49} \mathrm{OCOCH}_{3} ; \mathrm{C}, 81.98$ per cent; $\mathrm{H}, 11.18$ per cent. C, 81.57 per cent; H, 10.76 per cent. C, 81.63 per cent; H, 10.87 per cent.

Unknown Benzoate

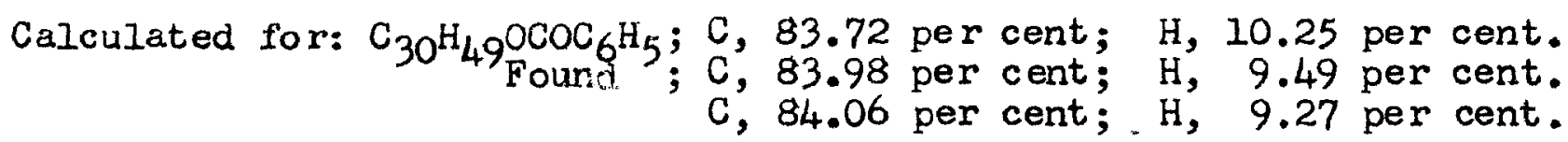

The isome rization, formerly reported, requires that the unknown 
alcohol, the unknown acetate and the unknown benzoate have molecular formulas the same as lupeol, lupeol acetate and lupeol benzoate respectively. That is, the unknown acetate must be the acetate of a monohydric triterpene alcohol having the same molecular formula as lupeol acetate.

The analyses reported indicate that the unknown acetate and lupeol acetate are isomeric compounds and that the unknown benzoate and lupeol benzoate are isomeric compounds. However, owing to the extreme difficulty of determining a molecular formula of this nature with complete accuracy, $(66,67)$ these formulas must await further confirmation. SAFONIFICATION EQUIVALENTS OF THE UNKNOWN ACETA'TE AND UNKNOWN BENZOATE

Saponification equivalents of the unknown acetate, having a melting point of $131.0^{\circ}-132.0^{\circ}$ (corr. $132.5^{\circ}-133.5^{\circ}$ ) and the unknown benzoate, having a melting point of $124.0^{\circ}-125.0^{\circ}$ (corr. $125.5^{\circ}-126.5^{\circ}$ ), were determined by the method outlined by Shriner and Fuson (68). SAPONIFICATION EQUIVALENT OF THE UNKNOWN ACETATE

$0.5020 \mathrm{Gm}$. of the unknown acetate was refluxed for two hours with $15.00 \mathrm{ml}$. of $0.2247 \mathrm{~N}$. alcoholic potassium hydroxide solution. After the addition of two drops of phenolphthalein solution, $9.55 \mathrm{ml}$. of $0.2422 \mathrm{~N}$. hydrochloric acid solution were required to produce a colorless solution. Back-titration of the solution until the color of the solution was a faint pink required $0.04 \mathrm{ml}$. of $0.2247 \mathrm{~N}$. alcoholic potassium hydroxide.

Saponification equivalent of the unknown acetate

$$
=\frac{0.5020 \times 1000}{(15.04 \times 0.2247)-(9.55 \times 0.2422)}=470.9
$$


The molecular weight of a given ester is equal to the saponification equivalent multiplied by the number of ester groups in the molecule (68).

If it is assumed that the unknown acetate molecule contains one ester group, then the experimental molecular weight of the unknown acetate is 470.9 . Compounds with the molecular formula $\mathrm{C}_{30} \mathrm{H}_{49} \mathrm{OCOCH}_{3}$ have a molecular weight and saponification equivalent of 468.7 . The experimental value agrees very closely with the calculated theoretical value.

The possibility of the presence of two ester groups in the unknown acetate molecule is excluded since the molecular formula $\mathrm{C}_{30} \mathrm{H}_{48}\left(\mathrm{OCOCH}_{3}\right)_{2}$ requires a theoretical saponification equivalent of 263.4 , a molecular weight of 526.8 , and a percentage carbon of 77.50 per cent. These theoretical values do not agree with the experimental values. SAPONIFICATION EQUIVALENT OF THE UNKNOWN BENZOATE

$0.2805 \mathrm{Gm}$. of the unknown benzoate was refluxed for two hours with $15.00 \mathrm{ml}$. of $0.2247 \mathrm{~N}$. alcoholic potassium hydroxide solution. After the addition of two drops of phenolphthalein solution, $11.70 \mathrm{ml}$. of $0.2422 \mathrm{~N}$. hydrochloric acid solution was required to produce a color less solution. Back-titration of the solution until the color of the solution was a faint pink required $0.04 \mathrm{ml}$. of $0.2247 \mathrm{~N}$. alcoholic potassium hydroxide.

Saponification of the unknown benzoate

$$
=\frac{0.2805 \times 1000}{(15.04 \times 0.2247)-(11.70 \times 0.2422)}=514.7
$$

If it is assumed that the unknown benzoate molecule contains one 
ester group, then the experimental molecular weight of the unknown benzoate is 514.7. Compounds with the molecular formula $\mathrm{C}_{30} \mathrm{H}_{49} \mathrm{OCOC}_{6} \mathrm{H}_{5}$ have a molecular weight and saponification equivalent of 530.8 . The experimental value agrees reasonably with the calculated theoretical value.

The possibility of the presence of two ester groups in the unknown benzoate molecule is excluded since the molecular formula $\mathrm{C}_{30} \mathrm{H}_{48}\left(\mathrm{OCOC}_{6}\right.$ $\left.\mathrm{H}_{5}\right)_{2}$ requires a theoretical saponification equivalent of 325.4 , a molecular weight of 650.9 and a percentage carbon of 91.07 per cent. These theoretical values do not agree with the experimental values. PAFEF PARTITION CHROMATOGRAPHY OF THE AICOHOLS AND THEIR DERIVATES ISOLATED FROM THE UNSAPONIFIABLE MATTER

The isolation of a new alcohol in the form of its acetate and the preparation of the corresponding free alcohol and benzoate, are discussed above. The separation of the unknown acetate from lupeol acetate and the separation of the unknown benzoate from lupeol benzoate were both based on the differences in audubilities of the two groups of compounds in various solvents.

Samples of the unknown acetate, which were isolated, had a melting point which could not be raised by recrystallization from the same solvents which did change the melting points of mixtures of the unknown acetate and lupeol acetate.

Similarly, samples of the unknown benzoate, which were isolated, had a melting point which could not be raised by recrystallization from the same solvents which did change the melting points of mixtures of the unknown benzoate and lupeol benzoate. Recrystallizations of the unknown acetate and unknown benzoate 
constituted one method used to show that each was homogeneous.

In order to be able to detect very small quantities of these, to differentiate them and to have another criterion to show that each compound was homogeneous, a method based on paper partition chromatography was developed. This method is discussed below.

Description of the Apparatus

The apparatus used to produce one cylindrical paper chromatogram is described below. Figure 1 is a photograph of the apparatus.

A cylinder of paper was prepared by a method similar to that described by Wolfson, Cohn and Devaney (69). From a larger sheet of Whatman's Number 1 filter paper, a rectangle, having the dimensions $30.5 \mathrm{~cm}$. by $48.5 \mathrm{~cm}$. was cut. A fold of $1.5 \mathrm{~cm}$. was made along one of the longer sides of the rectangle. A pencil line, which constituted the origin line, was drawn $3 \mathrm{~cm}$. from the fold. The rectangular sheet was shaped into a cylinder by overlapping the shorter sides of the sheet a distance of $4.5 \mathrm{~cm}$. and stapling the ends together.

Approximately 10 to 20 micrograms of the organic compound desired was applied to the paper in a circular area, approximately $5 \mathrm{~mm}$. in diameter, at the origin line by spotting from $0.001 \mathrm{ml}$. to $0.002 \mathrm{ml}$. of a one per cent solution of the organic compound in chloroform at the origin line, then allowing the chloroform to evaporate. Individual solutions of two different compounds were spotted alternately on the origin line, the spots being approximately $6 \mathrm{~cm}$. apart. Since the paper cylinder had a circumference of $39.5 \mathrm{~cm}$., each solution was spotted three times on each cylinder and the total number of spots was six. 


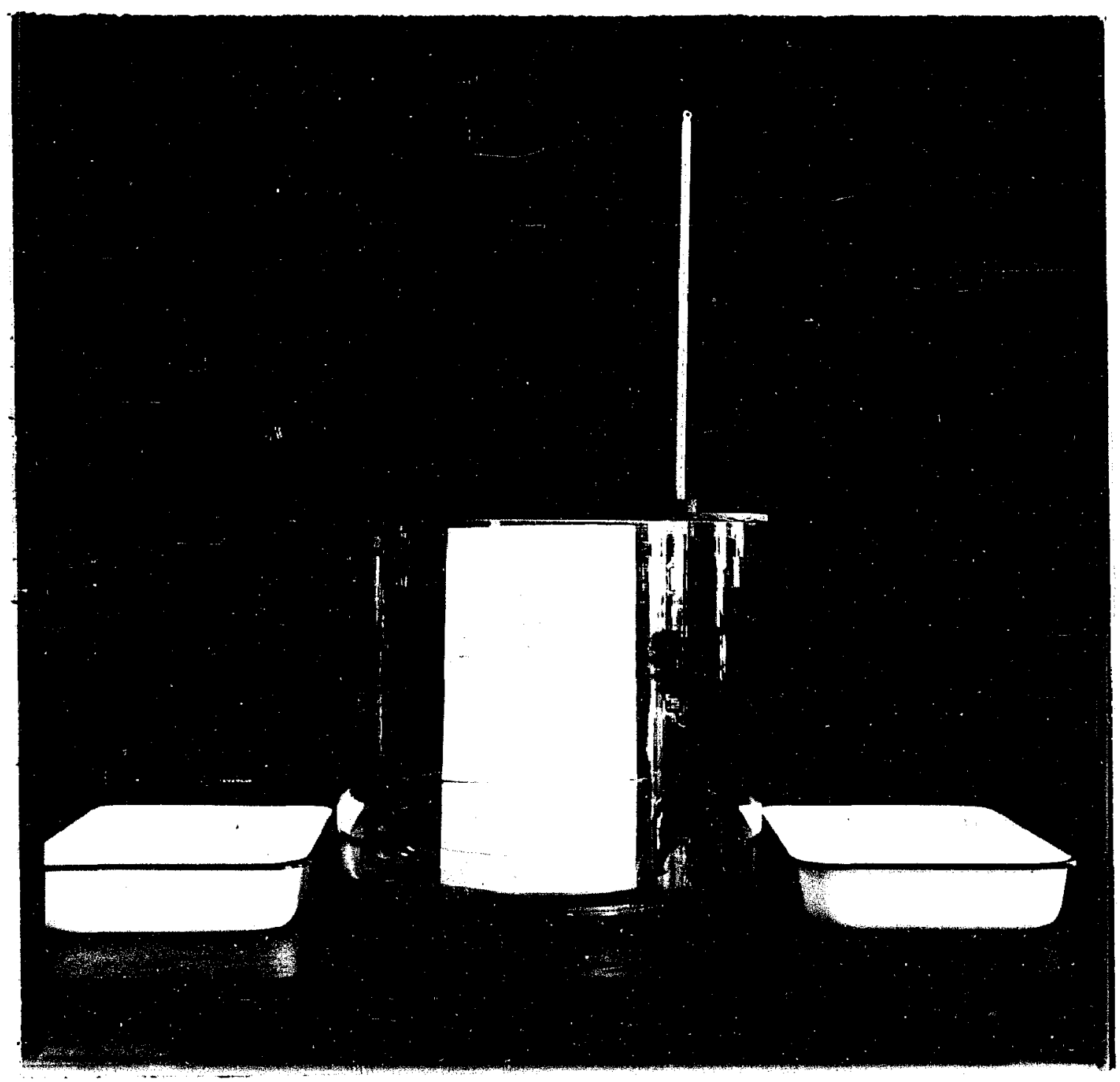

Fig.1. Photograph of Paper Partition Chromatography Apparatus 
The paper cylinder was then placed upright, resting on the fold, in a crystallizing dish, which was $9 \mathrm{~cm}$. high and had a diameter of $17 \mathrm{~cm}$. A $400 \mathrm{ml}$. beaker of water was placed in the center of the dish. This constituted assembly I.

The chromatography tank described by Wolfson, Cohn and Devaney (69) was a 20 gallon stainless steel tank. In this experimental work it was found that a large, cylindrical, glass water-bath, fitted with a groundglass plate, served suitably as a chromatography tank. The cylindrical glass water-bgth had a diameter of $29 \mathrm{~cm}$. and a height of $30 \mathrm{~cm}$. A ground-glass plate was fitted to the top of the water-bath and sealed with silicone stopcock lubricant. The ground-glass plate had an eccentric hole $2.3 \mathrm{~cm}$. in diameter and $5 \mathrm{~cm}$. from the edge. This hole served as a means to add solvents to the tank and to insert a thermometer into the tank while the chromatograms were being developed.

\section{Development of a Paper Chromatogram}

To develop a paper chromatogram, the glass plate was removed fram the top of the tank, assembly I was carefully lowered into the tank and placed so that the crystallizing dish rested in the center, and on the bottom of the tank. The glass plate was sealed on the top and a thermometer was inserted into the tank through the hole by means of a stopper. The tank was levelled by use of two spirit levels placed at right angles on the glass plate and by adjusting the position of the tank.

The apparatus was then allowed to stand for a determined $t$ ime in order to saturate the filter paper with water.

At the end of this time, the thermometer was removed and an organic 
solvent mixture was introduced into the crystal lizing dish at the base of the paper cylinder by means of a long glass tube and a funnel. The tank was then sealed quickly by reinserting the themometer in the hole of the plate. The solvent was allowed to ascend the paper cylinder for a determined period of time. Preliminary experiments disclosed that the best solvent mixture for separating the compounds studies was a mixture of $100 \mathrm{ml}$. of 95 per cent ethanol, $40 \mathrm{ml}$. of methanol and 35 ml. of water. This mixture is herein designated the "organic solvent mixture".

When the organic solvent mixture had ascended the paper cylinder to a sufficient height, the pape $r$ cylinder was removed from the tank, the location of the solvent boundary was marked with a pencil, then the paper was dried in an air-circulating oven at $105^{\circ}$ for five minutes. The dried paper cylinder was then cut into three strips, each strip containing a sample of each of the two different compounds originally applied to the paper.

Location of the Position of Compounds on the Developed Chromatogram

By preliminary investigations it was determined that the location on the paper chromatograms of all compounds studied, except lupeol, could be found by the method of Bush (70) who applied the method to steroids. The paper strips were dipped first into a saturated solution of iodine in petroleum ether. Each strip was allowed to dry in front of a fan. The violet background color quickly disappeared but the locations of the compounds studied were marked by, yellowish iodine spots on the paper. This method of location probably depends upon the 
addition of iodine to the olefinic double bonds of the compounds studied, followed by the slow release of the iodine from the addition. compound. When the iodine is released it leaves a visible yellow spot on the paper. These yellow spots faded rapidly, hence they were quickly outlined with a pencil.

Bush (70) suggested spraying such spots with starch solution to make the chromatograms more permanent. It was found, experimentally, that better chromatograms were obtained if the strips were dipped into an aqueous solution containing one per cent arrowroot starch and two per cent potassium iodide, after the background iodine had disappeared. The yellow spots then became a blue color against a pale blue background. After drying the strips at room temperature or at $105^{\circ}$ the brilliant blue spots changed to violet or reddish-brown while the background became a light reddish-brown. A permanent record of the chromatogram was thus obtained.

Calculation of $R_{f}$ Values and Interpretation of Results

Many authors (71) have shown that good separations of amino acids can be obtained on filter paper by allowing a suitable solvent, which has been previously saturated with water, to flow over the paper in a closed container, the air in which is saturated with the vapors of water and the solvent. Filter paper contains $20-25$ per cent of water under these conditions. The separation depends on the differences in partition coefficient of the amino acids between the stationery water phase and the moving solvent. It has been further shown (71) that for any individual amino acid, the value $R_{f}=\frac{\text { Distance travelled by the spot }}{\text { Distance travelled by the solvent }}$ 
is directly related to the partition coefficient, true adsorption by the cellulose playing little part.

Other investigators (71, 72) have successfully applied this method to the separation and identification of reducing sugars.

Bush (70) found that steroids were not successfully separated on ordinary filter paper but could be separated on alumina-impregnated filter paper. Identifications were made by means of comparisons with known steroids.

In the investigation herein reported, the method of paper partition chromatography has been successfully applied to triterpenes and their derivatives.

\section{Chromatograms comparing the Unknown Acetate with Lupeol Acetate}

Examination of the chromatograms prepared by the method outlined above showed that the unknown acetate could readily be differentiated from lupeol acetate. Depending upon the conditions, it was found that the unknown acetate moved up the paper a distance from $4.5 \mathrm{~cm}$. to $6.6 \mathrm{~cm}$. For a given strip, on which the unknown acetate had originally been spotted, the distance was measured from the top of the colored spot to the origin Iine; the distance from the bottom of the colored spot to the origin line was ineasured; the average of these two distances gave the distance from the center of the colored spot to the origin line; the latter distance is designated herein as "the distance travelled by the spot". For the same strip, the distance was measured from the solvent boundary to the origin line; this distance is designated as "the distance travelled by the solvent boundary". The $R_{f}$ value of the unknown acetate on this given strip was then calculated by determining 
the value of the quotient; distance travelled by the spot distance travelled by the solvent boundary

Table 7 gives the conditions of development, the measured distances and the calculated $R_{f}$ values for the unknown acetate on a series of chromatograms. The mean $R_{f}$ value for the unknown acetate was 0.26 and the value which included all extremes was $0.26 \pm 0.04$. In all experiments, under the same conditions, the lupeol acetate spots remained at the origin line and did not move up the paper at all. Therefore, the $R_{f}$ value of the lupeol acetate was zero on all the chromatograms.

Figure 2 is a photograph of a typical strip of a chromatogram. The lupeol acetate spot is at the origin line. The unknown acetate spot moved up the paper a distance of $5.5 \mathrm{~cm}$. from the origin line. The solvent boundary moved $20.0 \mathrm{~cm}$. during the six hour development period. For this strip the $R_{f}$ value of the lupeol acetate is zero and the $R_{f}$ value of the unknown acetate was $\frac{5.5}{20.0}$ or 0.28 . On this strip there was no spot at a distance of $5.5 \mathrm{~cm}$. above the lupeol acetate spot; this showed that the lupeol acetate sample used contained no unknown acetate as an impurity. On this strip there was no spot on the origin line where the unknown acetate had originally been spotted; this showed that the unknown acetate sample used contained no lupeol acetate as an impurity.

Figure 3 is a photograph of another strip of a chromatogram. The purpose for which this chromatogram was prepared was to show that different samples of the unknown acetate were homogeneous and that recrystallizations did not change the $R_{f}$ value of the unknown acetate under a given set of conditions. On the left of the strip, 10 to 20 
micrograms of Sample $\mathrm{V}$ of the unknown acetate were spotted at the origin line. In the center of the strip, 10 to 20 micrograms of Sample I of the unknown acetate were spotted. On the right of the strip, 10 to 20 micrograms of a $0.25 \mathrm{Gm}$. sample of the unknown acetate were spotted; this $0.25 \mathrm{Gm}$. sample was obtained by recrystallizing $0.39 \mathrm{Gm}$. of Sample I of the unknown acetate three times, the first time from a mixture of methanol-water (10:1), the second time from a mixture of acetone-water $(6: 1)$ and the third time from a mixture of acetone-water (5.5:1). After a seven hour development period, each of the unknown acetate spots had moved up the paper a distance of $5 \mathrm{~cm}$., while the solvent boundary had moved $21.2 \mathrm{~cm}$. Each of the unknown acetate samples, therefore, had the same $R_{f}$ value, under these conditions, namely $\frac{5.0}{21.2}$ or 0.24 . 


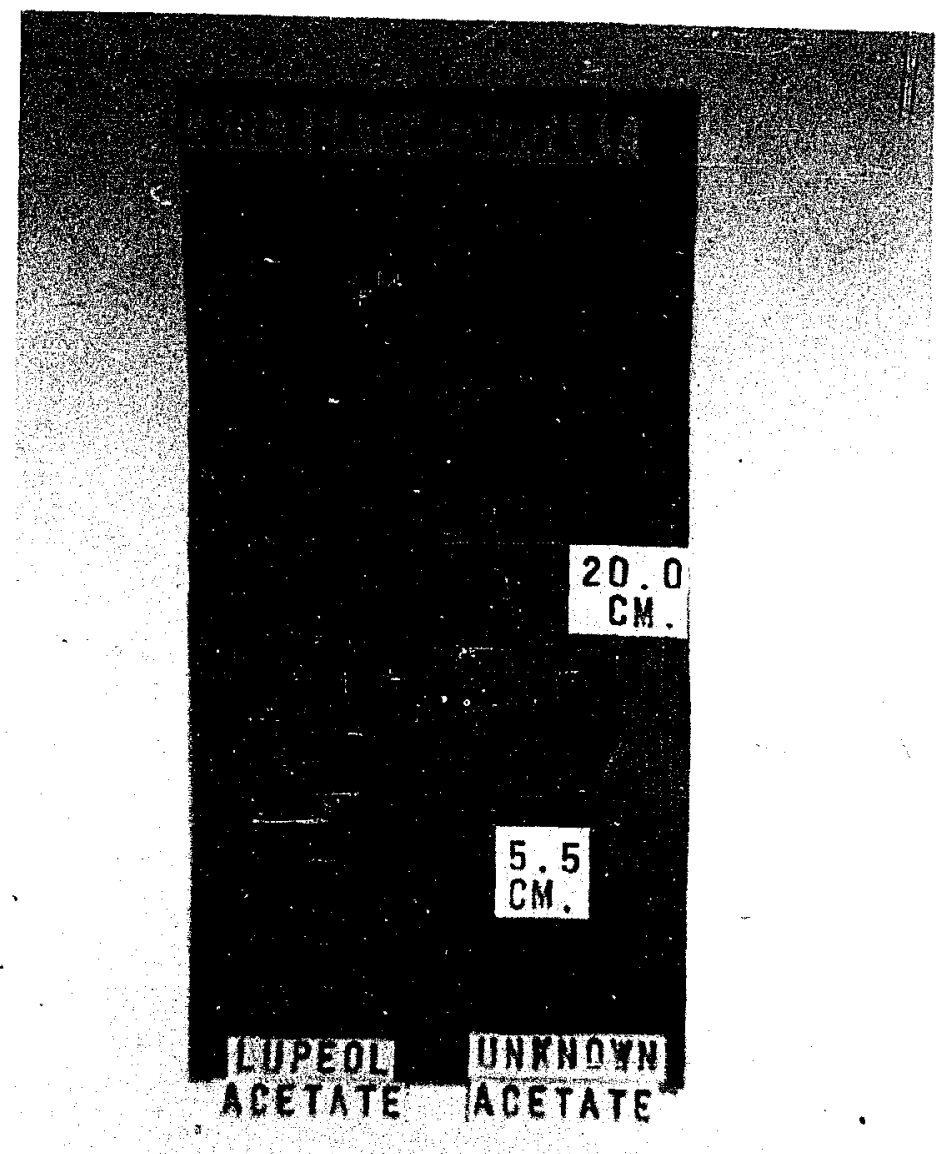

Fig.2. Chromatogram Comparing the Unknown Acetate with Lupeol Acetate 


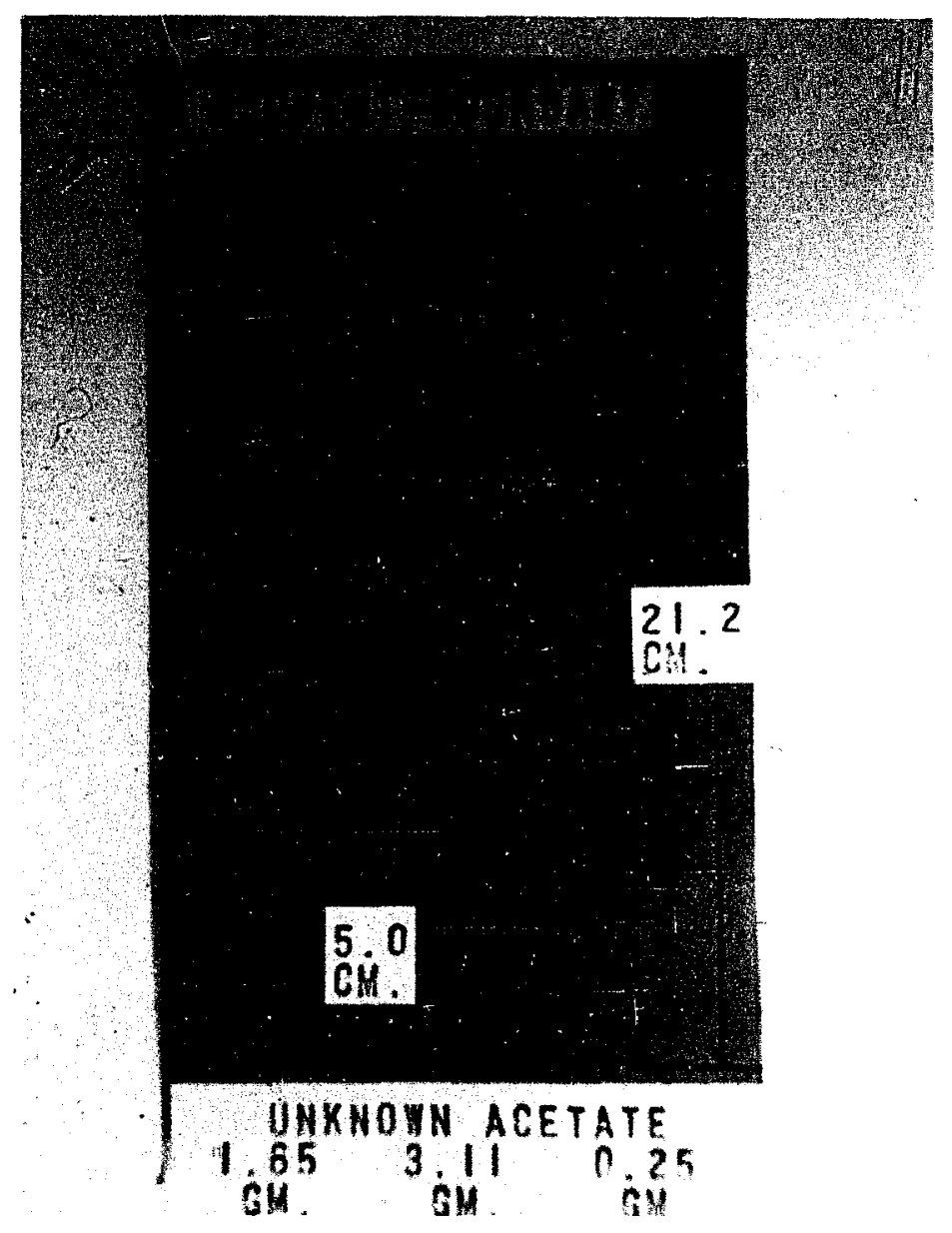

Fig.3. Chromatogram Comparing Three Different Samples of the Unknown Acetate. 


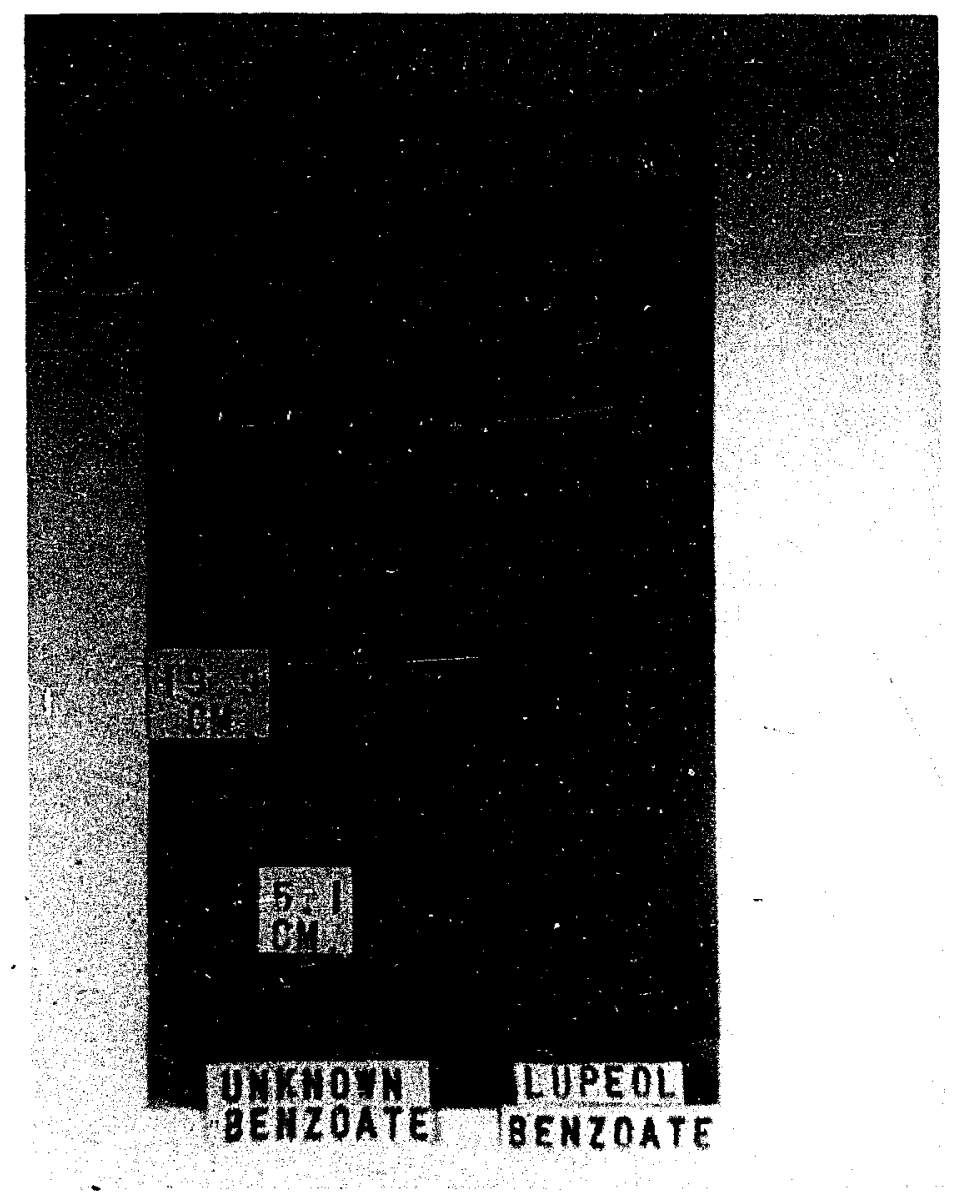

Fig.4. Chromatogram Compaxing the Unknown Benzoate with Lupeol Benzoate. 
81

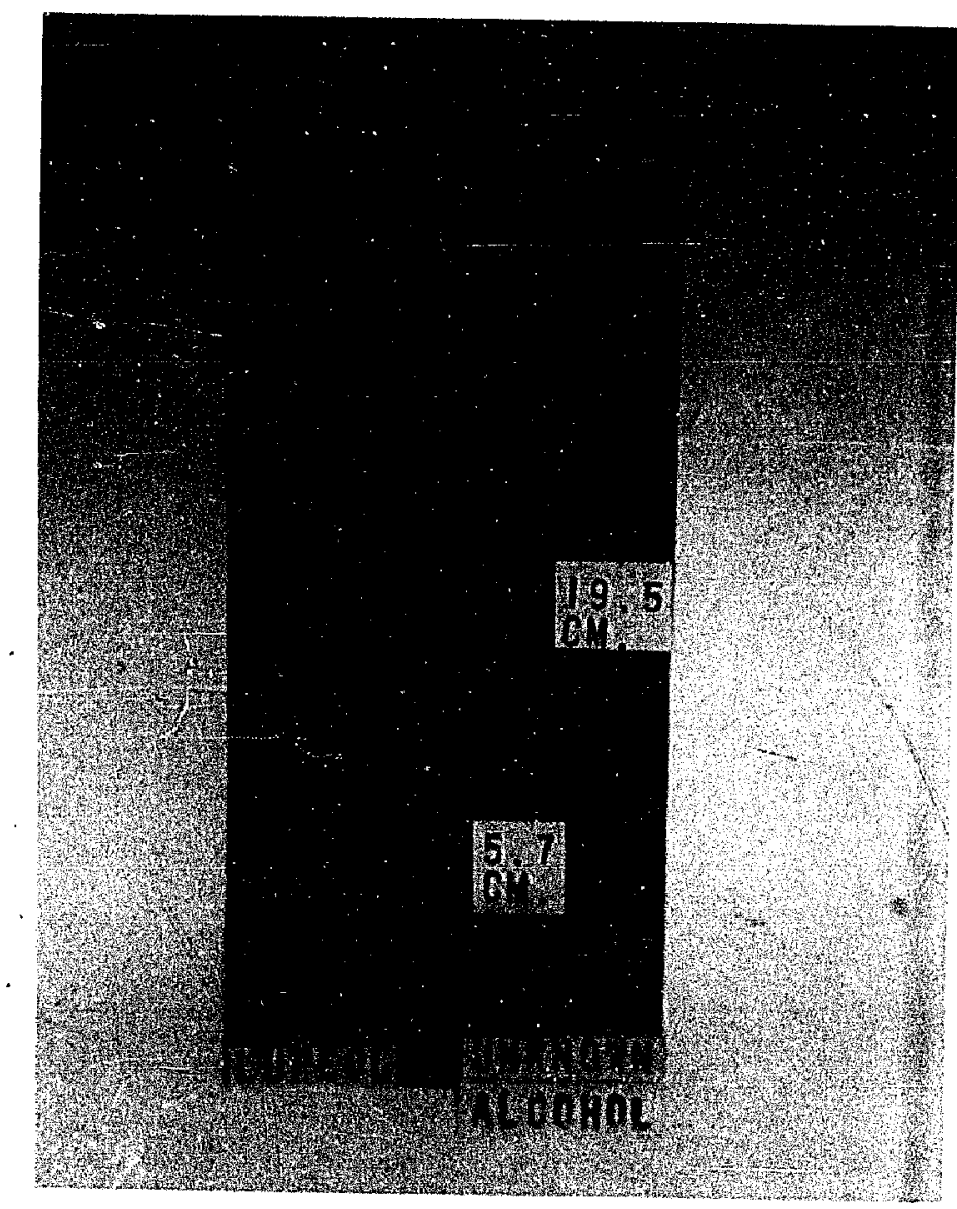

Fig.5. Chromatogram Comparing the Unknown Alcohol with Lupeol. 
TABLE?

PAPER PARTITION CHROMATOGRAPHY OF UNKNOWN ACETATE AND LUPEOL ACETATE

\begin{tabular}{|c|c|c|c|c|c|c|c|}
\hline \multirow[b]{2}{*}{$\begin{array}{l}\text { Temp- } \\
\text { erature } \\
\text { in Tank } \\
\left({ }^{\circ} \mathrm{c.}\right)\end{array}$} & \multirow[b]{2}{*}{$\begin{array}{l}\text { Time in } \\
\text { Tank } \\
\text { Before } \\
\text { Solvent } \\
\text { Added } \\
\text { (hours) }\end{array}$} & \multirow[b]{2}{*}{$\begin{array}{l}\text { Time of } \\
\text { Develop- } \\
\text { ment } \\
\text { (hours) }\end{array}$} & \multirow[b]{2}{*}{$\begin{array}{l}\text { Distance } \\
\text { Travelled } \\
\text { by the } \\
\text { Solvent } \\
\text { Boundary } \\
\text { (cm.) }\end{array}$} & \multicolumn{2}{|c|}{$\begin{array}{l}\text { Unknown } \\
\text { Acetate }\end{array}$} & \multicolumn{2}{|c|}{$\begin{array}{l}\text { Lupeol } \\
\text { Acetate }\end{array}$} \\
\hline & & & & $\begin{array}{l}\text { Distance } \\
\text { Travelled } \\
\text { by the } \\
\text { Spot } \\
(\mathrm{cm} .)\end{array}$ & $\underset{\text { value }}{\mathrm{R}_{\mathrm{f}}}$ & $\begin{array}{l}\text { Distance } \\
\text { Travelled } \\
\text { by the } \\
\text { Spot } \\
(\mathrm{cm} .)\end{array}$ & $\underset{\text { value }}{\mathrm{R}_{\mathrm{f}}}$ \\
\hline $\begin{array}{c}29-30 \\
29-30 \\
29-30 \\
29.5-30.5 \\
29.5-30.5 \\
29.5-30.5 \\
31.5-32.0 \\
31.5-32.0 \\
31.5-32.0 \\
31.5-32.0 \\
31.5-32.0 \\
31.5-32.0 \\
27-28 \\
27-28 \\
27-28 \\
27-28 \\
30 \\
26-27 \\
26-27 \\
26-27\end{array}$ & $\begin{array}{l}3 \frac{1}{4} \\
3 \frac{1}{4} \\
3 \frac{1}{4} \\
3 \frac{1}{4} \\
3 \frac{1}{4} \\
3 \frac{1}{4} \\
1 \frac{1}{2} \\
1 \frac{1}{2} \\
1 \frac{1}{2} \\
1 \frac{1}{2} \\
1 \frac{1}{2} \\
1 \frac{1}{2} \\
3 \frac{1}{4} \\
3 \frac{1}{4} \\
3 \frac{1}{4} \\
3 \frac{1}{4} \\
3 \frac{1}{4} \\
8 \\
8 \\
8\end{array}$ & $\begin{array}{l}6 \\
6 \\
6 \\
6 \\
6 \\
6 \\
5 \frac{1}{2} \\
5 \frac{1}{2} \\
5 \frac{1}{2} \\
5 \frac{1}{2} \\
5 \frac{1}{2} \\
5 \frac{1}{2} \\
7 \\
7 \\
7 \\
7 \\
6 \\
7 \\
7 \\
7\end{array}$ & $\begin{array}{l}20.0 \\
20.0 \\
20.0 \\
20.0 \\
20.0 \\
20.0 \\
20.5 \\
20.7 \\
21.0 \\
20.3 \\
20.3 \\
20.3 \\
21.2 \\
21.2 \\
21.2 \\
21.2 \\
21.5 \\
22.7 \\
20.3 \\
19.9\end{array}$ & $\begin{array}{l}5.5 \\
5.5 \\
5.5 \\
5.5 \\
5.5 \\
5.5 \\
5.1 \\
4.6 \\
4.8 \\
5.7 \\
4.5 \\
4.5 \\
5.0 \\
5.0 \\
5.0 \\
5.0 \\
6.0 \\
6.6 \\
4.7 \\
5.6\end{array}$ & $\begin{array}{l}0.28 \\
0.28 \\
0.28 \\
0.28 \\
0.28 \\
0.28 \\
0.25 \\
0.22 \\
0.23 \\
0.28 \\
0.22 \\
0.23 \\
0.24 \\
0.24 \\
0.24 \\
0.24 \\
0.28 \\
0.29 \\
0.23 \\
0.28\end{array}$ & $\begin{array}{l}0 \\
0 \\
0 \\
0 \\
0 \\
0 \\
0 \\
0 \\
0 \\
0 \\
0 \\
0 \\
0 \\
0 \\
0 \\
0 \\
0 \\
0 \\
0 \\
0 \\
0\end{array}$ & $\begin{array}{l}0 \\
0 \\
0 \\
0 \\
0 \\
0 \\
0 \\
0 \\
0 \\
0 \\
0 \\
0 \\
0 \\
0 \\
0 \\
0 \\
0 \\
0 \\
0 \\
0\end{array}$ \\
\hline
\end{tabular}

$\mathrm{K}_{f}$ value of unknown acetate $=0.26 \pm 0.04$

$R_{f}$ value of lupeol acetate $=0$

Chromatograms Comparing the Unknown Benzoate with Lupeol Benzoate

In an analogous series of chromatograms it was found that the

unknown benzoate could be readily differentiated from lupeol benzoate.

Table 8 gives the conditions of development, the measured distances and the calculated $R_{f}$ values for the unknown benzoate on a series of 
chromatograms. Depending on the conditions, it was found that the unknown benzoate moved up the paper a distance from 3.0 to $5.1 \mathrm{~cm}$. In all these experiments, the lupeol benzoate remained at the origin. The mean $R_{f}$ value for the unknown benzoate was 0.21 and the value which included all extremes was $0.21 \pm 0.07$. The wide range was due to "tailing" of the spots, that is the unknown benzoate spots were more diffuse on the paper than the unknown acetate spots. The $R_{f}$ value of lupeol benzoate was zero in all cases.

\section{TABLE 8}

PAPER PARTITION CHROMATOGRAPHY OF UNKNONN BENZOATE AND LUPEOL BENZOATE

\begin{tabular}{|c|c|c|c|c|c|c|c|}
\hline \multirow[b]{2}{*}{$\begin{array}{l}\text { Temp- } \\
\text { erature } \\
\text { in Tank } \\
\left({ }_{c} .\right)\end{array}$} & \multirow[b]{2}{*}{$\begin{array}{l}\text { Time in } \\
\text { Tank } \\
\text { before } \\
\text { Solvent } \\
\text { Added } \\
\text { (hours) }\end{array}$} & \multirow[b]{2}{*}{$\begin{array}{l}\text { Time of } \\
\text { Develop- } \\
\text { ment } \\
\text { (hours) }\end{array}$} & \multirow[b]{2}{*}{$\begin{array}{l}\text { Distance } \\
\text { Travelled } \\
\text { by the } \\
\text { Solvent } \\
\text { Boundary } \\
\text { (am.) }\end{array}$} & \multicolumn{2}{|c|}{$\begin{array}{l}\text { Unknown } \\
\text { Benzoate }\end{array}$} & \multicolumn{2}{|c|}{$\begin{array}{l}\text { Iupeol } \\
\text { Benzoate }\end{array}$} \\
\hline & & & & $\begin{array}{l}\text { Distance } \\
\text { Travelled } \\
\text { by the } \\
\text { Spot } \\
\left(\mathrm{cm}_{0}\right)\end{array}$ & $\mathrm{R}_{f}$ & $\begin{array}{l}\text { Distance } \\
\text { Travelled } \\
\text { by the } \\
\text { Spot } \\
\text { (cm.) }\end{array}$ & $\begin{array}{c}\mathrm{R}_{f} \\
\text { value }\end{array}$ \\
\hline $\begin{array}{c}31.5-32.0 \\
27-28 \\
30 \\
30 \\
26-27 \\
26-27 \\
26-27\end{array}$ & $\begin{array}{l}1 \frac{1}{2} \\
3 \frac{1}{4} \\
3 \frac{1}{4} \\
3 \frac{1}{4} \\
8 \\
8 \\
8\end{array}$ & $\begin{array}{l}5 \frac{1}{2} \\
7 \\
6 \\
6 \\
7 \\
7 \\
7\end{array}$ & $\begin{array}{l}21.6 \\
21.2 \\
21.7 \\
20.9 \\
19.9 \\
20.1 \\
22.4\end{array}$ & $\begin{array}{l}3.8 \\
3.0 \\
4.3 \\
4.7 \\
5.1 \\
4.8 \\
4.5\end{array}$ & $\begin{array}{l}0.18 \\
0.14 \\
0.20 \\
0.23 \\
0.26 \\
0.24 \\
0.20\end{array}$ & $\begin{array}{l}0 \\
0 \\
0 \\
0 \\
0 \\
0 \\
0\end{array}$ & $\begin{array}{l}0 \\
0 \\
0 \\
0 \\
0 \\
0 \\
0\end{array}$ \\
\hline
\end{tabular}

Figure 4 is a photograph of a chromatographic strip on which the unknown benzoate and lupeol benzoate had originally been spotted. The unknown benzoate, after development, moved up the paper a distance of $5.1 \mathrm{~cm}$. The solvent boundary had moved $19.9 \mathrm{~cm}$. For this strip, the $R_{f}$ value of the unknown benzoate was $\frac{5.1}{19.9}$ or 0.26 . The $R_{f}$ value of the 
84

lupeol benzoate was zero. There was no spot at a distance of $5.1 \mathrm{~cm}$. above the lupeol benzoate spot at the origin line, which indicated that the lupeol benzoate sample used contained no unknown benzoate as an impurity. There was no spot on the origin line where the unknown benzoate had originally been spotted; this indicated that the unknown benzoate sample used contained no lupeol benzoate as an impurity.

Chromatograms Comparing the Unknown Alcohol with Lupeol

When a third series of chromatograms were processed it was found that the unknown alcohol could be readily differentiated from lupeol in microgram quantities.

Table 9 gives the conditions of development, the measured distances and the calculated $R_{f}$ values for the unknown alcohol. The sample of the unknown alcohol used was part of the $0.813 \mathrm{Gm}$, having a melting point of $154.0^{\circ}-156.0^{\circ}$ (see page 54). When 10 to 20 micrograms of this sample of the unknown alcohol were spotted at the origin line by the method outlined above, the chromatograms developed under the conditions outlined in Table 9 and the location of the spots revealed as described above, it was found that the unknown alcohol had moved up the paper a distance from 5.7 to $6.4 \mathrm{~cm}$. The mean $R_{f}$ value for the unknown alcohol was 0.31 and the value which included all extremes was $0.31 \pm 0.02$. After treating the developed dried strips with the iodine solution, the unknown alcohol spots were distinctly yellow and could be readily outlined with a pencil; however, no yellow spots could be observed corresponding to the lupeol. When the strips were then dipped into the starch solution, the unknown alcohol spots changed to a very 
brilliant blue color which, after arying, became a violet or reddishbrown color. On many of the strips no colored spot was observed corresponding to the lupeol. When a few of the strips were held in front of a light immediately after the treatment with the starch solution, some faint blue streaks, which extended from the origin line where the lupeol had originally been spotted to a distance varying from 2 to $3 \mathrm{~cm}$. above the Iine, were observed. These streaks indicated bad "tailing" of the lupeol. No such streaks, extending from the origin line where the unknown alcohol had been spotted, were observed. Although this was not conclusive evidence, it indicated that the unknown alcohol contained no lupeol as an impurity.

Figure 5 is a photograph of a chromatographic strip on which the unknown alcohol and lupeol had originally been spotted.

\section{TABLE 9}

PAPER PARTITION CHROMATOGRAPHY OF UNKNOWN AICOHOL AND LUPEOL

\begin{tabular}{|c|c|c|c|c|c|}
\hline \multirow[b]{2}{*}{$\begin{array}{l}\text { Temp- } \\
\text { erature } \\
\text { in Tank } \\
\left(o_{c .}\right)\end{array}$} & \multirow[b]{2}{*}{$\begin{array}{l}\text { Time in } \\
\text { Tank } \\
\text { Before } \\
\text { Solvent } \\
\text { Added (hrs.) }\end{array}$} & \multirow[b]{2}{*}{$\begin{array}{l}\text { Time of } \\
\text { Develop- } \\
\text { ment } \\
\text { (hours) }\end{array}$} & \multirow[b]{2}{*}{$\begin{array}{l}\text { Distance } \\
\text { Travelled } \\
\text { by the } \\
\text { Solvent } \\
\text { Boundary }(\mathrm{cm} .)\end{array}$} & \multicolumn{2}{|c|}{ Unknown Alcohol } \\
\hline & & & & $\begin{array}{l}\text { Distance } \\
\text { Travelled } \\
\text { by the } \\
\text { Spot } \\
(\text { cm. })\end{array}$ & $\mathrm{R}_{\text {value }}$ \\
\hline $\begin{array}{c}25 \\
25 \\
25 \\
25 \\
25.5-28 \\
25.5-28 \\
25.5-28\end{array}$ & $\begin{array}{l}3 \frac{1}{4} \\
3 \frac{1}{4} \\
3 \frac{7}{4} \\
3 \frac{1}{4} \\
12 \\
12 \\
12\end{array}$ & $\begin{array}{l}7 \\
7 \\
7 \\
7 \\
6 \\
6\end{array}$ & $\begin{array}{l}19.6 \\
19.6 \\
19.5 \\
19.5 \\
19.5 \\
19.5 \\
19.5\end{array}$ & $\begin{array}{l}6.4 \\
6.4 \\
6.3 \\
6.3 \\
5.7 \\
5.9 \\
5.8\end{array}$ & $\begin{array}{l}0.33 \\
0.33 \\
0.32 \\
0.32 \\
0.29 \\
0.30 \\
0.30\end{array}$ \\
\hline
\end{tabular}

Reactivity of the Compounds with Iodine

During the processing of the chromatograms described above, it was 
observed that the unknown acetate and the unknown benzoate always gave much more pronounced yellow spots after treatment of the chromatogram with iodine and that these spots became a much more brilliant blue color after treatment of the chromatogram with the starch solution, than lupeol acetate or lupeol benzoate. Similarly, the unknown alcohol gave colored spots which were very vivid, whereas lupeol gave little or no discemable spots.

This was further verified as follows. One per cent chloroform solution of each of the six compounds were spotted individually on pieces of filter paper. When the chloroform had evaporated, the dried papers were dipped into a saturated solution of iodine in petroleum ether. After drying the papers in front of a fan, they were dipped into a solution of one per cent starch and two per cent potassium iodide. Lupeol, lupeol acetate and Iupeol benzoate gave medium blue spots. The unknown alcohol, unknown acetate and unknown benzoate gave very brilliant blue spots.

Possible explanations of these differences are as follows. First, the unknown compounds may take up more iodine than the corresponding Iupeol compounds and therefore, the unknown compounds release more iodine than the corresponding lupeol compounds. Secondly, lupeol and its derivatives may tend to retain the iodine more than the unknown alcohol and its derivatives. DIFFERENTIATION OF THE COMPOUNDS ISOLATED FROM THE UNSARONIFIABLE MATTER ON THE BASIS OF COLOR TESTS

The Liebermann-Burchard and Salkowski Color Tests are commonly used to identify and differentiate sterols. However, these reactions 
have been applied to triterpenols and their derivatives. Coelho and Alves (73) reported that B-amy rin gave a pink-violet color with the Liebermann-Burchard reagents $(74)$. Swift and Walter (33) reported that lupeol gives a red color with the Liebermann-Burchard reagents and that this color is also given by the dried latex of the osage orange.

These reactions have been applied to some of the compounds which were investigated. The differences in the colors produced provide a method to differentiate them.

The Liebermann-Burchard test. (74) was performed by dissolving about 1 to $2 \mathrm{mg}$. of the compound in $2 \mathrm{ml}$. of anhydrous chloroform in a dry test tube, then adding 10 drops of acetic anhydride and 3 drops of concentrated sulfurie acid followed by shaking.

The Salkowski test (74) was performed by dissolving about 1 to 2 $\mathrm{mg}$. of the compound in $2 \mathrm{ml}$. of anhydrous chloroform in a dry test tube, then adding an equal volume of concentrated sulfuric acid, followed by shaking .

Table 10 outlines the color changes which were observed when the various compounds were tested with the Liebermann-Burchard reagents.

Table 11 outlines the color changes which were observed when the various compounds were tested with the Salkowski reagents.

The immediate green colored solutions, which exhibited a green fluorescence, were characteristic of the unknown alcohol and the unknown acetate in the Liebermann-Burchard Test. Under the same conditions, lupeol and lupeol acetate gave only a slowly developing pink color, which deepened within a few minutes. Although Swift and Walter (33) 
reported that lupeol gave a red color with acetic anhydride and sulfuric acid in chloroform solution, it was found that a red color could be produced with these reagents only by adding an excess of sulfuric acid; when only three or four drops of sulfuric acid was used, the color was a deep pink.

\section{TABLE 10}

LIEBERMANN-BURCHARD TEST

Compound

Unknown alcohol

Lupeol

Unknown acetate

Lupeol acetate

\section{Color Changes}

Green color immediately which changed rapidly to a yellowish-green then to a yellowish-brown. The solution exhibited a strong green fluorescence.

Ten minutes later the color was yellowish-brown and the solution exhibited a strong green fluorescence.

Twenty-four hours later there were red globules at the bottom of a yellowish-brown liquid.

A pink color developed in about one minute; the pink color changed to a deeper pink within a few minutes. There was no fluorescence.

Twenty-four hours later there were red globules in a yellow solution.

Green color immediately which changed rapidly to a yellowish-green. Within a few minutes, red globules which exhibited a strong green fluorescence formed in a yellowish-brown solution.

Two hours later there were red globules which exhibited a strong green fluorescence in a yellowishbrown solution.

A pale pink color developed slowly. The color was not as intense as with lupeol. There was no fluorescence. A red color developed on addition of more sulfuric acid.

Twenty-four hours later there were red globules in a yellow solution. 


\section{TABLE 11}

\section{SALKOWSKI TEST}

Compound

Unknown alcohol

Lupeol

Unknown acetate

Lupeol acetate

\section{Color Changes}

Immediately, the acid layer was yellow and exhibited a faint green fluorescence. The chloroform layer was colorless.

Ten minutes later the colors were the same.

Twenty-four hours later the acid layer was greenishyellow and exhibited a strong green fluorescence; the chloroform layer was colorless.

Immediately, the acid layer was yellow and exhibited a green fluorescence. The chloroform layer was colorless.

Twenty-four hours later the color was the same.

Immediately, the acid layer was yellow and exhibited a faint green fluorescence. The chloroform layer was colorless.

Ten minutes later the acid layer was red and exhibited a green fluorescence. The chloroform laye $r$ was yellow.

One half hour later the acid layer was red and exhibited a green fluorescence; the chloroform layer was a violet to purple color.

Immediately, the acid layer was yellow and exhibited a green fluorescence; the chloroform layer was colorless.

Ten minutes later, one-half hour later and twentyfour hours later, the colors were the same.

The violet to purple color, which developed within one-half hour in the chloroform layer when the Salkowski test was applied to the unknown acetate, definitely differentiated it from lupeol acetate, which gave a colorless chloroform layer under the same conditions. 
When a few drops of the fresh latex of the osage orange fruit were shaken with $2 \mathrm{ml}$. of chloroform for five minutes and the suspension filtered, the filtrate gave a Liebermann-Burchand test which was the same as that described for the unknown alcohol or the unknown acetate in Table 10. This indicated the presence of either the unknown alcohol or the unknown acetate in the fresh latex.

Some of the white, milky latex was dried at $100^{\circ}$ to a brown, brittle solid. This solid was shaken with chloroform and the suspension filtered. When the Liebermann-Burchard test was applied to the filtrate a green colored solution which exhibited a strong green fluorescence, developed immediately; the green color changed to a yellow-green then to a yellow -brown; ten minutes later the solution was dark red and contained red globules. This was a different result than that reported by Swift and Walter (33) who mentioned only the final red color.

\section{ISOMERIZATION}

The possible steps in the sequences of reactions in which the isomerization could occur are; first, it could occur during the saponification of the unknown acetate; secondly, it could occur during the formation of the acetate or benzoates from the alcohol; thirdly, it could occur after the acetate or benzoate was formed. The thind possibility was eliminated by heating the unknown acetate with acetic anhydride over a prolonged period and recovering only the starting material; no lupeol acetate was detected. The details of the investigation are given on page 92 . 
The isomerizations, forme rly reported, are summarized below.

\section{$3.10 \mathrm{Gm}$. unknown acetate $\mathrm{m} . \mathrm{p} \cdot 131.0^{\circ}-132.0^{\circ}$ \\ saponified $2.47 \mathrm{Gm}$. crude unknown alcohol \\ (1) Benzoylated \\ (2) Fractional crystallization of benzoates}

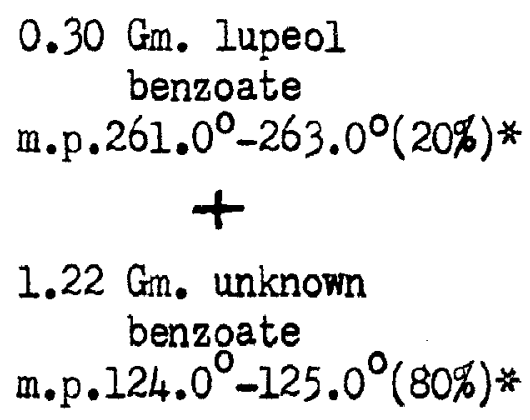

m.p. $261.0^{\circ}-263.0^{\circ}(20 \%) *$

$1.22 \mathrm{Gm}$. unknown benzoate m.p. $124.0^{\circ}-125.0^{\circ}(80 \%) *$

$1.65 \mathrm{Gm}$. unknown acetate m.p. $131.0^{\circ}-132.0^{\circ}$
saponified $0.813 \mathrm{Gm}$. crystalline unknown alcohol m.p. $154.0^{\circ}-156.0^{\circ}$

$200 \mathrm{mg}$. of unknown alcohol benzoylated crude benzoates

1 recrystallization

\section{$95 \mathrm{mg}$. impure lupeol benzoate} m.p. $143^{\circ}-251^{\circ}$

2 recrystallizations $50 \mathrm{mg} . \stackrel{\downarrow}{\downarrow}$ Iupeol benzoate m.p. $261.0^{\circ}-263.0^{\circ}$ $(60 \%) *$
$52 \mathrm{mg}$. impure unknown benzoate m. $0.113^{\circ}-116^{\circ}$

2 recrystallizations $33 \mathrm{mg}$. impure unknown benzoate m.p. $121.0^{\circ}-122.0^{\circ}$ $(40 \%) *$
$85 \mathrm{mg}$. of unknown alcohol acetylated

$59 \mathrm{mg}$. crude acetates

* The percentages refer to the proportionate amounts of final products. 
$0.50 \mathrm{Gm}$. of Sample I of the unknown acetate, having a melting point of $131.0^{\circ}-132.0^{\circ}$, was suspended in $15 \mathrm{ml}$. of acetic anhydride. After heating the mixture in a test-tube under a reflux condenser at a temperature of $137^{\circ}-140^{\circ}$ for ten minutes, all of the acetate dissolved in the acetic anhydride. The homogeneous solution was heated at the same temperature for a period of seven hours. The solution was colorless for about one hour but gradually changed to a yellow color.

The solution was allowed to cool for twenty minutes, then was poured, with stirring, into $60 \mathrm{ml}$. of ice water. A cream-colored, viscous oil separated. The mixture was stirred occasionally during three hours in order to hydrolyze the acetic anhydride. During this period the oil became crystalline but small, yellow, resinous globules contaminated the product. The yellow globules were mechanically separated from the crystals. The crystalline acetate was removed by filtration, washed free of acid with two $15 \mathrm{ml}$. portions of five per cent aqueous potassium carbonate, then subsequently with water until the aqueous washings were neutral to litmus. The acetate was dried in a vacuum oven at $62^{\circ} \pm 2^{\circ}$ for two hours. The yield was $0.45 \mathrm{Gm}$. of acetate or 90 per cent of the starting material.

The $0.45 \mathrm{Gm}$. of acetate was recrystallized from $15 \mathrm{ml}$. of 95 per cent ethanol. The first crop of crystals weighed $0.42 \mathrm{Gm}$. and had a melting point of $127^{\circ}-129^{\circ}$. From the mother liquor was obtained 0.03 $\mathrm{Gm}$., which melted over the range $124^{\circ}-131^{\circ}$. The $0.42 \mathrm{Gm}$. of acetats, which melted at $127^{\circ}-129^{\circ}$, was re- 
crystallized from a mixture of $25 \mathrm{ml}$. of acetone and $2 \mathrm{ml}$. of water. The first crop of crystals weighed $0.32 \mathrm{Gm}$. and had a melting point of $131.0^{\circ}-132.0^{\circ}$ (corr. $\left.132.5^{\circ}-133.5^{\circ}\right)$; the melting point was not depressed on admixture with Sample I of the unknown acetate. From the mother liquor was recovered $0.07 \mathrm{Gm}$., which melted over the range $127.5^{\circ}$ $131.0^{\circ}$ and which gave the same melting point range when admixed with Sample I of the unknown acetate.

The $0.03 \mathrm{Gm}$. of acetate, which melted over the range $124^{\circ}-131^{\circ}$, was combined with the $0.07 \mathrm{Gm}$. of acetate, which melted over the range $127.5^{\circ}-131^{\circ}$. Recrystallization of these combined fractions from a mixture of $6 \mathrm{ml}$. of acetone and $0.5 \mathrm{ml}$. of water, yielded $0.06 \mathrm{Gm}$. of acetate, which melted at $131.0^{\circ}-132.0^{\circ}$ (corr. $132.5^{\circ}-133.5^{\circ}$ ); the melting point was not depressed on admixture with Sample I of the unknown acetate.

The total recovery of the unknown acetate was $0.38 \mathrm{Gm}$. or 76 per cent of the starting material. No trace of lupeol acetate, which would have been detected by its higher melting point, was found. The percentage recovery would have been higher if resinification of some of the unknown acetate had not occurred. However, the prolonged heating at the elevated temperature did cause resinification.

The above experiment showed that isomerization of the unknown acetate to lupeol acetate did not occur under acetylation conditions.

If the isomerization occurred during the saponification of the unknown acetate then this would require that the "unknown alcohol" was a mixture containing lupeol. The Liebermann-Burchard reaction could not be used to detect the possible presence of lupeol in the 
"unknown alcohol" since, when the test was applied to a mixture of equal parts of the unknown alcohol and lupeol, the green color given by the unknown alcohol was dominant and the pink color given by lupeol alone could not be detected. The fact that on the paper chromatograms the unknown alcohol gave one definite defined spot with an $R_{f}$ value $0.31 \pm 0.02$ and showed no "tailing" away from the origin as did lupeol in some cases, indicated that the "unknown alcohol" contained only one component and that no lupeol was present. When the unknown alcohol was recrystallized the melting point could be raised to $164^{\circ}-166^{\circ}$ but one further recrystallization did not change the melting point. Lupeol melts at $214^{\circ}-215^{\circ}$ but no trace of such a high melting point fraction was observed on recrystallization of the unknown al.cohol.

Although not conclusive, the above facts indicate that the isome rization did not occur during the saponification of the unknown acetate.

The third possibility is that the isomerization occurred during the formation of the acetates or benzoates from the unknown alcohol. An example of the isomerization of a triterpenol under esterification conditions was reported by Biedebach (33), who isolated three isomeric formates after heating lupeol with concentrated formic acid.

Further investigation of the isomerization would require much larger quantities of the compounds than were available. The report of the isomerization is a contribution to the triterpene field of chemistry but is collateral to the investigation which was carried out. 
SUGGESTED NAMES FOR THE NEW COMPOUNDS

The name lurenol is suggested for the unknown alcohol.

The name lurenyl acetate is suggested for the unknown acetate.

The name lurenyl benzoate is suggested for the unknown benzoate. ISOLATION OF CRYSTALIINE FRACTIONS FROM THE RESINOUS RESIDUE D-1

As described previously, a crude, crystalline acetate mixture of the unknown acetate and lupeol acetate precipitated from the reaction mixture on cooling, after an acetylation of the unsaponifiable matter. When the crystalline acetates were removed by filtration and the filtrate poured into ice water, a yellowish-brown resinous residue was obtained. This residue could be extracted with ether, the ther extract washed free of acid, the ether evaporated and the yellowishbrown resinous substance recovered. The residue is described as resinous (75) since it was amorphous, soft and sticky, fusible and almost completely insoluble in water.

The constituents of plant resins have been classified $(75,76)$ into three groups. The first group consists of the resin alcohols or resinols; the triterpene alcohols a-amyrin, B-amyrin and lupeol fall into this category. These alcohols may occur free or as esters in plant resins. The second group consists of resinotannols which are probably condensation products of phenol derivatives and are yellow or brown in color (76). These give a color reaction with ferric chloride (75). The third group consists of resin acids or resinol acids. For example, Siam Benzoin, a balsamic resin, contains about 6 per cent siaresinolic acid (77), a triterpene acid with the molecular formula $\mathrm{C}_{30} \mathrm{H}_{48} \mathrm{O}_{4}$. Oleanolic acid $(78)$ is another example of a resin acid. 
As stated previously, the dried unsaponifiable matter consisted of white, crystalline material and a yellow, resinous substance, which was difficult to separate from the crystalline material. The acetylation procedure separated most of the crystalline substances and it appeared that the resinous residue described above was a concentrate of the yellow resinous substance originally present in the unsaponifiable matter. The crystalline fraction of the unsaponifiable matter was shown to consist of triterpenols. Since plant resins have been shown to contain similar triterpene compounds, an investigation was undertaken to determine if crystalline substances could be separated from the resinous residue.

The $23.5 \mathrm{Gm}$. of resinous residue, D-l, isolated from $83.5 \mathrm{Gm}$. of the unsaponifiable matter was used in this investigation. First, an attempt was made to isolate crystalline fractions from the resin by a chromatographic procedure. Since aluminum oxide, when used as an adsorbent in the chromatography of the unsaponifiable matter, failed to strongly adsorb the yellow resinous substance a different adsorbent was tried. Kraybill and co-workers (34) described the preparation of an aluminum silicate adsorbent which they stated was useful to adsorb pigments, sterols and associated substances from liquids containing them. This adsorbent was prepared according to their directions (34). Twenty grams of the adsorbent was packed, while dry, into a chromatography tube $23 \mathrm{~mm}$. in diameter and $460 \mathrm{~mm}$. long. The column of adsorbent was $180 \mathrm{~mm}$. high. The $23.5 \mathrm{Gm}$. of resinous residue, D-l, was dissolved in $200 \mathrm{ml}$. of thiophene-free, anhydroús benzene. Ten $\mathrm{ml}$. of this benzene solution were diluted to $100 \mathrm{ml}$. with anhydrous petroleum 
ether and the solution was poured on the top of the column. When almost all the solution had man through the column, $100 \mathrm{ml}$. of petroleum ether were added. This process was repeated until all the benzene solution was utilized. The eluates from the bottom of the column were collected in $100 \mathrm{ml}$. fractions and evaporated on the steam bath. All of the concentrated eluates, even the first one, were yellow in color and when completely free of solvent, resembled the resinous residue, D-1, in physical appearance. No strang adsorption took place on the column of adsorbent since a quantitative recovery of the resinous residue was obtained. When attempts were made to crystallize the concentrated eluates from various solvents, only semi-crystalline masses and oils were obtained. This procedure is not discussed in any further detail since it failed to lead to a separation of crystalline fractions from the resin.

The concentrated eluates were combined and dried at $105^{\circ}$. The $23.5 \mathrm{Gm}$. of resinous residue recovered was dissolved in about $200 \mathrm{ml}$. of acetone. This solution was refrigerated at $-18^{\circ}$ for twenty-four hours. The solution deposited some white crystals which were contaminated with yellow resinous material. Filtration yielded $1.36 \mathrm{Gm}$. of yellowish-white crystals which melted over the range $118^{\circ}-123^{\circ}$.

The filtrate was placed in a freezing mixture of dry ice and acetone. A yellow oil and some white crystals separated from the solution. The mixture was filtered and $1.90 \mathrm{Gm}$. of yellowish-white crystals, which melted over the range $102^{\circ}-120^{\circ}$, were obtained. The very low temperature obtained with dry ice appeared to cause the separation of a yellow oil faster than the crystals hence this procedure 
was abandoned.

When the filtrate, resulting from the removal of the $1.90 \mathrm{Gm}$. fraction, was refrigerated at $-18^{\circ}$ for three days more crystallization took place. The crystals were removed by filtration, washed with acetone and dried at $100^{\circ}$. The yield was $5.44 \mathrm{Gm}$. of yellowish-white crystals.

The total yield of crude crystalline fractions isolated was 8.70 Gm. or 37 per cent of the weight of the original resinous residue D-1. Concentration of the remaining acetone solution of the resin, followed by refrigeration, resulted in no further crystallization.

Recrystalizations of the crude crystalline fractions were carried out as follows.

The $1.36 \mathrm{Gm}$., melting over the range $118^{\circ}-123^{\circ}$, was combined with the $1.90 \mathrm{Gm}$., melting over the range $102^{\circ}-120^{\circ}$. This $3.26 \mathrm{Gm}$. was recrystallized from acetone-water, using activated charcoal to decolorize the solution. A yield of $1.73 \mathrm{Gm}$. of white crystals, which melted over the range $118^{\circ}-124^{\circ}$, was obtained. Concentration of the mother liquor and refrigeration of the concentrate yielded only an uncrystallizable oil. The $1.73 \mathrm{Gm}$., which melted over the range $118^{\circ}-124^{\circ}$, was recrystallized from a mixture of $25 \mathrm{ml}$. of methanol and $33 \mathrm{ml}$. of ethanol. The first crop of crystals weighed $1.34 \mathrm{Gm}$. and had a melting point range of $122^{\circ}-124^{\circ}$. After concentration of the mother liauor, addition of sufficient water $(2.5 \mathrm{ml}$.) to produce a faint turbidity and refrigeration of the turbid solution, were obtained $0.17 \mathrm{Gm}$. which melted over the range $115^{\circ}-120^{\circ}$.

The $5.44 \mathrm{Gm}$. of yellowish-white crystals on recrystallization from 
95 per cent ethanol yielded two fractions of crystals; $1.38 \mathrm{Gm}$., which melted over the range $127^{\circ}-132^{\circ}$ and $0.39 \mathrm{Gm}$., which melted over the range $120^{\circ}-122^{\circ}$.

All of the impure crystalline fractions isolated from the resinous residue gave color changes in the Liebermann-Burchard Test (74) which were the same as those given by the unknown acetate. The melting point range and solubilities of these fractions were the same as impure fractions of the unknown acetate. Hence it was apparent that a large fraction of the resinous residue consisted of the unknown acetate. Other constituents present hindered crystallization of the acetate from solutions of the resinous residue.

An alcoholic solution of the resinous residue (D-1) gave a dark green color with ferric chloride solution. This color may be due to a resinotannol but would not be due to the pigments, osajin and pomiferin, which are soluble in excess alkali and hence would not be present. The crystalline fractions, isolated from the resinous residue, gave no change in color on addition of ferric chloride to an alcoholic solution of each fraction of the crystals. INFRARED SPECTRA

The utility of infrared spectroscopy lies in the fact that the wave lenghts of infrared absorption bands are characteristic of the absorbing molecule and of the various groups in the molecule (79). Hence one useful application of infrared spectroscopy is to identify functional groups in organic molecules (80). Since no two organic compounds possess completely identical spectra, it is possible to identify compounds and in favorable circumstances, even mixtures of 
compounds, by comparison with reference spectra (80).

A survey of the literature revealed no report on the infra-red spectra of lupeol and lupeol acetate. Since the recording of such spectra contributes to the knowledge of the compounds and may aid in their identification from other sources by comparison, the spectra of these compounds are herein recorded. For similar reasons, the infrared spectra of the unknown alcohol and the unknown acetate are also herein recorded.

With the kind help of Dr. C.I. Wilson, the spectra of the four compounds were obtained in the Spectrographic Laboratory of the Chemistry Department of The Ohio State University. The instrument used was the Baird Associates Infrared Recording Spectrophotometer with sodium chloride prism. The concentration used in each case was the same, namely 10 per cent weight in volume. The solvent used was anhydrous chloroform.

The following points are noteworthy. The spectrum of the unknown alcohol and lupeol are very similar, but differ in some details and the spectrum of the unknown acetate and lupeol acetate are very similar but differ in some details. The small size (low intensity) of the hydroxyl hand of the unknown alcohol and lupeol indicates a relatively small amount of hydroxyl in the molecule since the molecules are very large. There is apparently no carbonyl group in the unknown alcohol or lupeol molecules since there is no band at $5.8 \mathrm{u}\left(1724 \mathrm{~cm}^{-1}\right)$ which is characteristic of the carbonyl in such molecules as acetone (80). The spectra of the unknown acetate and lupeol acetate have a marked 
resemblance to the spectrum of cholesteryl acetate. Even though cholesteryl acetate contains a carbon-carbon double bond its infrared spectrum shows little or no absorption bond on the long wave length side of $6.0 \mathrm{u}$ which is characteristic of this grouping (80). However, the spectra of the unknown alcohol, the unknown acetate, lupeol and lupeol acetate all exhibit an absorption band in this region, indicative of the presence of a carbon-carbon double bond in each molecule.

The following brief analysis of the spectra herein recorded indicates the groups responsible for some of the absorption bands; assignments were made on an empirical basis $(80,81)$.

\begin{tabular}{|c|c|c|c|c|}
\hline Compound & $\begin{array}{l}\text { Absorption } \\
\text { Band with } \\
\text { Peak At }\end{array}$ & $\begin{array}{l}\text { Assigned } \\
\text { Grouping }\end{array}$ & $\begin{array}{l}\text { Range } \\
(80,81)\end{array}$ & $\begin{array}{l}\text { Examples } \\
(80,81)\end{array}$ \\
\hline $\begin{array}{l}\text { Unknown alcohol } \\
\text { Lupeol }\end{array}$ & $\begin{array}{l}2.80 u \\
2.80 u)\end{array}$ & $\begin{array}{l}\text { Hydroxyl } \\
(-\mathrm{OH})\end{array}$ & $2.66-2.98 u$ & $\begin{array}{l}(-\mathrm{OH} \text { in formic acid } \\
2.80 \mathrm{u} \\
\text { (-OH in hydroxy- } \\
\text { propionitrile } 3.30 \mathrm{u}\end{array}$ \\
\hline $\begin{array}{l}\text { Unknown acetate } \\
\text { Lupeol acetate } \\
\text { Unknown alcohol } \\
\text { Lupeol }\end{array}$ & $\left.\begin{array}{l}3.43 \mathrm{u} \\
3.41 \mathrm{u} \\
3.41 \mathrm{u} \\
3.41 \mathrm{u}\end{array}\right)$ & $\mathrm{C}-\mathrm{H}$ & $3.05-3.7 u$ & $\begin{array}{l}(\mathrm{C}-\mathrm{H} \text { in methane } \\
3.43 \mathrm{u} \\
(\mathrm{C}-\mathrm{H} \text { in cyclobutane } \\
3.45 \mathrm{u}\end{array}$ \\
\hline $\begin{array}{l}\text { Unknown acetate } \\
\text { Lupeol acetate }\end{array}$ & $\left.\begin{array}{l}5.82 \mathrm{u} \\
5.80 \mathrm{u}\end{array}\right)$ & \multicolumn{3}{|c|}{$\begin{array}{cl}\text { Carbonyl of } & \text { Unconjugated } \\
\text { ester group } & \text { carbonyl } \\
0 & 6.68-5.81 \mathrm{u} \\
\text { "I ' } & \\
\text { R-C_OR } & \end{array}$} \\
\hline $\begin{array}{l}\text { Unknown acetate } \\
\text { Lupeol acetate } \\
\text { Unknown acetate } \\
\text { Lupeol }\end{array}$ & $\left.\begin{array}{l}6.10 \mathrm{u} \\
6.05 \mathrm{u} \\
6.05 \mathrm{u} \\
6.07 \mathrm{u}\end{array}\right)$ & $c=c$ & $6.02-6.11$ & $c=c$ in propylene \\
\hline $\begin{array}{l}\text { Unknown acetate } \\
\text { Lupeol acetate }\end{array}$ & $\begin{array}{l}8.00 \mathrm{u}) \\
7.95 \mathrm{u})\end{array}$ & \multicolumn{3}{|c|}{$\begin{array}{l}\text { Ether linkage } \\
\text { C-0-C } 8-9 \mathrm{u}\end{array}$} \\
\hline $\begin{array}{l}\text { Unknown acetate } \\
\text { Lupeol acetate } \\
\text { Unknown alcohol } \\
\text { Lupeol }\end{array}$ & $\begin{array}{l}11.25 \mathrm{u} \\
11.3 \mathrm{u} \\
11.3 \mathrm{u} \\
11.3 \mathrm{u}\end{array}$ & $c=c$ & $10.2-12.2 \dot{u}$ & $\begin{array}{c}c=c \text { in butadiene } \\
11.00 \mathrm{u} \\
c=c \text { in allene } 11.74 \mathrm{u}\end{array}$ \\
\hline
\end{tabular}




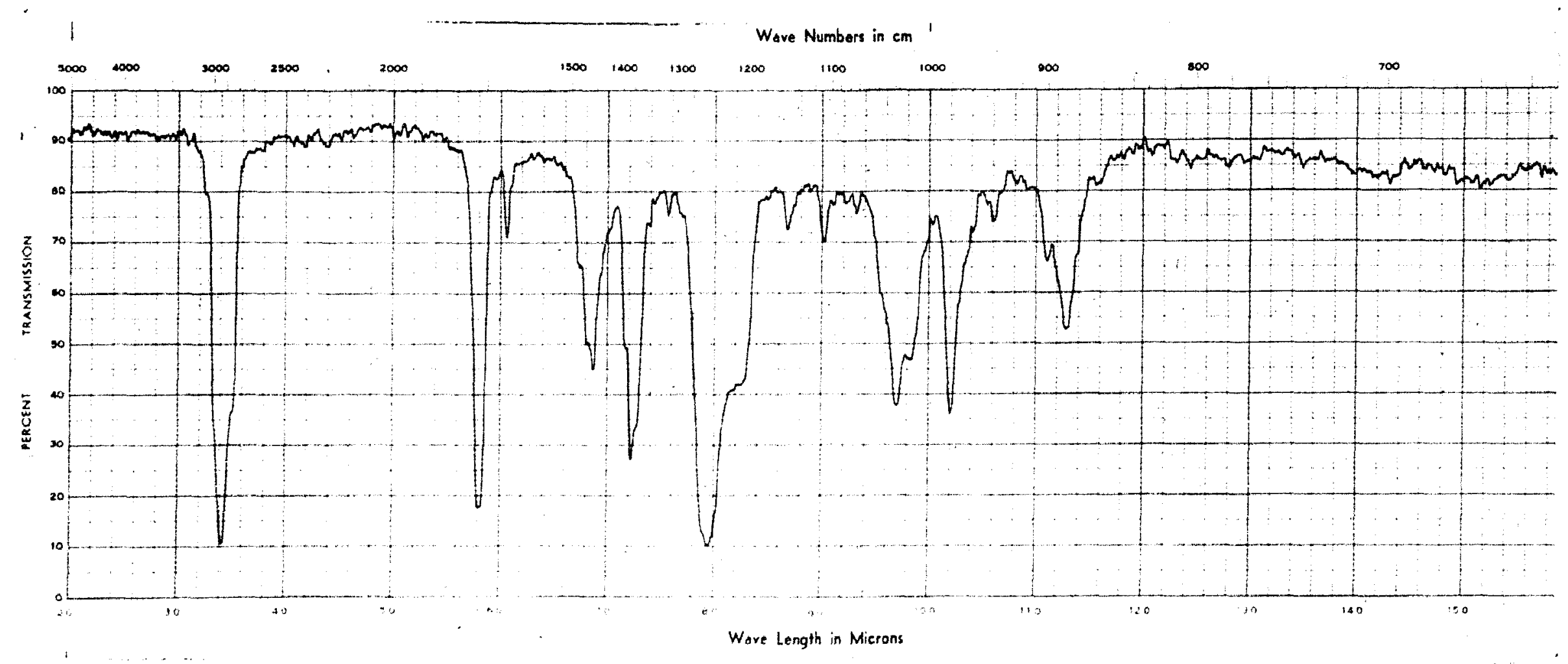

占

Fig. 6. Infrared Spectrogram of Lupeol Acetate 


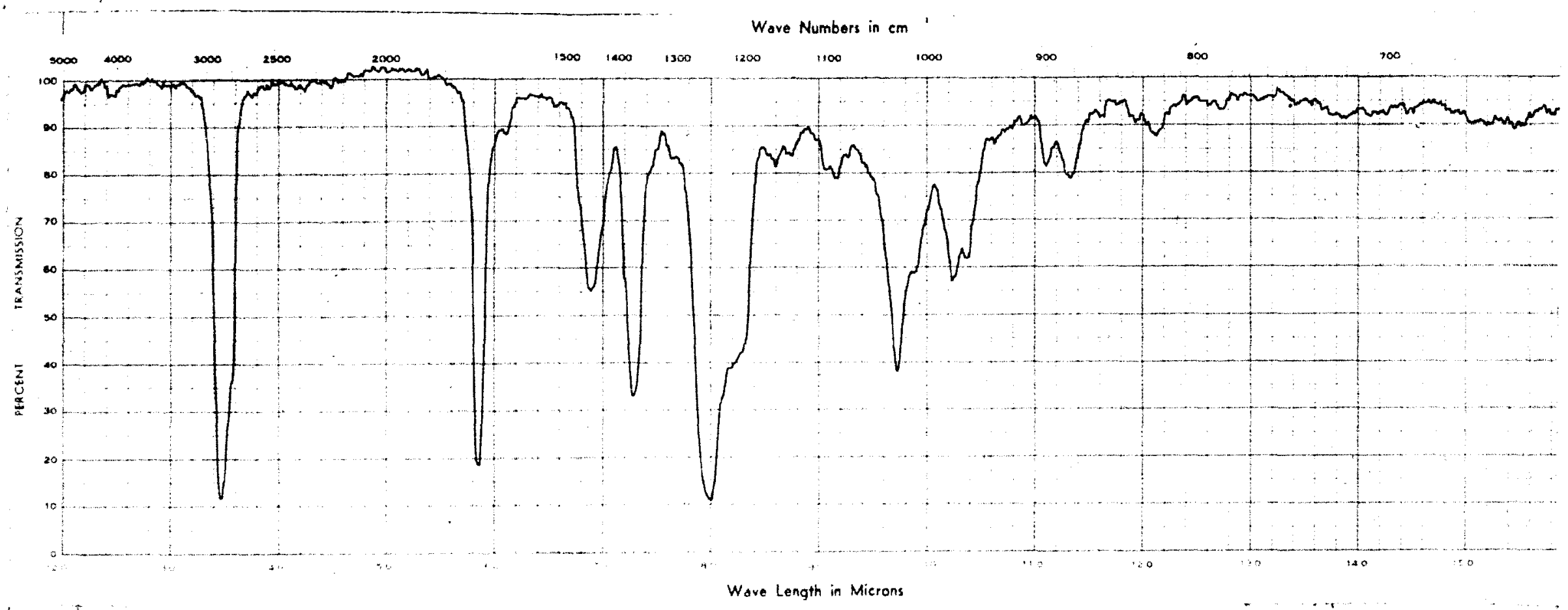

Fig. 7. Infrared Spectrogram of Unknown Acetate 


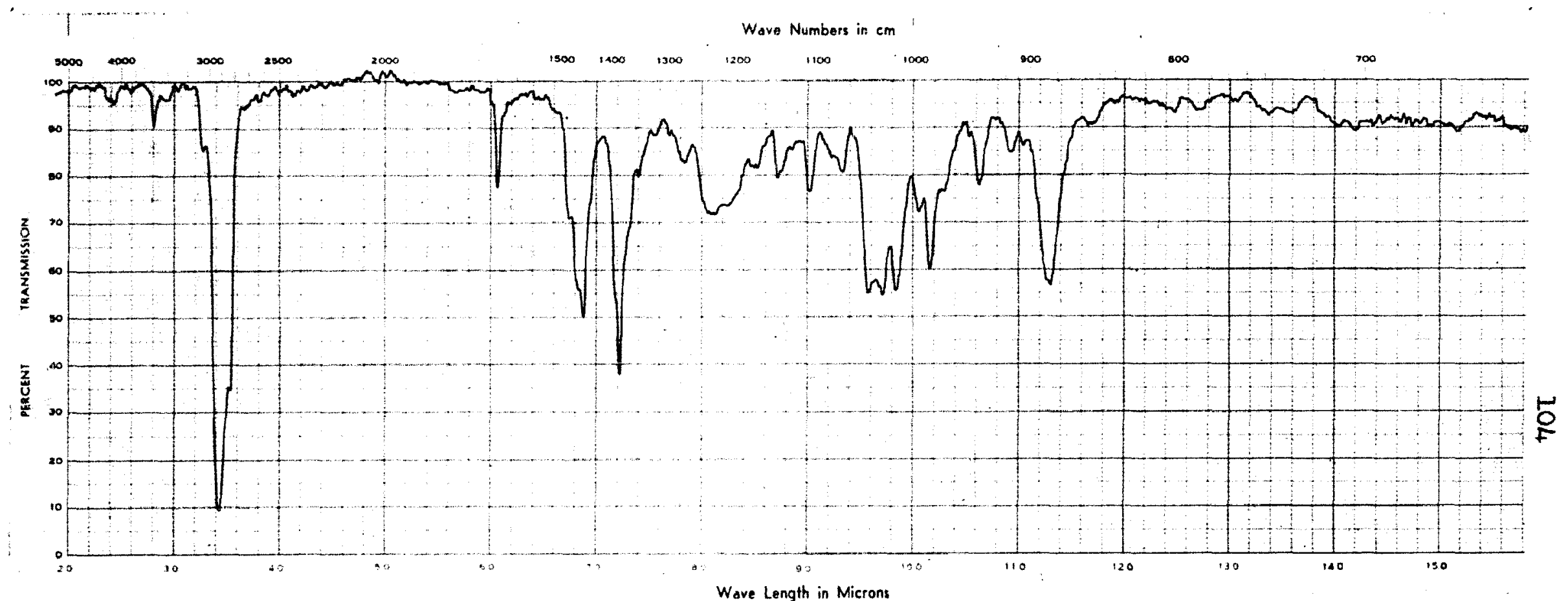

Fig. 8. Infrared Spectrogram of Lupeol 


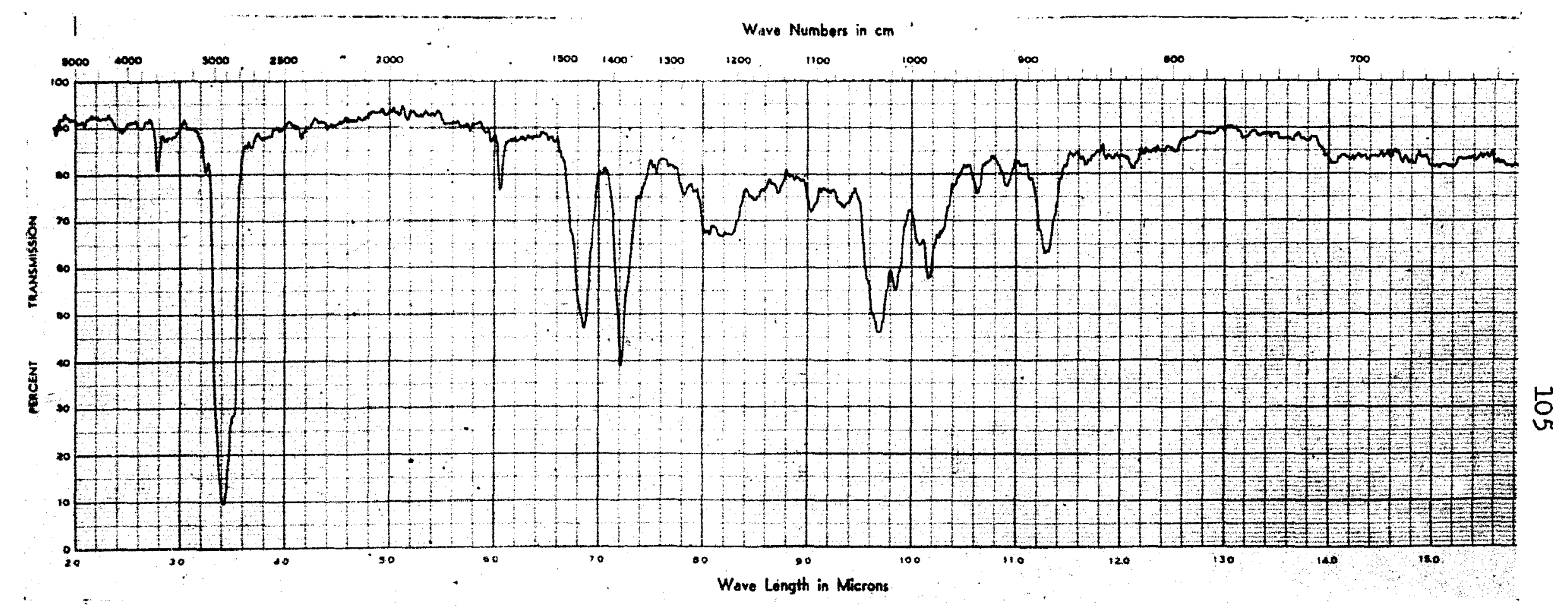

Fig. 9. Infrared Spectrogram of the Unknown Alcohol 
INVESTIGATION OF THE DIETHYL ETHER EXTRACT: ISOLATION OF THE PIGMENTS, OSAJIN AND POMIFERIN

The extraction of $200 \mathrm{Gm}$. of dried osage orange fruit by the general method of Rosenthaler (59) was described on pages 24-26. The weights of the extracts obtained are given in Table 4, page 26. Most of these extracts were investigated phytochemically and these investigations are discussed below, beginning with the investigation of the diethyl ether extract.

The procedure described by Wolfrom and Mahan (24) in a slightly modified form was used to isolate the pigments, osajin and pomiferin. Wolfrom and Wahan extracted dried osage orange fruit with petroleum benzine then with diethyl ether but utilized only the ether extract to obtain the pigments.

In this investigation it was found that some of the pigment was removed by the petroleum ether.

The $47.0 \mathrm{Gm}$, of petroleum ether extract (Table 4) was heated under reflux with $2.4 \mathrm{~L}$. of petroleum ether. The suspension was filtered after cooling to room temperature; a fine yellow powder was retained on the filter paper. This yellow powder was combined with the $4.50 \mathrm{Gm}$. of diethyl ether extract (Table 4) and the mixture recrystallized from $60 \mathrm{ml}$. of xylene, using activated charcoal to clarify the solution. Refrigeration of the xylene solution yielded crystalline material which was removed by filtration and dried in $80^{\circ}$ in vacuo. The yield of crude pigments was $13.34 \mathrm{Gm}$., having a melting point range of $177^{\circ}-180^{\circ}$. This yield represented 6.67 per cent of the dried osage orange fruit. The $13.34 \mathrm{Gm}$. of crude pigments was dissolved in $220 \mathrm{ml}$. of hot 
95 per cent ethanol. A solution of $10.3 \mathrm{Gm}$. of lead acetate in 18 ml. of methanol was added to the ethanolic pigment solution. A yellow precipitate formed. After standing overnight the suspension was filtered through a Buchner funnel precoated with Celite No.535 (JohnsManville). The combined yellow precipitate and Celite was shaken with $137 \mathrm{ml}$. of hot acetone and permitted to stand until the lead complex of pomiferin had settled. The suspension was filtered through a Buchner funnel precoated with Celite No. 535 and the material retained on the filter was washed with $14 \mathrm{ml}$. of hot acetone. The residue on the filter was removed and treated with $137 \mathrm{ml}$. of hot glacial acetic acid to dissolve the lead complex of pomiferin. The suspension was filtered to remove the Celite, then the filtrate was poured slowly, with stirring, into $820 \mathrm{ml}$. of ice cold water. The precipitated pomiferin was removed by filtration and washed with water. The yield of crude pomiferin was $7.02 \mathrm{Gm}$.

The above alcohol filtrate and all of the acetone wash liquors were combined, concentrated to about $100 \mathrm{ml}$. and poured slowly, with stirring, into $750 \mathrm{ml}$. of ice and water. The precipitated osajin was removed by filtration. The yield of crude osajin was $4.15 \mathrm{Gm}$, but part of the crude pigment was lost accidentally in the drying operation and the yield should have been higher.

Two recrystalizations of the crude osajin from 95 per cent ethanol yielded $1.80 \mathrm{Gm}$. pure osajin, melting point $191.0^{\circ}-191.5^{\circ}$ (corr.195.0 $\left.195.5^{\circ}\right)$. From the alcoholic mother liquors were obtained $0.31 \mathrm{Gm}$. of impure osajin, melting point $183^{\circ}-185^{\circ}$, which on one further recrystallization from 95 per cent ethanol gave $0.27 \mathrm{Gm}$. of osajin, melting 
point $189.5^{\circ}-190.0^{\circ}$ ( corr. $\left.193.5^{\circ}-194.0^{\circ}\right)$.

Two recrystallizations of the crude pomiferin from 10 parts of xylene, using Celite No.535 to pre-coat the filter paper, gave $2.96 \mathrm{Gm}$. of pure pomiferin of melting point $200,0^{\circ}-200.5^{\circ}$ ( $\operatorname{corr} .204 .0^{\circ}-204.5^{\circ}$ ). From the xylene mother liquors were obtained $1.37 \mathrm{Gm}$. of impure pomiferin, which on recrystallization from 10 parts of xylene, yielded $1.01 \mathrm{Gm}$. of pure pomiferin of melting point $200.0^{\circ}-200.5^{\circ}$ (corr.204.0 $\left.-204.5^{\circ}\right)$. Hence the total yield of pure pomiferin was $3.97 \mathrm{~cm}$. having a melting point of $200.0^{\circ}-200.5^{\circ}$ (corr. $204.0^{\circ}-204.5^{\circ}$ ).

A comparison of the yields and melting points obtained with those of Wolfrom and Mahan is given in Table 12.

TABLE 12

Wagner, J.G.
Wolfrom, M.L. and Mahan, $J$. Reported $(24)(16)$

\begin{tabular}{|c|c|c|c|c|c|c|}
\hline Weight of Dried Fru & & $200.0 \mathrm{Gm}$. & & & $3000 \mathrm{Gm}$. & \\
\hline & $\begin{array}{l}\text { Weight } \\
(\mathrm{Gm} .)\end{array}$ & $\begin{array}{l}\text { Percent of } \\
\text { Dried Fruit }\end{array}$ & $\begin{array}{l}\text { Melting } \\
\text { Point }\end{array}$ & $\begin{array}{l}\text { Weight } \\
\left(\mathrm{Gm}_{\bullet}\right)\end{array}$ & $\begin{array}{l}\text { Percent } \\
\text { of Dried } \\
\text { Fruit }\end{array}$ & $\begin{array}{l}\text { Melting } \\
\text { d Point }\end{array}$ \\
\hline $\begin{array}{l}\text { Mixture of Pigments } \\
\text { recrystallized once } \\
\text { from xylene }\end{array}$ & 13.34 & 6.67 & & 97.5 & 3.25 & \\
\hline Pomiferin & 3.97 & $\begin{array}{l}1.99 \\
\quad(\operatorname{corr} .20\end{array}$ & $\begin{array}{l}200.0^{\circ}- \\
200.5^{\circ-} \\
04.0^{\circ}-204 .\end{array}$ & $\begin{array}{l}43.5 \\
0)\end{array}$ & 1.45 & $200.5^{\circ}$ \\
\hline Osajin & 0.27 & $\begin{array}{l}\text { (corr.1 } \\
1.04 \\
\text { (corr.1 }\end{array}$ & $\begin{array}{l}191.0^{\circ}- \\
191.5^{\circ} \\
95.0^{\circ}-195 . \\
189.5^{\circ}- \\
190.0^{\circ} \\
93.5^{\circ}-194 .\end{array}$ & $\begin{array}{l}28 \\
\text { )) } \\
\text { P) }\end{array}$ & 0.93 & $\begin{array}{c}189^{\circ} \\
(\operatorname{corr} .1939)\end{array}$ \\
\hline
\end{tabular}


INVESTIGATION OF THE CHLOROFORM EXTRACT

The dried chloroform extract $(1.26 \mathrm{Gm}$.) was yellowish-brown in color and had a pleasant aromatic odor. The dried extract was extracted with $25 \mathrm{ml}$. of neutral water ( $\mathrm{pH} .6 .6$ ) and the aqueous extract was filtered to yield a yellow filtrate, E-l, which was acid to litmus. When a drop of 5 per cent phosphomolybdic acid in 10 per cent nitric acid was added to a few drops of the filtrate E-1, a yellowish precipitate formed and the supernatant liquid became green; after standing for twenty-four hours the precipitate turned greenish-blue. No precipitate or cloudiness appeared when a few drops of the filtrate I-1 was treated with a saturated aqueous solution of picric acid. The filtrate, E-1, gave no immediate precipitate with Mayer's reagent (82) and no precipitate after standing for twenty-four hours.

The residual chloroform extract, after extraction with neutral water, was extracted with $25 \mathrm{ml}$. of 1 per cent aqueous sulfuric acid solution. The aqueous phase was filtered to yield a filtrate E-2, designated the acidified aqueous extract of the chloroform extract. A drop of 5 per cent phosphomolybdic acid in 10 per cent nitric acid added to a few drops of the filtrate, $\mathrm{E}-2$, caused the production of a yellow precipitate and green supe matant liquid, which changed overnight to a blue precipitate and blue supematant liquid. Wagner's reagent (83) gave some cloudiness on addition to the acidified aqueous extract and after standing overnight there was some reddish-brown precipitate. When the filtrate, $1-2$, was mixed with an equal volume of a saturated solution of picric acid some cloudiness in the solution was observed; twenty-four hours later a yellow precipitate had formed. 
The filtrate, E-2, gave a positive Liebermann test $(84,85)$ which indicated the presence of a secondary or tertiary aromatic amine or an aromatic phenol. Addition of ferric chloride test solution (86) to the filtrate, $\mathrm{C}-2$, gave a dark green precipitate. The filtrate, E-2, discharged the color of bromine water (87) and yielded a yellow precipitate.

The tests performed on the chloroform extract indicated the possible presence of an alkaloid in that extract. Nore extensive tests would have to be performed to verify the presence of an alkaloid. INVESTIGATION OF THE ABSOLUTE ALCOHOL EXTRACT

The absolute alcohol extract was light to dark brown in color; from its appearance and the following tests it was concluded that it consisted mainly of sugars.

To the $31.5 \mathrm{Gm}$. of dry absolute alcohol extract (see Table 4) was added $100 \mathrm{ml}$. of water. The mixture was shaken occasionally during three hours at room temperature, then filtered. Most of the extract was water-soluble but a residue was retained on the filter, which, after drying weighed $1.0 \mathrm{Gm}$.

The water soluble portion ( F-1) gave negative tests for alkaloids with Mayer's reagent (82), 5 per cent phosphomolybdic acid in 10 per cent nitric acid and saturated picric acid solution. The solution F-1, gave a positive Molisch test ( 88 ) and a positive Selivanoff test (88). An osazone was formed from the solution F-I according to Shriner and Fuson (89), a known sugar, glucose, being used for comparison. The osazone was shown to be phenyl-D-glucosazone by means of melting point, mixed melting point and crystal structure. 
Paper partition chromatograms, spotted with the aqueous solution F-I, were prepared using the apparatus described on page 7I. The application of this method to sugars is fully described on page 121 . The chromatograms, on which the solution $F-1$ was spotted, indicated the presence of glucose and fructose in the absolute alcohol extract.

There was no evidence of an aglycone formed from a glycoside after acid hydrolysis of some of the solution F-I. INVESTIGATION OF THE 70 PER CENT ALCOHOE EXTRACT

The boiling 70 per cent alcohol extract (see Table 4) weighed 34.0 Gm. The extract was a dark brownish-red, very viscous symp.

Titrations with Benedicts' Quantitative Sugar Reagent (90) showed that the dried extract contained 32 per cent reducing sugars calculated as glucose. This value was not increased by acid hydrolysis, indicating the absence of simple hydrolysable carbohydrates.

A solution $(\mathrm{G}-1)$ of the extract in $250 \mathrm{ml}$. of 40 per cent ethanolwater tasted astringent and bitter. The solution, $G-1$, gave a greenishbrown precipitate upon the addition of a few drops of ferric chloride test solution (86). The solution, G-1, gave no precipitate with a gelatin solution (91), which indicated the absence of tannin. The solution, G-l, when diluted with an equal volume of water and treated with a saturated solution of lead subacetate, gave a copious, yellow precipitate. The ambermcolored solution, G-1, gave a red color when an equal volume of 10 per cent sodium hydroxide solution was added. When I drop of the solution, G-1, was added to a colorless solution of 1 drop of gold chloride test solution (92) in $20 \mathrm{ml}$. of water, a purple color was produced within ten minutes; the purple color was indicative 
of reduced gold; a 2 per cent solution of glucose and a 2 per cent solution of fructose, under the same conditions, gave no purple color. The solution, $\mathrm{G}-1$, gave a positive Liebe mann nitroso reaction ( 84,85 ) for an aromatic phenol. The above tests indicated the possible presence of a phenolic substance in the 70 per cent alcohol extract. An attempt to isolate this substance is described below.

To $110 \mathrm{ml}$. of solution G-2, representing about 44 per cent of the 70 per cent alcohol extract, was added $15 \mathrm{ml}$. of an aqueous solution containing $6 \mathrm{Gm}$. of neutral lead acetate. The yellow precipitate which formed was washed with $5 \mathrm{ml}$. of neutral lead acetate solution, then 50 ml. of water and dried on suction. The resulting yellow solid was refluxed at the boiling point with $400 \mathrm{ml}$. of 95 per cent ethanol. The suspension was filtered while hot. Part of the yellow solid was soluble in the hot alcohol and yielded a yellow filtrate; part was insoluble in the hot alcohol and remained on the filter. The yellow filtrate was freed of lead by bubbling hydrogen sulfide through the solution. The lead sulfide was removed by filtration and the resulting yellow filtrate was concentrated by distillation under reduced pressure. Addition of a little ether to the concentrate and slow evaporation yielded a few milligrams of colorless, needle-shaped crystals. These crystals melted to a colorless liquid at $113.5^{\circ}-114.0^{\circ}$. The crystals, when dissolved in water and the solution treated with a drop of ferric chloride test. solution, gave a pale green color. No satisfactory identification could be made due to the small quantity of the crystals available. The isolation was not repeated due to its lack of relative importance. 
INVESTIGATION OF THE ACIDIFIED AQUEOUS EXTRACT

Slight precipitation occurred on storage of the acidified aqueous extract in the refrigerator. After filtration there was insufficient residue on the filter to carry out any identification tests. The filtrate measured $850 \mathrm{ml}$.

A $100 \mathrm{ml}$. aliquot portion of the filtrate was one-half saturated with ammonium sulfate; some precipitation occurred. The precipitate may have been plant globulins (93). Ammonium sulfate was added to full saturation and the mixture warmed whereby coagulation occurred. A palebrown gelatinous precipitate was removed by filtration. An aqueous solution of the gelatinous precipitate gave only a slight precipitate with Millon's reagent (94) but no color change and only a weak Biuret (94) reaction for protein. It was concluded that some protein was present in the gelatinous precipitate but that the major portion was not protein in nature. Pectin was suspected and it was found expe rimentally, that pectin is precipitated from aqueous solution on addition of ammonium sulfate to full saturation followed by warming. Tests were performed on the filtrate obtained by removal of the gelatinous precipitate. Addition of 10 per cent sodium hydroxide solution to $5 \mathrm{ml}$. of the filtrate until the solution was strongly alkaline caused no precipitation; neither was a precipitate obtained with Mayer's reagent (82). These tests indicated the absence of alkaloids in the acidified aqueous extract. No color or precipitate was obtained when the filtrate was treated with ferric chloride test solution (86). A Molisch test (88) for carbohydrates was positive. After neutralization of a portion of the filtrate with sodium bicarbonate a Qualitative Benedict's (90) 
test for reducing sugars was negative.

The remainder of the acidified aqueous extract $(750 \mathrm{ml}$.) was concentrated by distillation under reduced pressure to about two-thirds its original volume. To the $500 \mathrm{ml}$. of solution was added an equal volume of 95 per cent ethanol. A gelatinous precipitate formed. Filtration yielded a residue of the gelatinous precipitate and a yellowish-brown filtrate. The gelatinous precipitate was washed with 95 per cent ethanol. The yield was $55.72 \mathrm{Gm}$. of jelly-like material. Preparation of Mucic Acid from the Jelly-Like Material

An amount of $30.25 \mathrm{Gm}$. of the jelly-like material was heated for one hour on a boiling water bath with $20 \mathrm{ml}$. of concentrated nitric acid. The solution was filtered while hot and the filtrate refrigerated. After twelve hours refrigeration, no crystallization had occurred. The solution was seeded with a crystal of authentic mucic acid prepared by the oxidation of pectin with nitric acid (95). Large, colorless, needleshaped crystals formed. On microscopic examination the crystals appeared the same as those in a photomicrograph of mucic acid crystals (88). The crystals were removed by filtration, washed with cold water then with cold 95 per cent ethanol-water and finaliy with ether then dried with suction. The gield was $0.81 \mathrm{Gm}$. of crystals having a melting point of $99.5^{\circ}-100.0^{\circ}$ (corr. $100.1^{\circ}-100.6^{\circ}$ ). Huthentic mucic acid was prepared also from lactose by the same procedure as described in Beilstein (95); this product also melted at $99.5^{\circ}-100.0^{\circ}$ (corr. $100.1^{\circ}-100.6^{\circ}$ ). A mixed melting point was the same. These melting points were taken in capillary tubes using an oil bath and heating at the rate of about $1^{\circ}$ per minute. 
When the $0.81 \mathrm{Gm}$. sample of melting point $99.5^{\circ}-100.0^{\circ}$ (corr. $100.1^{\circ}$ $\left.-100.6^{\circ}\right)$ and the authentic mucic acid were dried in an air-oven at $96^{\circ}$ for five hours the colorless crystals became white and opaque. After further heating for five hours at $100^{\circ}$ both the $0.81 \mathrm{Gm}$. sample and the authentic mucic acid melted at $189.0^{\circ}-189.3^{\circ}$ (corr. $192.6^{\circ}-193.1^{\circ}$ ). A mixed melting point of the authentic mucic acid and the $0.81 \mathrm{~cm}$. sample was the same.

Concentration of the filtrate obtained after removal of the 0.81 Gm. of crystals to one-third its volume, followed by refrigeration yielded $0.31 \mathrm{Gm}$. of colorless needles of melting point $99.5^{\circ}-100.0^{\circ}$ (corr. $100.1^{\circ}-100.6^{\circ}$ ).

The remainder of the jelly-like material $(25.47 \mathrm{Gm}$ ) by the same treatment as described before, yielded the same type of colorless needles. When the crystals were removed by filtration they were washed with a small portion of hot water, followed immediately by absolute alcohol then ether:. The hot water dissolved most of the crystals but $0.15 \mathrm{Gm}$. of a fine, white, microcrystalline powder of melting point $211.0^{\circ}-212.0^{\circ}$ (corr. $215.4^{\circ}-216.4^{\circ}$ ) remained on the filter. One reported (96) melting point of mucic acid is $213^{\circ}$ with decomposition. Concentration of the filtrate to one-third its volume and refrigeration yielded 0.70 $\mathrm{Gm}$. of long, needle-shaped erystals of melting point $99.5^{\circ}-100.0^{\circ}$ (corr. $\left.100.1^{\circ}-100.6^{\circ}\right)$, unchanged on admixture with mucic acid of the same melting point prepared from lactose. The total yield of crystalline material was $1.97 \mathrm{Gm}$. from $55.72 \mathrm{Gm}$. of jelly-like material or 3.53 per cent.

Pectic substances are believed (97) to be composed of a methylated 
polygalacturonic acid, an araban and a galactan. When galactose is oxidized with nitric acid, mucic acid is formed (88). The experimental evidence presented indicates that the jelly-like material was pectin and that the crystalline material isolated from it after nitric acid oxidation was mucic acid. The long, needle-shaped crystals of melting point $99.5^{\circ}-100.0^{\circ}$ appear to be a hydrated form of mucic acid. A survey of the literature showed that the melting point or existence of such a hydrate had not been reported. Various authors appear to disagree on the melting point of mucic acid; the following melting points having been found:

$206^{\circ}$ (95); $213^{\circ}$ (96); $202^{\circ}$ (98); $205^{\circ}$ (98); $225^{\circ}$ (99); $255^{\circ}$ (99). INVESTIGATION OF THE 5 PER CENT SODIUM HYDROXIDE EXTRACT

As stated previously, the hot 5 per cent sodium hydroxide extract was neutralized with hydrochloric acid. By evaporation at room temperature in a current of air the volume of the neutral solution was reduced to $100 \mathrm{ml}$. To the $100 \mathrm{ml}$. of concentrated solution was added $50 \mathrm{ml}$. of 95 per cent ethanol which caused a dark brown precipitate to form. The suspension was filtered through a one-quarter inch bed of Celite 535 filter aid. The residue, mixed with the Celite on the filter, gave a positive Millon's test (94) and positive Biuret test (94) for protein. The residue gave a negative test with Benedict's solution (90) for reducing saccharides but after hydrolysis with hydrochloric acid and subsequent neutralization of the hydrolysate with sodium bicarbonate, a Benedict's test (90) was positive.

The remainder of the residue was tested for the presence of pentosans (100). The remainder of the residue was placed in a distillation 
flask to which was added $100 \mathrm{ml}$. of 12 per cent aqueous hydrochloric acid. The mixture was distilled continuously, replacing the acid when necessary until about $300 \mathrm{ml}$. of distillate was collected. The distillate was pale yellow color which changed to a reddish-brown on exposure to air. To $100 \mathrm{ml}$. of the distillate was added a saturated solution of phloroglucinol in 12 per cent hydrochloric acid. The mixed solutions at first became green in color, then very dark green and appeared black after storage for twenty-four hours. About $2 \mathrm{ml}$. of the distillate was added to a mixture of a few drops of aniline and acetic anhydride; a red color developed. The color changes of the distillate with phloroglucinol and aniline acetate are characteristic of furfural.

This investigation showed the presence of a pentosan or some other hydrolysable hemicellulose in the 5 per cent sodium hydroxide extract. INVESTIGATION OF THE FRESH FRUIT

PREPARATION OF PHENYL-D-GLUCOSAZONE FROM THE LATEX OF OSAGE ORANGE FRUIT

Fresh osage orange fruit, which had been washed well with water and dried with a towel, were expressed in a hand-press. The white latex obtained was strained through two layers of cheesecloth. The yield was $528.5 \mathrm{Gm}$. of strained latex from $4997 \mathrm{Gm}$. of fresh fruit. The strained latex was placed in a large Erlenmeyer flask, which was stoppered and stored in a cold-room at about $0^{\circ}$ for three days. At the end of this time the latex had separated into two layers, a central jelly-like mass surrounded by an almost clear, tan-colored liquid (H- 1 ). Part of the liquid $(36.0 \mathrm{Gm}$.) was filtered through No. 50 Whatman filter paper to yield $34.0 \mathrm{Gm}$. of filtrate. 
To the $34.0 \mathrm{Gm}$. of filtrate was added $15 \mathrm{ml}$. of water, $4.0 \mathrm{Gm}$. of phenylhydrazine hydrochloride and $6.0 \mathrm{Gm}$. of anhydrous sodium acetate. The mixture was heated on a boiling water bath for twenty minutes. The yellow osazone partially separated from the hot solution after four minutes heating. After slowly cooling the reaction mixture, the crude osazone was removed by filtration and dried at room temperature. The crude osazone was divided into two equal portions. One portion $(0.6 \mathrm{Gm}$.) was suspended in $400 \mathrm{ml}$. of water and the suspension heated to boiling. The hot suspension was filtered on a steam-heated Buchner funnel. On cooling the filtrate slowly at room temperature bright yellow crystals of the osazone were obtained. The osazone was removed by filtration and dried at $105^{\circ}$. The yield was $0.3 \mathrm{Gm}$. of melting point $205.0^{\circ}$ (corr. $209.5^{\circ}$ ), unchanged on admixture with an authentic specimen of phenyl-D-glucosazone prepared from D-glucose and of melting point $205.0^{\circ}\left(\operatorname{corr} .209 .5^{\circ}\right)$. A microscopic examination of the osazone crystals indicated they were identical to the known osazone and to photomicrographs of crystals of phenyl-D-glucosazone. PREPARATION OF PHENYL-D-GLUCOSOTRIAZOIE FROM THE PHENYL-D-GLUCOSAZONE

The method of Hann and Hudson (101) was used. The second portion of the crude phenyl-D-glucosazone $(0.6 \mathrm{Gm}$.) was suspended in $54 \mathrm{ml}$. of water containing $1.8 \mathrm{Gm}$. of copper sulfate pentahydrate. To this suspension was added $3 \mathrm{ml}$. of $0.5 \mathrm{~N}$. aqueous sulfuric acid solution and $12 \mathrm{ml}$. of $\mathrm{N}$-butanol. The mixture was refluxed for one hour, the reaction mixture was filtered hot, and the filtrate concentrated on the steam bath to about $10 \mathrm{ml}$. After cooling to room temperature, the concentrated solution was placed in a dry-ice bath at $-35^{\circ}$ for 15 
minutes whereby a light tan colored precipitate formed. The precipitate was removed by filtration and redissolved in hot water; to the hot solution was added $0.1 \mathrm{Gm}$. of activated charcoal and the suspension was filtered while hot. The filtrate gave long colorless needles, melting point $194^{\circ}-195^{\circ}$. The yield was $0.03 \mathrm{Gm}$. Concentration of the mother liquors yielded only a trace of the same material. The reported melting point of phenyl-D-glucosotriazole is $195^{\circ}-195^{\circ}$. The above is confirmatory evidence that the osazone was phenyl-D-glucosazone. Since D-fructose, D-glucose and D-mannose give the same osazone, phenyl-D-glucosazone, the isolation of this derivative from the fresh latex established that any one of these monosaccharides or any combination of them were originally present in the latex of the osage orange fruit. COLOR TESTS FOR SUGARS

Some of the liquid, $H-1$, gave a positive Selivanoff test (88) for a. ketose. Some of the liquid $\mathrm{H}-1$, also gave the specific test for fructose described by Dehn, Jackson and Ballard (102); for this test some of the liquid $\mathrm{H}-1$ was heated with a dilute cobaltous chloride solution, the solution was cooled, and a few drops of 10 per cent ammonium hydroxide was added; a violet to purple color developed which is indicative of fructose; other carbohydrates give only green cobaltous hydroxide.

A color test, which is described as specific for mannose by Dehn, Jackson and Ballard (102), was applied to the liquid H-l but the test was negative. Attempts to prepare mannose phenylhydrazone and mannose 2, 4-dinitrophenylhydrazone by the procedures described by Shriner and 
Fuson were unsuccessful.

EXTRACTION OF THE SUGARS WITH AQUEOUS ALCOHOLIC MEDIA

Although it was shown that fructose and possibly glucose were present in the freshly expressed latex considerable amounts of saccharides still remained in the marc after expression of the latex.

The marc of the $4997 \mathrm{Gm}$. of fresh fruit, which remained after the $528.5 \mathrm{Gm}$. of strained latex was expressed, was macerated with 800 ml. of 95 per cent ethanol in a closed container for twenty-six days. The aqueous-alcoholic extract was poured off, the marc was pressed and the extract filtered through heavy cotton. The filtrate, which measured $1800 \mathrm{ml}$., was concentrated by vacuum distillation at a temperature below $50^{\circ}$ to a concentrate which weighed $426 \mathrm{Gm}$. This concentrate was clarified by filtration through a bed of charcoal and sand. The filtrate weighed $348.5 \mathrm{Gm}$, and had a clear straw-yellow color. This filtrate ( $\mathrm{J}-1$ ) gave a positive cobaltous chloride test (I02) for fructose. However, the presence of a hexose other than fructose, in the filtrate $\mathrm{J}-\mathrm{I}$ was shown by the method of Partridge (104). According to Partridge, a paper chromatogram on which fructose is spotted gives little or no color when sprayed with a solution of aniline hydrogen phthalate in water-saturated butanol and dried at $100^{\circ}$ for five minutes. One per cent solutions of glucose, mannose, and fructose and some of the filtrate $\mathrm{J}-1$ were spotted individually on a large sheet of Whatman's number 1 filter paper and the papers were dried in air. The papers were sprayed with the aniline hydrogen phthalate reagent and dried at $100^{\circ}$ for five minutes. Fructose gave only the pale yell.ow background. color whereas glucose, mannose and the plant extract, J-I, gave buff to 
light brown colors.

PAPER PARTITION CHROMATOGRAPHY OF SUGARS

A large, cylindrical, one-dimensional, paper partition chromatogram was prepared using the apparatus described on page 70 . A twophase mixture of 40 per cent n-butanol, 10 per cent ethanol, and 50 per cent water by volume was prepared and allowed to come to equilibrium. The lower aqueous phase of the mixture was placed in the beaker at the bottom of the glass tank; the upper organic layer was placed in the crystallization dish and was used to feed the paper column.

A one per cent aqueous solution of glucose, a one per cent aqueous solution of fructose, an aqueous solution containing one per cent glucose and one per cent fructose, and some of the filtrate J-l were spotted on the dry paper at intervals of about $3 \mathrm{~cm}$. on the origin line by means of a $0.2 \mathrm{ml}$. pipette. When the spots were dry the paper was placed in the tank, the solvents added, the glass plate sealed on and the chromatogram allowed to develop for a period of nineteen and onehalf hours. The cylindrical paper was removed from the tank and dried at $100^{\circ}$ for five minutes, after marking the position of the solvent boundary. The paper was then sprayed rapidly and evenly with a mixture containing equal parts of $\mathrm{N} / 10$ silver nitrate solution and $5 \mathrm{~N}$ ammonium hydroxide solution. The paper was then dried again in the oven at $100^{\circ}$ for 10 minutes.

The positions of the sugars on the paper chromatogram were indicated by the dark brown spots on a light brown background. These spots were outlined with a pencil as well as the position of the solvent boundary since, on storage, the background gradually darkened. 
Table 13 outlines the positions of the sugars on the chromatogram.

\section{TABLE 13}

\begin{tabular}{lllll}
$\begin{array}{l}\text { Solution } \\
\text { Spotted }\end{array}$ & $\begin{array}{l}\text { Distance from } \\
\text { Top of Spot } \\
\text { to Origin } \\
\text { Line (cm.) }\end{array}$ & $\begin{array}{l}\text { Distance from } \\
\text { Bottom of } \\
\text { Spot to } \\
\text { Origin } \\
\text { Line (cm.) }\end{array}$ & $\begin{array}{l}\text { Distance from } \\
\text { Mid-Hoint of } \\
\text { Spot to } \\
\text { Origin } \\
\text { Line (cm.) }\end{array}$ & $\begin{array}{l}\text { Distance from } \\
\text { Soundary } \\
\text { To Origin } \\
\text { Line (cm.) }\end{array}$ \\
\hline $\begin{array}{c}\text { Filtrate } \\
\text { J-1 }\end{array}$ & 5.2 & 2.0 & 3.6 & 20.3 \\
$\begin{array}{c}\text { Glucose- } \\
\text { Fructose }\end{array}$ & 5.2 & 2.0 & 3.6 & 20.3 \\
$\begin{array}{l}\text { Combination } \\
\text { Glucose }\end{array}$ & 4.0 & 2.6 & 3.3 & 20.1 \\
Fructose & 5.5 & 4.1 & 4.8 & 20.1 \\
\hline
\end{tabular}

Both the glucose-fructose combination and the plant extract, filtrate A-2, gave identical spots which were the same distance from the origin line. By observation of the chromatogram it was obvious that each of these large spots was a composite which could be formed by overlapping the fructose spot on top of the glucose spot.

Using the solvent mixture reported by Jermyn and Isherwood (105) a second paper partition chromatogram was prepared. A two-phase mixture of 3 parts of benzyl alcohol, 3 parts of water and 1 part of glacial acetic acid by volurne was prepared and allowed to come to equilibrium. The aqueous layer was used in the bottom of the tank; the organic layer was placed in the crystallization dish to feed the paper column. The only difference in the procedure was that this chromatogram was allowed to develop for twenty-three hours rather than nineteen and a half hours. Table 14 outlines the positions of the sugars on the second chromatogram. 


\section{TABIE 14}

\begin{tabular}{lcccc}
$\begin{array}{l}\text { Solution } \\
\text { Spotted }\end{array}$ & $\begin{array}{l}\text { Distance from } \\
\text { Top of Spot } \\
\text { to Origin } \\
\text { Line (cm.) }\end{array}$ & $\begin{array}{l}\text { Distance from } \\
\text { Bottom of Spot } \\
\text { to Origin } \\
\text { Line (cm.) }\end{array}$ & $\begin{array}{l}\text { Distance from } \\
\text { Mid-Point of } \\
\text { Spot to } \\
\text { Origin } \\
\text { Line (cm.) }\end{array}$ & $\begin{array}{l}\text { Distance from } \\
\text { Solvent } \\
\text { Boundary to } \\
\text { Origin } \\
\text { Iine (cm.) }\end{array}$ \\
\hline $\begin{array}{l}\text { Filtrate } \\
\text { J-1 }\end{array}$ & 3.5 & 1.1 & 2.3 & 26.5 \\
$\begin{array}{l}\text { Glucose- } \\
\text { Fructose }\end{array}$ & 3.5 & 1.1 & 2.3 & 26.5 \\
$\begin{array}{l}\text { Combination } \\
\text { Glucose }\end{array}$ & 2.4 & 0.8 & 1.6 & 26.5 \\
Fructose & 3.5 & 2.1 & 2.8 & 26.5 \\
\hline
\end{tabular}

In this case also, both the glucose-fructose combination and the plant extract $J-1$, gave identical spots which were the same distance from the origin line. Each of these spots was a composite of the individual fructose and glucose spots. ATTEMPTED ISOLATION OF CRYSTALLINE SUGAES OR THEIR DERIVATIVES

The filtrate $\mathrm{J}-\mathrm{I}$ was concentrated under reduced pressure to a very viscous symu, (J-2), which weighed approximately $100 \mathrm{Gm}$. A sample of this syrup yielded phenyl-D-glucosazone when prepared according to Shriner and Fuson (89). The time of formation of the osazone from the plant syrup, J-2, was three minutes and five seconds. Known D-fructose, known D-glucose and a mixture of known D-fructose and D-glucose, under the same conditions, gave osazones which formed in one minuted and forty-five seconds, four minutes and twenty-five seconds, and two minutes and forty seconds respectively. The time of formation indicated the syrup contained a mixture of glucose and fructose. No 
mannose phenyl-hydrazone was obtained.

Attempts to prepare a sugar benzoate by the method of fieser (106) from the syrup, yielded no satisfactory crystalline product. Attempts to prepare a sugar acetate from the syrup $\mathrm{J}-2$ by the method of Shriner and Fuson (107) yielded only a brownish-black syrup which could not be crystallized. Attempts to identify the free sugars present in the syrup $J-2$ by recrystallization from various solvents according to Quense and Dehn (108) yielded no satisfactory results.

The syrup, J-2, contained no protein since it gave a negative Millon's reaction (94) and a negative Xanthoproteic reaction ( 94 ). It contained no starch as evidenced by a negative iodine test. It apparently contained no tannin or phenolic compounds since it gave no color with ferric chloride solution (86).

When $26.67 \mathrm{Gm}$. of the syrup J-2 was stirred with $100 \mathrm{mI}$. of methanol, the supernatant liquid decanted, and the residue dried over drierite in a vacuum desiccator, $14.94 \mathrm{Gm}$. of light brown, amorphous, hygroscopic solid ( J-3) was obtained. The solid, J-3, melted at $39^{\circ}-$ $44^{\circ}$ when quickly heated; it readily absorbed moisture on exposure to air and became syrupy. A dilute, aqueous solution of the solid J-3 was titrated with Benedict's Quantitative Sugar Reagent (90). The results indicated that the solid $\mathrm{J}-3$ had 50.5 per cent of the reducing power of D-glucose; this value was not increased by acid hydrolysis, which indicated the absence of simple hydrolyzable carbohydrates in the solid $J-3$

The formation of phenyl-D-glucosazone from the fresh plant extracts established that any one of the monosaccharides, D-fructose, D-glucose 
or D-mannose, or any combination of these monosaccharides, were originally present in the fresh fruit. The inability to prepare mannose phenylhydrazone (103) and the negative color test for mannose (102) indicated the absence of mannose in the fresh plant extracts. The positive Selivanoff test ( 88 ) and the positive specific test for fructose (102) given by the fresh plant extracts indicated the presence of fructose in these extracts. The aniline hydrogen phthalate test (104) indicated the presence of a hexose other than fructose in the fresh plant extracts. The paper partition chromatograms indicated that both fructose and glucose were present in the fresh plant extracts.

\section{SUMMARY AND CONCLUSIONS}

1. A discussion of the pharmacological, phytochemical, and industrial investigations of the fruit of Maclura pomifera is presented. 2. The dried fruit was extracted with a series of solvents and the weights of the extracts were recorded.

3. A new method for the separation of the constituents of the unsaponifiable matter of the petroleum ether extract of the dried fruit has been presented. This method involved direct acetylation of the unsaponifiable matter, separation of the crystalline acetates, and fractional crystallization of the acetates. Two other methods, which gave unsatisfactory results, are discussed.

4. By means of the above method, a new crystalline acetate and Iupeol acetate were isolated from the unsaponifiable matter.

5. The new crystalline acetate was saponified and yielded a new crystalline alcohol. 
6. When the crystalline alcohol was acetylated two acetates were separated from the acetylation mixture, namely the original crystalline acetate and lupeol acetate. When the crystalline alcohol was benzoylated two benzoates were separated from the benzoylation mixture, namely a new crystalline benzoate and lupeol benzoate. These results constituted evidence of an isomerization. The action of hot acetic anhydride over a prolonged period did not cause the conversion of any of the new acetate to lupeol acetate.

7. The melting points and specific rotations of the new crystalline alcohol, its acetate, and its benzoate, are reported. 8. The results of carbon and hydrogen analyses, the experimentally determined saponification equivalents, and the isomerization denoted that the new acetate was the acetate of a triterpene alcohol and that the new acetate was an isomer of lupeol acetate; the experimental results similarly denoted that the new benzoate was the benzoate of a triterpene alcohol and that the new benzoate was an isomer of lupeol benzoate.

9. The new acetate and the new benzoate were shown to be much more soluble in ethanol and acetone and mixtures of these solvents with water, than lupeol acetate and lupeol benzoate respectively. 10. Comparisons were made between the new alcohol and lupeol, between the new acetate and lupeol acetate, and between the new benzoate and lupeol benzoate by a method based on paper partition chromatography. This method detected very small quantities of the compounds, differentiated them and provided a criterion to show that. each compound was homogeneous. 
11. Repeated recrystallizations of the new acetate failed to raise its melting point. Recrystallization of mixtures of the new acetate and lupeol acetate from the same solvent mixtures caused a change in melting point. This was another criterion which showed the homogeniety of the new acetate. Similarly, repeated recrystallizations of the new benzoate failed to raise its melting point. Recrystallizations of mixtures of the new benzoate and Iupeol benzoate from the same solvent mixtures caused a change in melting point. This was another criterion which showed the homogeniety of the new benzoate. 12. The Liebermann-Burchard and Salkowski tests were applied to the new alcohol, lupeol, the new acetate and lupeol acetate. The new alcohol was found to give an entirely different sequence of colors than lupeol in the Liebe mann-Burchard test hence this test provided a means to differentiate the compounds. The new acetate was found to give an entirely different sequence of colors than lupeol acetate both in the Liebermann-Burchard and Salkowski tests hence this test provided a means to differentiate the compounds. The fresh latex of Maclura pomifera was found to give a sequence of colors in the LiebermannBurchard test which was the same as that given by the new acetate and new alcohol.

13. Crystalline fractions were isolated from the resinous residue obtained after the acetylation of the unsaponifiable matter. The range of melting points of these fractions and the colors which they gave in the Liebermann-Burchard test indicated that these fractions were impure samples of the unknown acetate. 
14. The infrared spectra of the unknown acetate, the unknown alcohol, lupeol and lupeol acetate have been recorded.

15. The name lurenol is suggested by the author for the unknown alcohol. The name lurenyl acetate is suggested by the author for the unknown acetate.

The name lurenyl benzoate is suggested by the author for the unknown benzoate. 16. A modified method has been presented for the isolation of the pigments, osajin and pomiferin. A higher melting point than that formerly reported was reported for osajin. The corrected melting points of both osajin and pomiferin are reported.

17. D-glucose and D-fructose were shown to be present in fresh plant extracts and the absolute alcohol extract of the dried fruit by means of: (1) the preparation of phenyl-D-glucosazone (2) specific color tests and (3) paper partition chromatography. 18. A pectic substance, which yielded mucic acid on oxidation, was isolated from the acidified aqueous extract of the dried fruit. 19. A pentosan or some other hydrolysable hemicellulose was shown to be present in the 5 per cent aqueous sodium hydroxide extract. 20. No definite evidence of the presence of an alkaloid or a glycoside in the fruit was obtained. 21. An unidentified substance, which melted at $113.5^{\circ}-114.0^{\circ}$ and which gave a color reaction with ferric chloride solution, was isolated from the 70 per cent alcohol extract of the dried fruit. 22. A brief botanical description of Maclura pomifera is presented. 


\section{APFENDIX I}

BOTANICAL DESCRIPTION OF MACLURA PONTFERA

GEOGRAPHICAL SOURCE

Maclura pomifera is a native tree of the regions south of the Missouri, near the Arkansas River and in the neighborhood of New Mexico (1). The Osage Indians, whose original home was on the banks of the Osage River in western Missouri (9) planted the trees near their villages. The Osage Indians used the hard wood to make their bows and from the pigmented fruit they made war paint (9). Trees were later introduced into the gardens of St. Louis and Philadelphia (1). The tree now grows extensively throughout the southern, midwestern and eastern states and as far north as Albany, New York (9). PLANT HABIT

In rich soil the tree reaches a height of 50 to 60 feet $(9,58)$. The cultivated tree, or in northern regions, may reach a height of only 30 feet (58). The deciduous tree has bent and erratic branches, a tough fibrous bark, hard yellow wood, red roots, and deep green alternate obovate entire leaves on long supple thomy branchlets ( 9 ). DESCRIPTION OF THE F'RUIT

The female trees begin bearing large ouantities of fruit at from six to ten years of age (13). The fruit is a globular syncarp (58) formed, as in the pineapple, by the persistant perigones adhearing together, with the sutures scarcely visible, and forming a fleshy epidermis (1). At maturity, the fruit has a greenish yellow color, an average diameter of $3 \frac{1}{2}$ inches and an average weight of one to one and a 
half pounds (13). The fruit consists of a dense, pear-shaped core at the center from which radiate rather long, irregular sized cells that terminate in an enlarged or club form, thus making an irregular surface. These cells are made up of two parts, the milk sacs and seed sacs. The milk sacs form about two-thirds of the entire length of the cell and extend to the surface. The seed sacs lie beneath the milk sacs and are attached to the core at their base (13). The milk sacs contain a white, milky latex.

TAXONOMY

Bailey (58) classifies Maclura pomifera in the Moraceae or Nulberry Family. This family comprises about 55 genera and about 1000 species of herbs, shrubs, trees and vines, most of wich are tropical and often have a milky juice.

The important genera of the Moraceae are (58):

1. Morus (Mulberry)

2. Broussonetia (Paper Mulberry)

3. Maclura

4. Artocarpus

5. Ficus (Fig)

6. Humulus (Hop)

ILLUSTRATIONS OF MACLURA POMIFERA

Figure 10 and Figure $i I$ are drawings of the various plant parts of Maclura pomifera and admirably show the morphology. The drawings presented are photostatic copies of those made by Camillo Karl Schneider (5). 


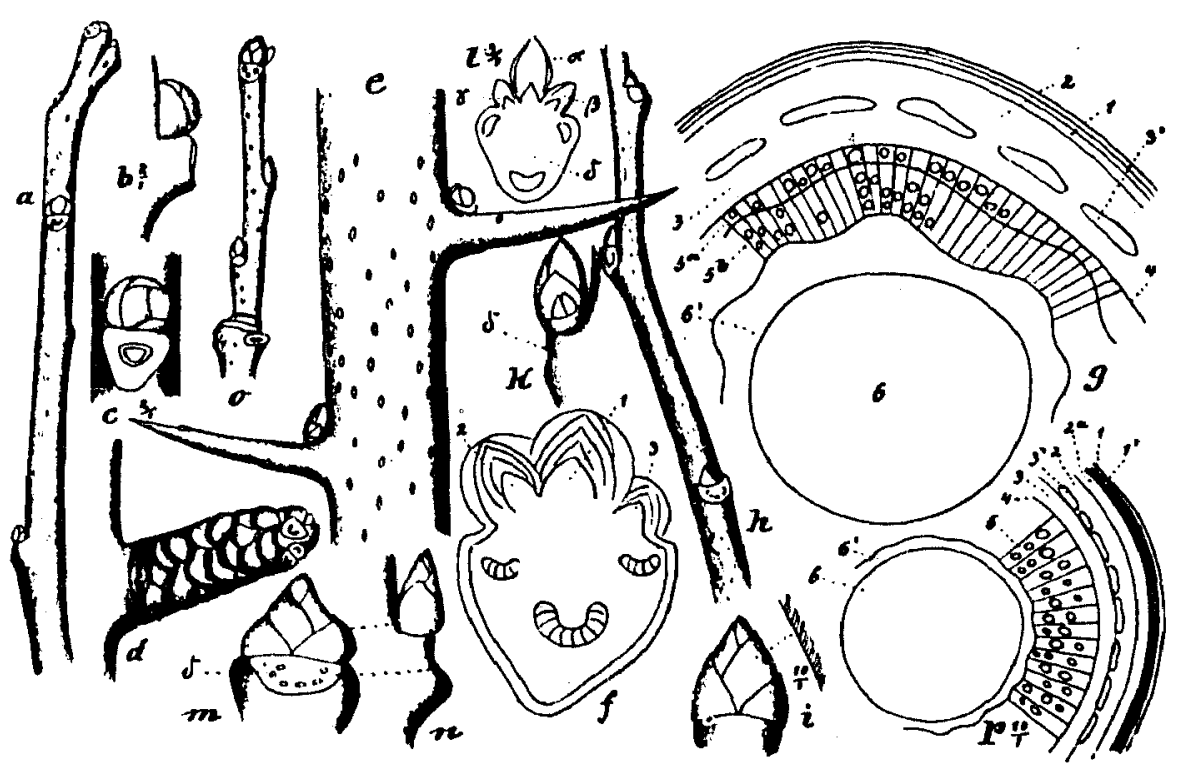

Fig. 10 a. to g. Maclura pomifera

a. A twig one year old.

b. and c. Leaf buds.

d. Shoot or sprout.

e. A twig with thoms.

f. Section through a bud and leaf scar parallel to the twig.

1. The bud. 2. and 3. Near the bud.

g. Transverse section of a twig.

1. Epidermis

2. Cortical parenchyma

3. Bast or phloem

$3^{1}$. Mechanical elements (Primary bast fibers)
4. Cambium

5. Wood

$6^{1}$. Coronary pith

6. Pith

h. to p. Morus alba. 


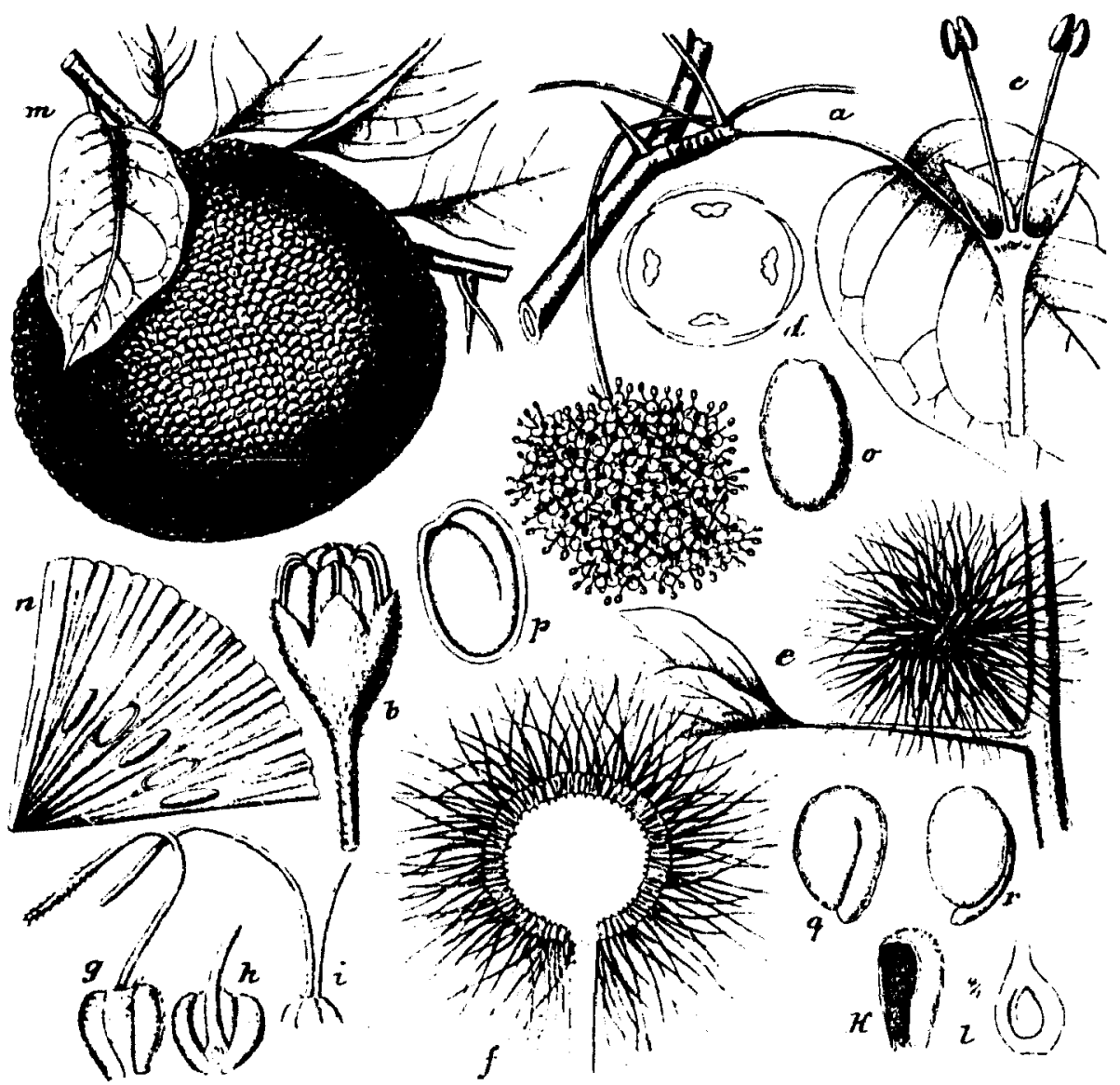

Fig. 11 a. to t. Maclura pomifera

a. Male corolla.

b. Young male flower.

c. Longitudinal section of a male flower.

d. Diagram of a male flower.

e. Female corolla.

f. Longitudinal section of a female corolla.

g. Female flower.

h. Anterior of female flower with perigone removed. i. Style with lateral branch.

k. Perigone.

1. Longitudinal section of ovary.

m. Fruit ( $1 / 3$ natural size)

n. Section of fruit showing seeds embedded in receptacle. ( $\frac{1}{2}$ natural size)

o. Seed.

p. Seed in longitudinal section.

$q$. and $t$. The embryo. 


\section{BIBLIOGRAPHY}

1. Rafinesque, C.S. "Description of IOXYLON POMIFERUM, a New Genus of North American Tree." Am. Monthly Mag., Vol. II, No. II (1817), pp. 118-19.

2. Nuttall, T. "The Genera of North American Plants and a Catalogue of the Species to the Year 1817." Philadelphia: D. Heartt, 1818, Vol. II, pp. 233.

3. Rafinesque, C.S. Am. Monthly Mag. IV (1818), pp. 188 .

4. Rafinesque, C.S. "Autikon Botanikon or Botanical Illustrations of $2500 \mathrm{New}$, Rare and Beautiful Trees, Shrubs, Plants, Vines, Lilies, Grasses, Ferns, etc., of all Regions but Chiefly North America, with Descriptions, etc. and 2500 Self-Figures or Specimens." Philadelphia; $1815-1840$

5. Schneider, C.K. "Illustriertes Handbuch der Laubholzkunde." Jena: Verlag von Gustav Fischer, 1906, Band I, pp. 239-240.

6. Pammel, I.H. "A Manual of Poisonous Plants." Cedar Rapids, Iowa: The Torch Press, 1911, pp. 106, 414.

7. Muenscher, W. C. "Poisonous Plants of the United States." New York: The MacMillan Company, 1939, pp. 9.

8. American Joint Committee on Horticultural Nomenclature. "Official Code of Standardized Plant Names." Pennsylvania; J. Horace McFarland Company, Mount Pleasant Press, Harrisburg, 1917, pp. 3596.

9. Fox, C.P. "So-called 'Osage Orange Rubber'-a Product of Kansas." Orig. Com. 8th Inter. Cong. Appl. Chem. (appendix) 25 (1912), pp. 593.

10. Gerber, M.C. and Salkind, J. "Action Physiologique des Latex. V. Injections Sous-Cutanées Des Latex Frais ou Bouillis De Maclura aurantica, Morus nigra, Norus alba chez le Pigeon, Le Rat, La Grenouille et La Sarran." Compt. rend. soc. biol., 74 (1913), pp. $721-23$.

11. Gerber, M.C. "Comparaison des diastases hydrolysantes du latex de Maclura aurantica avec celles de Ficus Carica et de Broussonetia papyrifera." Comptes rendus des séances de l'académie des Sciences 156 (1913), pp. 1573-75.

12. Ramsbottom, J.M. and Paddoch, L.S. "Enzymic Tenderizing of Animal Tissues." U.S. Patent 2,454,716 (Nov. 23, 1948). 
13. McHargue, J.S. "Some Important Constituents in the Fruit of the Osage Orange." J. Ind. Eng. Chem., 7 (1917), pp. 612.

14. Wehmer, Carl. "Die Pflanzenstoffe". Jena: Verlag von Gustar Fischer, 1929, Erster Band, pp. 236-7.

15. Kressman, F.W. "Osage Orange - Its Value as a Commercial Dyestuff." J. Ind. Eng. Chem., 6 (1914), pp. 462-64.

16. Walter, E.D., Wolfrom, H.I. and Hess, W.W. "A Yellow Pigment from the Osage Orange (Kaclura pomifera Raf.)!" J. Am. Chem. Soc., $\underline{60}$ (1938), pp. 574-77.

17. Wolfrom, if.L., Benton, F.L., Gregory, A.S., Hess, W.W., Wahan, J.E., and Morgan, P.W. "Osage Orange Pigments II. Isolation of a New Pigment, Pomiferin." J. Am. Chem. Soc., 6I (1939), pp. 2832-36.

18. WoIfrom, M.I. and Gregory, A.S. "Osage Orange Pigments III. Fractionation and Oxidation." J. Am. Chem. Soc., 62 (1940), pp. 651-52.

19. Wolfrom, W.L. and Horgan, P.W. and Benton, F.L. "Osage Orange Figments IV. Degree of Unsaturation and Flavone Nature." J. Am. Chem. Soc., 62 (1940), pp. $1484-89$.

20. Wolfrom, M.I., Benton, F.I., Gregory, A.S., Hess, W.W., Wahan, J.E. and Morgan, $F . W$. "Osage Orange Pigments $V$. Isomerization." J. Am. Chem. Soc., 63, 422-26 (1941).

21. Holfrom, H.L., Wahan, J.E., korgan, F.H., and Johnson, G.F. "Osage Orange Pignents VI: Isoflavone Nature of Osajin." J. Am. Chem. Soc., 63 (1941), pp. 1248-53.

22. Foifrom, H.I. and kahan, J.E. "Osage Orange Pigments VII. Isoflavone Nature of Pomiferin." J. Am. Chem. Soc., 63 (194I), pp. 1253-56.

23. HoIfram, M.I. and Gregory, A.S. "Osage Orange Pigments VIII. oxidation." J. Atr. Chem. Soc., 63 (1941), pp. 3356-58.

24. Wolfrom, ti.L. and Jahan, J.E. "Osage Orange Pigments IX. Improved Separation; Astaolishment of the isopropylidene Group." J. Am. Chem. Soc., 64 (1942), po. 308-i1.

25. Nolfrom, W.I. and lioffett, S.M. NOsage Orange Pigments $\ddot{X}$. Oxidation." J. Ar. Chem. Soc., 64 (1942), pp. 311-15.

2ó. Tolfrom, W.I., and Johnson, G.F., Harris, H.D., and Nildi, B.S. "The Structires of Osajin and Pomiferin." Commications to the Editor: 3. Am. Chen. Soc., 65 (1943), po. 1434-35. 
27. Wolfrom, M.I., Harris, W.D., Johnson, G.F., Mahan, J.E., Moffett, S.M., and Wildi, B.S. "Osage Orange Pigments XI. Complete Structures of Osajin and Pomiferin." J.Am. Chem. Soc., 68 (1946), pp.406-18.

28. Wolfrom, Mi.L. and Wildi, B.S. "Osage Orange Pigments XII. Synthesis of Dihydro-iso-osajin and of Dihydro-isopomiferin." J. Am. Chem. Soc., 73 (Jan., 1951), pp. 235.

29. Waud, R.A. "The Actions of a Flavone Glucoside on the Heart." Proc. Amer. Soc. Pharm. Exp. Therap., 69 (Mar. 13-16, 1940), pp. 309.

30. Smith, H.W. and Waud, R.A. "Some Pharmacological Actions of Flavones and Related Substances." Proc. Can. Phy. Soc., Seventh Annual Meeting, Seigniory Club, Montebello, Quebec, Oct. 24th and 25th, 1941.

31. Waud, R.A., Stewart, J.D. and Loynes, J. "The Actions of Sterols on the Heart." Proc. Can. Phy. Soc., Twelfth Annual Meeting, Laval University, Quebec City, Oct. 15th and 16th, 1948.

32. Waud, R.A., Guwdey, C.W. and Loynes, J.S. "Cardiac-Active Principles in Osage Orange." Federation Proceedings. Part I. Fed. Amer. Soc. for Exp. Bir,, g, No. I (Mar., 1949), pp. 344.

33. Swift, L.J. and Walter, E.D. "Isolation of Lupeol from the Osage Orange (Maclura pomifera Raf.)." J. Am. Chem. Soc., 64 (Nov., 1942), pp. 2539.

34. Kraybill, H.R., Brewer, F.H. and Thornton, M.H. "Processes of Producing an Adsorbent Agent." U.S. Patent No. 2,174,177 (Sept. 26, 1939).

35. Dieterle, H. "Ueber Lupeol I. Mitteilung." Arch. Pharm., 261 (1923), pp. 89.

36. Dieterle, $H_{-}^{-}$and Salomon, A. "Uber Lupeol II. Mitteilung." Arch. Pharm., 270 (1932), pp. 540 .

37. Dieterle, H. and Biedebach, F. "Über Lupeol III. Mitteilung." A rch. Pharm., $\underline{276}$ (1938), pp. 312-316.

38. Biedebach, F. "Über Lupeol IV. Mitteilung." Arch. Pharm., 277 (1939), pp. 163.

39. Ruzicka, L. and Rosenkrantz, G. "Zur Kenntnis der Triterpene: Uber Lupenal and Lupenalol, sowie deren weitere Umwandlungen." Helv. chim. acta., 23 (1940), pp. 1311. 
55. Beal, Jack. "Determination of Quercitin-Like Substances in Several Mid-Western Plants." Trans. Kansas Acad. Sci., 52 (1949), pp. 209-18.

56. Clopton, John, R. and Roberts, Ammarette. "Osage Orange - A Potential Source of Edible Oil and Other Industrial Raw Materials." J. Am. Oil Chemists' Soc., 26 (1949), pp. 470-72.

57. Beal, J. L. and Wenzel, D.G. "Osage Orange Oil." Trans. Kansas Acad. Sci., 54, No. 1 (1951), pp. 94-98.

58. Bailey, L.H. "Manual of Cultivated Plants kiost Commonly Grown in the Continental United States and Canada." New York: The MacMillan Company, Revised Edition, 1949.

59. Rosenthaler, L. "The Chemical Investigation of Plants." London: G. Bell and Sons, Ltd., 1930, pp. 35-4l.

60. "The Pharmacopoeia of the United States of America." Easton Pa.: Mack Printing Company, Fourteenth Flevision, 1950, pp. 809.

61. Reichstein, T. and Shoppee, C.W. "Chromatography of Steroids and Other Colorless Substances by the liethod of Fraction Elution."

Discussions of the Faraday Society, \#7 (1949), pp. 305-11.

62. Fieser, L.F. "Experiments in Organic Chemistry." New York: D.C. Heath and Company, 2nd ed., 194I, pp. 358-370.

63. Shriner, R.L. and Fuson, R.C. "The Systematic Identification of Organic Compounds.". New York: John Wiley and Sons, Inc., 1948, pp. 50.

64. Heilbron, I.Mi., Moffet, G.I. and Spring, F.S. "The Non-Saponifiable Matter of Shea Nut Fat. Part I." J. Chem. Soc. 1583 (1934).

65. Hendricks, S.B. and Wildman, S.G. "A Triterpene Ester Isolated from Crystostegia madagascariensis Latex." Arch. Biochem. 10 (1946), pp. 157-162.

66. Todd, A.R., Bergel, F., Waldmann, H. and Work, T.S. "Sterols from Rice Germ Oil." Biochem. J., 31 (1937), pp. 2247-2257.

67. Fieser, L.F. and Fieser, Mary. "Natural Products Related to Phenanthrene." New York: Reinhold Publishing Corporation, 1949.

68. Shriner, R.L. and Fuson, R.C. "The Systematic Identification of Organic Compounds." New York: John Wiley and Sons, Inc., 3rd ed., (1948), pp. 134-35.

69. Wolfson, W.Q., Cohn, C. and Devaney, W.A. "An Improved Apparatus and Procedure for Ascending Paper Chromatography on Large Size Filter Sheets." Science, 109 (May 27, 1949), pp. 541. 
40. Ruzicka, L. and Brenner, M. "Zur Kenntnis der Triterpene: Über Oxydationsprodukte von Betulin und von Betulin-diacetat." Helv. chim. acta., 23 (1940), pp. 1325.

41. Ruzicka, L. and Rey, Ed. "Zur Kenntnis der Triterpene: Abbau des Diacetoxy-nor-lupanons und der Acetyl-betulinsäure zur Acetoxy-bisnorlupandisäure." Helv. chim. acta., 26 (1943), pp. 2143-51.

42. Ruzicka, I., Jeger, $O$, and Huber, W. "Zur Kenntnis der Triterpene (98) Mitteilung). Abbau des Lupeols in den Ringen A und B zu einer $\mathrm{C}_{26}$-Tricarbonsäre." Helv. chim. acta., 27 (1944), pp. 942-4.

43. Jones, E.R.H. and Meakins, R.J. "The Constitution of Lupeol." J. Chem. Soc. (1941), pp. 757.

44. Bilham, P., Jones, E.R.H. and Meakins, R.J. "Surface Films of Lupane Derivatives." J. Chem. Soc., (1941), pp. 761-66.

45. Spring, F.S. "Triterpenes III Lupeol Group-Lupeol and Betulin" Ann. Rep. Chem. Soc., 38 (1941), pp. 201-205.

46. Cohen, N.H. "Lupeol und B-amyrin aus Bresk." Arch. Pharm., 245 (1907), pp. 236.

47. Noller, C.R. "The Chemistry of the Triterpenes." Ann. Rev. Biochem., 14 (1945), pp. 383-406.

48. Ames, T.R. and Jones, E.R.H. "Structure of Triterpenes-an Interrelation between the Lupeol and B-amyrin Series." Nature 164 (1949), pp. 1090-91.

49. Benyon, J.H., Heilbron, I.M. and Spring, F.S. "A Novel Interrelationship in the Triterpene Group." Nature, 138 (1936), pp.1017.

50. Benyon, J.H., Heilbron, I.M. and Spring, F.S. "Characterization of Basseol, a Tetracyclic Triterpene Alcohol and Its Isomerization to B-amy renol." J. Chem. Soc., (1937), pp. 989-91.

51. Duerden, A., Heilbron, I.M., McMeeking, W. and Spring, F.S. "Acidic Oxidation Products of Lupenyl Esters. The Addition of Hydrogen Chloride to Lupeol." J. Chem. Soc., (1939), pp. 322-24.

52. Biedebach, F. "Über Lupeol V Mitteilung." Arch. Pharm., 280 (1942), pp. 304-315.

53. Biedebach, F. "Über Lupeol VI Mitteilung." A rch Pharm., 281 (1943), pp. 49-62.

54. Pullar, M.E. "Five Suspected Poisonous Plants." Australian Vet. J., 15 (1939), pp. 19-23. Through Chem. Abs., 33 (1939), pp. $6964^{3}$. 
70. Bush, I.E. "Chromatography of Steroids on Alumina-Impregnated Filter Paper." Nature 166 (Sept. 9, 1950), pp. 445-6.

71. Partridge, S.M. "Application of the Paper Chromatogram to the Qualitative Analysis of Reducing Sugars." Nature 158 (Aug. 24, 1946), pp. 270 .

72. Jermyn, M.A. and Isherwood, F.A. "Improved Separation of Sugars on the Paper Partition Chromatogram." Biochem. J., 44 (1949), pp. 402.

73. Coelho, F.P. and Alves, F.A. "Liebermann-Burchard Reaction." Nature 157 (1946), pp. 803.

74. Hawk, P.B., Oser, B.I. and Summerson, W.H. "Practical Physiological Chemistry." 12th ed., Philadelphia: The Blakiston Company, 1947, pp. 261 .

75. Jenkins, G.L., Hartung, W.A. "The Chemistry of Organic Medicinal Products." New York: John Wiley and Sons, Inc., 2nd ed., 1945, pp. 293.

76. Kostychev, S. "Kostychev's Chemical Plant Physiology."

Philadelphia: P. Blakiston's Son and Co., Inc., 1931, pp. 347.

77. "The Dispensatory of the United States of America." Philadelphia: J.B. Lippincott Company, 1947, 24th edition, pp. 147 .

78. Ohata, Y. "The Components of Viscum Album II Free resin acids and Unsaponifiable Matter of Fesin-Wax Contained in the Woody Portion."

J. Agr. Chem. Soc. Japan 17 (1941), pp. 222-9, through Chem. Abs., 45 (1951), pp. $3912^{\mathrm{c}}$.

79. Gibb, T.R.P. "Optical Miethods of Chemical Analysis." New York: MicGraw Hill Book Company, Inc., Ist. ed., 1942, pp. 114.

80. Randall, H.M., Fowler, R.G., Fuson, N., and Danzl, J.R. "Infrared Determination of Organic Structures." New York: D. Van Nostrand Company, Inc., 1949.

81. Infrared Transparencies supplied by: Samuel P. Sadtler and Sons, Inc., Philadelphia, Pa.

82. "The Mierck Index." Rahway, N.J.: Merck and Co. Inc., 5th ed., 1940, pp. 831.

83.

84. ibid

ibid pp.956.

pp. 813. 
85. Shriner, R.L. and Fuson, R.C. "The Systematic Identification of Organic Compounds." New York: John Wiley and Sons, Inc., 1948, pp. 114. 86. ibid pp. 98-9.

87. ibid pp. 87.

88. Hawk, P.B., Oser, B.L. and Summerson, W.H. "Practical Physiological Chemistry." Philadelphia: The Blakiston Company, 12th ed., 1947, pp. 54-66.

89. Shriner, R.L. and Fuson, R.C. "The Systematic Identification of Organic Compounds." New York: John Wiley and Sons, Inc., 1948, pp. $116-117$.

90. Hawk, P.B., Oser, B.L. and Summerson, W.H. "Practical Physiological Chemistry." Philadelphia: The Blakiston Company, 12th ed., 1947, appendix, pp. 1223.

91. Denston, T.C. "A Textbook of Pharmacognosy." London: Sir Isaac Pitman and Sons, Ltd., 3rd ed., 1939, pp. 36-37.

92. "The Pharmacopoeia of the United States of America." Easton, Pa.: Mack Printing Company. Fourteenth Revision, 1950, pp. 939.

93. Hawk, F.B., Oser, B.L. and Summerson, W.H. "Practical Physiological Chemistry." Philadelphia; The Blakiston Company, I2th ed., 1947, pp. 174 .

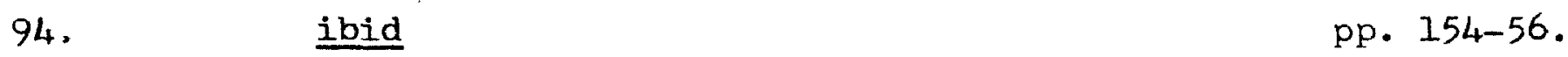

95. Beilstein, F.K. "Beilstein's Handbuch der Organischen Chemie." Band III, System-Number 195-322, pp. 581.

96. Shriner, R.L. and Fuson, R.C. "The Systematic Identification of Organic Compounds." New York: John Wiley and Sons, Inc., 1948, pp. 225.

97. Gortner, R.A. and Gortner, W.A. "Outlines of Biochemistry." New York: John Wiley and Sons, Inc., 3rd ed., 1949, pp. 729-30.

98. Winterfeld, $K$, and Dorle, E. Uber die Wirkstoffe der Mistel (Viscum album L.). Arch. Pharm., 280 (1942), pp. 23-26.

99. "The Mierck Index." Rahway, N.J.: Merck and Co. Inc., 5th ed., 1940 , pp. 367.

100. "Official and Tentative Methods of Analysis of the Association of Official Agricultural Chemists." Washington, D.C.: Association of Official Agricultural Chemists, 6th ed., 1945, pp. 412. 


\section{0}

101. Hann, R.M. and Hudson, C.S. "The Action of Copper Sulfate on Phenylosazones of the Sugars. Phenyl-D-glucosotriazole." J. Am. Chen. Soc., 66 (1944), pp. 735.

102. Dehn, W.M., Jackson, K.E. and Ballard, D.A. "Identification of Common Carbohydrates." Ind. Eng. Chem. Anal. Ed., 4 (1932), pp. 413.

103. Shriner, R.L. and Fuson, R.C. "The Systematic Identification of Organic Compounds." New York: John Wiley and Sons, Inc., 1948, pp. $97,116$.

104. Partridge, S.M. "Aniline Hydrogen Phthalate as a Spraying Reagent for Chromatography of Sugars." Nature 164 (Sept. 10, 1949), pp. 443.

105. Jermyn, M.A. and Isherwood, F.A. "Improved Separation of Sugars on the Paper Partition Chromatogram." Biochem. Jour. 44 , \#4 (1949), pp. 402.

106. Fieser, L.F. "Experiments in Organic Chemistry." New York: D.C. Heath and Company, 2nd ed., 1941, pp. 127.

107. Shriner, R.L. and Fuson, R.C. "The Systematic Identification of Organic Compounds." New York: John Wiley and Sons, Inc., 1948, pp. 165.

108. Wuense, J.A. and Dehn, W.M. Microscopic Identification of Sugars." Ind. Eng. Chem. Anal. Ed., 11 (1939), pp. 555. 
141

AUTOBIOGRAPHY

I, John Gamet Wagner, was born in Weston, Ontario, Canada, March 28, 1921. I received my secondary school education at Humberside Collegiate Institute in the city of Toronto, Canada. After graduation, I served a two year apprenticeship in Pharmacy, then joined the Royal Canadian Air Force in September, 1941. I served a total of 49 months of which 36 months were overseas. My undergraduate training was obtained at the University of Toronto and the University of Saskatchewan. From the University of Toronto, I received the degree Bachelor of Pharmacy in 1947. While in residence at the University of Toronto, I was the recipient of The Lieutenant George R. Parke, Phm.B., Memorial Scholarship and Silver Medal, The John Roberts Gold Medal for Pharmacy and Chemistry, and The Borden Company, Limited, Bursary. From the University of Saskatchewan, I received the degree Bachelor of Science in Pharmacy with Distinction in 1948 and the degree Bachelor of Arts with Great Distinction in 1949. While in residence at the University of Saskatchewan I was the recipient of The Third Year Scholarship, College of Pharmacy. In June, 1949, I enrolled in the Graduate School, The Ohio State University. While in residence at The Ohio State University I received an appointment as Fel.low of the American Foundation for Pharmaceutical Education. I held this position from September, 1949 to September, 1951. On October 1, 1951, I was appointed as Instructor in the College of Pharmacy, The Ohio State University. I held this position while completing the requirements for the degree Doctor of Philosophy. 